Arquitetura híbrida inteligente para navegação autônoma de robôs

Rodrigo Calvo 



\title{
Arquitetura híbrida inteligente para navegação autônoma de robôs
}

\author{
Rodrigo Calvo
}

Profa. Dra. Roseli Aparecida Francelin Romero

Dissertação apresentada ao Instituto de Ciências Matemáticas e de Computação - ICMC-USP, como parte dos requisitos para obtenção do título de Mestre em Ciências - Ciências de Computação e Matemática Computacional.

\section{"VERSÃO REVISADA APÓS A DEFESA"}

Data da Defesa:

09/03/2007

Visto do Orientador:

\author{
USP - São Carlos \\ Maio/2007
}





\section{Agradecimentos}

Agradeço a Deus, fonte de incentivo e força de vontade para a realização do trabalho.

À minha família que sempre esteve do meu lado nos momentos mais difíceis. Meus pais, Milton e Helena, e meus irmãos, Fabio e Fernando. Pessoas que me ajudaram em todos os sentidos, e apoiando todo o tempo que estive longe de casa. Devo muito a eles, pela dedicação, pela atenção e paciência.

Agradeço a Roseli pelo esforço sem medida em me orientar, sempre disposta a ajudar. Agradeço pela confiança depositada, pela liberdade dada para trabalhar e pelos ensinamentos durante esse período de mestrado.

Ao professor Maurício pelo apoio, por ter me iniciado nessa caminhada. Tudo o que eu obtive devo as suas conversas e dedicação em me apoioar nas minhas decisões.

Aos meus amigos que se tornaram meus irmãos em São Carlos, Adriano e Renato. Foram muitas as horas de conversa até altas horas da madrugada, muitos conselhos, brincadeiras e muitas tentativas de fazer aquela janta, pizzas, pão italiano, lasanha e outras coisas mais que eles se aventuravam em fazer. Agradeço pelo companheirismo, por sempre estarem por perto para ouvir, por dar broncas quando necessário. Foram fundamentais para o andamento deste trabalho.

Ao grande amigo Bruno. Amizade incomparável, sempre por perto pra ajudar, atencioso e cheio de graça querendo fazer brincadeira. Pessoa que influenciou diretamente nesta dissertação, apoiando quando eu desanimava. E sempre emprestava seu celular para assuntos extra importantes.

Agradeço ao Marcelo Kaminski, que mesmo a distância sempre tinha algo de importante para acrescentar em minha vida. Suas visitas a São Carlos foram momentos divertidos e de muita descontração.

Agradeço em especial, Delane e Jão, grandes amigos que estiverem sempre por perto. Agradeço pelas conversas, todas reflexivas nos mais diversos assuntos, pelos momentos "divertidões" e felizes. Aprendi muito com eles.

À grande amiga Paula. Companheira nas viagens para Maringá. Não deixou eu ficar perdido nos primeiros meses em São Carlos. Valeu pelas vezes que parou para me ouvir e me aconselhar, 
obrigado por se importar comigo e estar sempre pronta para ouvir.

Aos irmãos Eler's, Danilo e Marcelo. Responsáveis por conhecermos todas as pizzarias de São Carlos, por levar no caminho da corrida. Valeus pelas sábias palavras, pelos momentos Small sessions. Exemplos de pessoa.

Ao pessoal da PgCompUSP-04. Esta turma é inesquecível, sempre unida, sempre pronta pra não deixar ninguém pra baixo longe de suas famílias. Amigos que sempre estiveram juntos desde a época das disciplinas, até os lamentáveis momentos quando alguns vão mais longe depois do curso, e mesmo assim sempre aparecem para relembrar os bons momentos. Amigos que sempre tentavam manter a alegria nos momentos mais difíceis fazendo as saudosas jam sessions na Casa Velha, os esquentas, pizzadas. Até os pequenos instantes em que ficávamos juntos para o café diário na cantina. São amizades que sempre levarei comigo.

Ao pessoal do futebol, que ajudaram a descontrair nos momentos tensos, pelos momentos divertidos e cansativos. Turma que toda semana tinha a boa notícia em falar que o futebol já estava marcado. Ao time de futebol da PgCompUSP-04 pelo inédito terceito lugar no campeonato.

Aos amigos do LABIC, pelas horas de convivência, por oferecer um ambiente agradável de trabalho, pelos momentos divertidos dentro do laboratório. Aos amigos que tiveram muita importância no desenvolvimento do trabalho, Bianchi, Quiles, Andrew, Eder e Ronaldo. Pessoas que paravam de fazer suas coisas para me ajudar, sempre com opiniões, sugestões para engrandecer o trabalho.

Aos funcionários da USP, ao pessoal da limpeza que sempre mantiveram os laboratórios limpos para trabalharmos. Aos vigilantes que se tornaram meus amigos, Camilo, Dornela, Roberto, Mamute, Moacir. Pelas intermináveis conversas risadas de madrugada.

Aos funcionários do CompreBem por ceder material de madeira para a construção de ambientes de atuação do robô utilizado neste trabalho.

Ao Seu Arnaldo, funcionário do Laboratório de Madeira e Estrutura de Madeira (LAMEMEESC-USP) pela disponibilidade em confeccionar placas de madeiras que serviram de obstáculos para os experimentos em ambientes reais.

Agradeço também à CAPES pelo auxílio financeiro para andamento do mestrado. 
Este projeto consiste em um sistema de navegação autônomo baseado em redes neurais nebulosas modulares capacitando o robô a alcançar alvos, ou pontos metas, em ambientes desconhecidos. Inicialmente, o sistema não tem habilidade para a navegação, após uma fase de experimentos com algumas colisões, o mecanismo de navegação aprimora-se guiando o robô ao alvo de forma eficiente. Uma arquitetura híbrida inteligente é apresentada para este sistema de navegação, baseada em redes neurais artificiais e lógica nebulosa. A arquitetura é hierárquica e costitiui-se de dois módulos responsáveis por gerar comportamentos inatos de desvio de obstáculos e de busca ao alvo. Um mecanismo de aprendizagem por reforço, baseada em uma extensão da lei de Hebb, pondera os comportamentos inatos conflitantes ajustando os pesos sinápticos das redes neurais nos instantes de captura do alvo e de colisão contra obstáculos. A abordagem consolidada em simulação é validada em ambientes reais neste trabalho. Para tanto, este sistema foi implementado e testado no simulador Saphira, ambiente de simulação que acompanha o robô Pioneer I e que denota um estágio anterior aos testes em ambientes reais por apresentar comportamentos do robô similares aos comportamentos do robô móvel. Modificações na arquitetura híbrida foram necessárias para adaptar o sistema de navegação simulado ao sistema incorporado no Pioneer I. Experimentos em ambientes reais demonstraram a eficiência e a capacidade de aprendizagem do sistema de navegação, validando a arquitetura híbrida inteligente para aplicação em robôs móveis. 

This project consists in a autonomous navigation system based on modular neuro-fuzzy networks that is able to guide the robot in unknown environments from a initial point to the goal. Initially, the system is not able to navigate, but after a trial and error period and some collisions, it improves in guiding the robot to the goal efficiently. A intelligent hybrid architecture is presented for this naviga tion system based on artificial neural networks and fuzzy logic. This architecture is hierarquical and consists in two modules that generate innate behaviors, like obstacles avoiding and target reaching. A reinforcement learning mecanism, based on the extended Hebb law, balances this conflicting innate behaviors adjusting the neural network synaptic weights as obstacle and collision avoidance and target reaching takes place. In this project, the approach is consolidated in simulation and validated in real environments. To this end, this system has been implemented by using Saphira simulator and Pioneer I simulation environment. This simulated evironment is a previous stage of tests performed real time and presents simulated robot behaviors similar to real mobile robot behaviors. The hybrid architecture was modified to adapt the simulated navigation system into Pioneer I software. Experiments in a real environments show the efficiency and learning capabilities of the navigation system, validating the intelligent hybrid architecture for mobile robots applications. 

$\begin{array}{ll}\text { Resumo } & 7\end{array}$

$\begin{array}{ll}\text { Abstract } & 9\end{array}$

1 Introdução $\quad \mathbf{1}$

1.1 Inteligência, Autonomia e Aprendizagem . . . . . . . . . . . . . . 1

1.2 Navegação Autônoma de Robôs . . . . . . . . . . . . . . . . . . . . 2

1.3 Robôs Cooperativos . . . . . . . . . . . . . . . . . . . 6

1.4 Metodologia a ser estendida . . . . . . . . . . . . . . . . . . . . . . . .

1.5 Objetivos e Justificativas . . . . . . . . . . . . . . . . . . . . . . . . . . . . . . . .

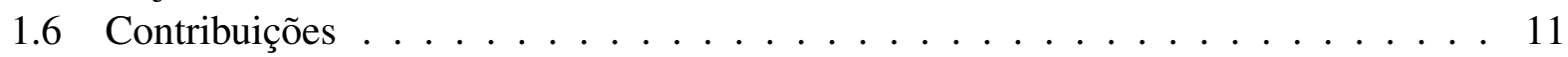

1.7 Organização do texto . . . . . . . . . . . . . . . . . 12

2 Fundamentação Teórica 13

2.1 Introdução . . . . . . . . . . . . . . . . . . . . . 13

2.2 Redes Neurais Artificiais . . . . . . . . . . . . . . . . . . . . . . . . . . . . . . . . . . 14

2.2.1 Topologia das Redes Neurais . . . . . . . . . . . . . . . . . 18

2.2 .2 Aprendizagem . . . . . . . . . . . . . . . 21

2.3 Introdução aos Conjuntos Nebulosos . . . . . . . . . . . . . . . . . . 28

2.3.1 Funções de Pertinência . . . . . . . . . . . . . . . . . . . 28

2.3.2 Operadores sobre Conjuntos Nebulosos . . . . . . . . . . . . . . 30

2.3.3 Computação com Regras Nebulosas: Raciocínio Aproximado ...... 32

2.3 .4 Variáveis Lingüísticas . . . . . . . . . . . . . . . . . 32

2.3.5 Regras Nebulosas . . . . . . . . . . . . . . . . . . 33

2.3.6 Raciocínio Aproximado e Inferência Nebulosa . . . . . . . . . . . . . . . . 36

2.3.7 Sistemas Nebulosos . . . . . . . . . . . . . . . . 37

2.4 Sistemas Híbridos . . . . . . . . . . . . . . . . . . . . . . . 41

2.4.1 Redes Neurais Nebulosas . . . . . . . . . . . . . . . . . . . . . . . . . . . . . . . 42

2.5 Fundamentos de Condicionamento . . . . . . . . . . . . . . . . . . . 42

2.6 Considerações Finais . . . . . . . . . . . . . . . . . . . . 43

3 Sistema Neural Nebuloso $\quad \mathbf{4 5}$

3.1 Introdução . . . . . . . . . . . . . . . . . . . . . 45

3.2 Modelo do Robô Ideal . . . . . . . . . . . . . . . . . . . . . . . . . . . . . . . . . . . . .

3.3 Modelo do Ambiente . . . . . . . . . . . . . . . . . . . . . 48 
3.4 Sistema de Navegação Autônomo . . . . . . . . . . . . . . . . . . . . . . . 49

3.4.1 Arquitetura do Controlador Autônomo . . . . . . . . . . . . . . . 50

3.4.2 Sistema Nebuloso de Desvio de Obstáculos (SDO) . . . . . . . . . . . . 51

3.4.3 Sistema Nebuloso de Busca ao Alvo (SBA) . . . . . . . . . . . . . . . 51

3.4 .4 Repertório de Coordenação (RC) . . . . . . . . . . . . . . . . . . 52

3.4.5 Rede Neural Nebulosa de Desvio de Obstáculos (RDO) . . . . . . . . . . . 52

3.4.6 Rede Neural Nebulosa de Busca ao Alvo (RBA) . . . . . . . . . . . . 55

3.4.7 Rede Neural Nebulosa de Distância ao Alvo (RDA) . . . . . . . . . . . . . 56

3.4 .8 Neurônio de Saída (NS) . . . . . . . . . . . . . . . . . . . . 57

3.4 .9 Aprendizagem do Repertório de Coordenação . . . . . . . . . . . . . . . . . 58

3.5 Considerações Finais . . . . . . . . . . . . . . . . . . . 65

4 Robô e Software de Controle $\quad 67$

4.1 Introdução . . . . . . . . . . . . . . . . . . . . . . . . 67

4.2 Robôs manipuladores . . . . . . . . . . . . . . . . . . . . . . 68

4.3 Robôs móveis autônomos . . . . . . . . . . . . . . . . . . . . . . . . 69

4.4 Paradigmas da Robótica . . . . . . . . . . . . . . . . . . . . 70

4.4 Paradigma Hierárquico . . . . . . . . . . . . . . . . 70

4.4.2 Paradigma Reativo . . . . . . . . . . . . . . . . . . . 71

4.4.3 Paradigma Híbrido Reativo/Deliberativo . . . . . . . . . . . . . . . . . 72

4.5 Robô Pioneer I . . . . . . . . . . . . . . . . . . . . . . . . 72

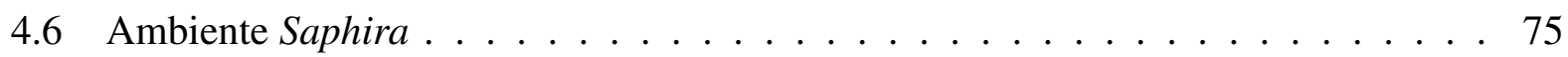

4.7 Considerações finais . . . . . . . . . . . . . . . . . 75

5 Implementação e Resultados $\quad 77$

5.1 Introdução . . . . . . . . . . . . . . . . . . . . . 77

5.2 Método de Localização de Alvos . . . . . . . . . . . . . . . . . . . . . 81

5.2.1 Método de Localização $(\mathrm{ML})$. . . . . . . . . . . . . . . . . . . . . . . . . . . . . . . . . 82

5.3 Método de Mapeamento(MM) . . . . . . . . . . . . . . . . . . . . 84

5.4 Sistema Nebuloso de Desvio de Obstáculos . . . . . . . . . . . . . . . . 85

5.5 Sistema Nebuloso de Busca ao Alvo . . . . . . . . . . . . . . . . . . . . 87

5.6 Repertório de Coordenação . . . . . . . . . . . . . . . . . . . . . . 91

5.7 Considerações Finais . . . . . . . . . . . . . . . . . . . 97

6 Conclusão $\quad 99$

6.1 Conclusão . . . . . . . . . . . . . . . . . . . . . . . 99

6.2 Trabalhos Futuros . . . . . . . . . . . . . . . . . . 100

$\begin{array}{ll}\text { A Sistemas Nebulosos SDO e SBA } & 113\end{array}$

A.1 Variáveis Lingüísticas e Termos Lingüísticos . . . . . . . . . . . . . . . . . 113 


\section{Lista de Figuras}

1.1 Arquitetura do sistema de navegação autônomo baseado em redes neurais nebulosas 9

2.1 Neuônio Biológico . . . . . . . . . . . . . . . . . . . . 15

2.2 Neurônio Artificial . . . . . . . . . . . . . . . . . . . . . . 16

2.3 Topologias de Redes Neurais Artificiais (a) Rede Direta; (b) Rede Recorrente; (c) Topologia de um Perceptron; (d) Modelo de Rummelhart; (e) Modelo de Hopfield . 20

2.4 Funções de ativação não-lineares (a) função linear; (b) função rampa; (c) função degrau; (d) função sigmoidal . . . . . . . . . . . . . . . . . . . . . . . . . . . . . . . . . . 21

2.5 Aprendizado Supervisionado . . . . . . . . . . . . . . . . . . . . 22

2.6 Aprendizado Não-Supervisionado . . . . . . . . . . . . . . . . . . . 25

2.7 Aprendizado por Reforço . . . . . . . . . . . . . . . . . . . . 26

2.8 Função de pertinência de conjuntos nebulosos (a) triangular; (b) trapezoidal; (c) gaussiana; $(\mathrm{d})$ singleton. . . . . . . . . . . . . . . . . . . 29

2.9 Normalidade (a) conjunto nebuloso normal; (b) conjunto nebuloso subnormal. . . . 30

2.10 Operações com conjuntos nebulosos: (a) Conjuntos $A$ e $B$; (b) união; (c) interseção; (d) complemento. . . . . . . . . . . . . . . . . . . 31

2.11 Partição Nebulosa: (a) partição uniforme; (b) partição não-uniforme . . . . . . . . 33

2.12 Organização modular de um sistema nebuloso . . . . . . . . . . . . . . . 38

3.1 Modelo do robô e seus sensores de obstáculo e de alvo . . . . . . . . . . . . . 47

3.2 Modelo gráfico para a obtenção dos sinais dos sensores de direção ao alvo . . . . . 48

3.3 Modelo gráfico para a obtenção dos sinais dos sensores de distância ao alvo . . . 48

3.4 Ambiente de simulação . . . . . . . . . . . . . . . . . . . . . . . . . . . . . . . . .

3.5 Arquitetura do sistema de navegação autônomo . . . . . . . . . . . . . . 50

3.6 Modelo de neurônio nebuloso. . . . . . . . . . . . . . . . . . . . 53

3.7 Arquitetura da Rede Neural Nebulosa para o Repertório de Coordenação. . . . . . . 54

3.8 Operador de medida de possibilidade . . . . . . . . . . . . . . . . 54

3.9 Modelo de neurônio de saída. . . . . . . . . . . . . . . . . . . . 57

4.1 Paradigma Hierárquico . . . . . . . . . . . . . . . . . . . . 71

4.2 Paradigma Reativo . . . . . . . . . . . . . . . . . 71

4.3 Paradigma Híbrido . . . . . . . . . . . . . . . . 72

4.4 Pioneer I . . . . . . . . . . . . . . . . . . . . . . . . . . . . . . . . 73

4.5 Pioneer I (a) Vista lateral; (b) Vista superior . . . . . . . . . . . . . . . . . 73

4.6 Sonares aclopados no Pioneer I . . . . . . . . . . . . . . . . . . . . . . . . . . . . . . . . . . . . . . . . .

4.7 Proximity Laser Scanner . . . . . . . . . . . . . . . . . . . 74 
5.1 Modelo de ambientes utilizado nos experimentos reais . . . . . . . . . . . . 79

5.2 Arquitetura do sistema de navegação autônomo para ambientes reais . . . . . . . . 82

5.3 Modelo de ambiente para o experimento do sistema SDO (a) simulador SR; (b) simulador $S S ;$ (c) AR . . . . . . . . . . . . . . . . . 87

5.4 Trajetória do robô quando somente o sistema SDO é executado (a) simulador SR; (b) simulador SS; (c) AR . . . . . . . . . . . . . . . . . . . . 88

5.5 Modelo de ambiente para o experimento do sistema SDO (a) simulador SR; (b) simulador $\mathrm{SS}$; (c) AR . . . . . . . . . . . . . . . . . . . . 88

5.6 Trajetória do robô quando somente o sistema SDO é executado (a) simulador SR; (b) simulador SS; (c) AR . . . . . . . . . . . . . . . . . . . . . . 89

5.7 Modelo de ambiente sem obstáculos para o experimento do sistema SBA (a) simulador SR; (b) simulador SS; (c) AR . . . . . . . . . . . . . . . . . . 90

5.8 Trajetória do robô no simulador SR (a) Primeiro alvo; (b) Segundo alvo; (c) Terceiro alvo . . . . . . . . . . . . . . . . . . . . . . 90 90

5.9 Trajetória do robô no simulador SS (a) Quarto alvo; (b) Quinto alvo; (c) Sexto alvo 90

5.10 Trajetória do robô em AR (a) Primeiro alvo; (b) Segundo alvo; (c) Terceiro alvo; (d) Quarto alvo; (e) Quinto Alvo; (f) Captura de todos os alvos . . . . . . . . . . . . 91

5.11 Desempenho do sistema de navegação autônomo para o sistema SBA em um ambiente sem obstáculos (a) simulador SR; (b) simulador SS; (c) AR . . . . . . . . . 91

5.12 Modelo de ambiente com obstáculos para o experimento do sistema SBA (a) simulador SR; (b) simulador SS; (c) AR . . . . . . . . . . . . . . . . . 92

5.13 Trajetória do robô quando somente o sistema SBA é executado (a) simulador SR; (b) simulador $\mathrm{SS}$; (c) AR . . . . . . . . . . . . . . . . . . . . . . 92

5.14 Desempenho do sistema de navegação autônomo para o sistema SBA em um ambiente com obstáculos (a) simulador SR; (b) simulador SS; (c) AR

5.15 Modelo de ambiente com obstáculos para o experimento do RC (a) simulador SR; (b) simulador SS; (c) AR . . . . . . . . . . . . . . . . . . . . . . . . . 94

5.16 Trajetória do robô no simulador SR para o experimento do RC (a) Primeiro alvo; (b) Segundo alvo . . . . . . . . . . . . . . . . . . . . . . . . . . . 94

5.17 Trajetória do robô no simulador SS para o experimento do RC (a) Terceiro alvo; (b) Quarto alvo

5.18 Trajetória do robô em AR no o experimento do RC (a) Primeiro alvo; (b) Segundo

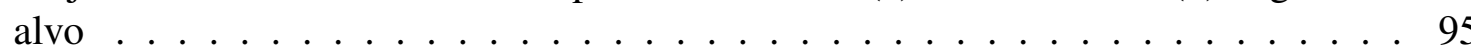

5.19 Desempenho do sistema de navegação autônomo para o sistema SBA em um ambiente com obstáculos (a) simulador SR; (b) simulador SS; (c) AR . . . . . . . . . 95

5.20 Modelo de ambiente com obstáculos para o experimento do RC (a) simulador SR; (b) simulador $\mathrm{SS}$; (c) AR . . . . . . . . . . . . . . . . . . . . 96

5.21 Trajetória do robô no simulador SR para o experimento do do RC (a) Primeiro alvo; (b) Segundo alvo . . . . . . . . . . . . . . . . . . . 96

5.22 Trajetória do robô no simulador SS para o experimento do RC (a) Terceiro alvo; (b) Quarto alvo . . . . . . . . . . . . . . . . . . . . . 96

5.23 Trajetória do robô em AR no o experimento do RC (a) Primeiro alvo; (b) Segundo alvo . . . . . . . . . . . . . . . . . . . . . . 97

5.24 Desempenho do sistema de navegação autônomo para o sistema SBA em um ambiente com obstáculos (a) simulador SR; (b) simulador SS; (c) AR 
A.1 Variáveis língüísticas e seus termos lingüísticos do sistema SDO (a) antecedente: distância do obstáculo; (b) antecedente: direção do obstáculo; (c) conseqüente: ajuste da direção do robô . . . . . . . . . . . . . . . . . . . . . . . . 114

A.2 Variáveis língüísticas e seus termos lingüísticos do sistema SBA (a) antecedente: direção do alvo; (c) conseqüente: ajuste da direção do robô . . . . . . . . . . . . . . . 114 


\section{CAPÍTULO \\ 1 \\ Introdução}

\subsection{Inteligência, Autonomia e Aprendizagem}

O desenvolvimento de novas tecnologias segue diretamente as aspirações da humanidade por critérios progressivamente mais rígidos de desempenho (Figueiredo, 1997). No entanto, há áreas do conhecimento que sempre foram desafiadoras. Uma dessas áreas é a inteligência pelo fato de ainda não ser de total conhecimento de pesquisadores, seu modo de operar e reproduzir artificialmente.

Vários pesquisadores de diversas áreas como biologia, psicologia e computação são motivados pela busca do entendimento, compreensão e reprodução artificial dos sistemas biológicos que expressam algum grau de inteligência. Tal grau se manifesta em diversos seres presentes na natureza com intensidades distintas. Há vestígios de inteligência tanto nos seres simples quanto nos complexos assim como no comportamento isolado e coletivo dos seres.

Em sistemas biológicos, a inteligência não se manifesta isoladamente, sua existência está fortemente ligada a características importantes dos seres. Uma dessas características é a autonomia. Um ser autônomo é aquele capaz de agir por si só, tomar suas decisões sem nenhuma interferência externa. A característica de autonomia está intimamente ligada à capacidade de aprendizagem. A partir da aprendizagem, um ser torna-se capaz de atuar em seu ambiente, no qual alterações são imprevisíveis, mantendo o bom desempenho. Neste caso a adaptação ao meio é um fator essencial. No entanto, a aprendizagem é responsável por inferir a adaptação de um ser em seu ambiente. Sistemas biológicos são em geral autônomos, isto é, suas estruturas não são impostas por agentes 
externos, mas sim desenvolvidas e mantidas por eles próprios por meio de mecanismos como auto-organização, evolução, adaptação e aprendizagem. Um agente artificial inteligente e não autônomo não é, de fato, inteligente, pois suas habilidades são pré-determinadas pelo projetista e não são adquiridas após um período de experiências e/ou treinamento, não sendo capaz de aprender e de adaptar seus comportamentos.

Em 1997, Smithers (Smithers, 1997) apresenta uma definição ainda mais abrangente para o termo "autonomia", quando aplicado a um sistema de controle artificial. De acordo com esta definição, "autonomia" se refere não apenas à capacidade de ação e decisão independente de influências externas, mas sobretudo à capacidade de autoprodução do mecanismo que gera a ação. Em outras palavras, um sistema autônomo deve ser capaz de sintetizar suas próprias leis de ação sobre o ambiente.

\subsection{Navegação Autônoma de Robôs}

A necessidade da criação de sistemas e desenvolvimento de novas tecnologias para a substituição do trabalho humano é uma vertente em ascensão na humanidade. Tais sistemas devem ser capazes de executar tarefas sem que haja alguma interferência externa (sistemas independentes). Incluindo-se nesta classe, o problema de navegação autônoma de robôs consiste no desenvolvimento de mecanismos de tomada de decisão para um ou mais robôs móveis em um ambiente arbitrário no qual devem realizar determinadas tarefas de forma autônoma. Em outras palavras, sistemas de navegação autônoma devem ser capazes de guiar robôs sem nenhuma interferência externa e definir ações para estes, como atingir alvos, desviar de obstáculos, explorar ambiente, etc (Calvo e Figueiredo, 2003a), (Cazangi e Figueiredo, 2002), (Crestani et al., 2002), (Borenstein et al., 1996). As diversas aplicações para tais sistemas vêm motivando os pesquisadores desta área, como por exemplo, limpeza de ambientes, embarcações, transporte de materiais, sistema de vigilância e tarefas consideradas arriscadas para o ser humano (Rao e Fuentes, 1996).

O problema de navegação, incorpora diversos fatores que influenciam no seu desempenho, alguns deles são: configuração do ambiente de navegação, modelo do robô e conjunto de tarefas a serem realizadas. Vários parâmetros caracterizam o ambiente de atuação do robô, dentre eles: número de dimensões, configuração, meio social, dinâmica e complexidade. Muito embora aplicações reais ocorram em três dimensões, em muitos casos, para efeitos de projeto e análise de resultados, é possível considerar que o robô móvel se desloca em duas dimensões. A configuração estática do ambiente caracteriza-se pela presença de objetos de mesmas propriedades geométricas cuja posição no ambiente não são alteradas, enquanto que em ambientes com configuração dinâmica, tais propriedades variam ao longo da trajetória assim como a posição dos objetos 
presentes (Crestani, 2001). Três tipos principais de meios sociais são sugeridos: cooperativo, competitivo e indiferente. Tanto em meios sociais cooperativos quanto em competitivos, os robôs móveis têm objetivos comuns. Em ambientes em que o meio social é cooperativo, os robôs atuam de forma conjunta, agregando capacidades, para alcançar o objetivo e compartilhar resultados. Em meios sociais competitivos, os robôs atuam individualmente sendo que somente um deles alcança o objetivo. Caso a atuação de cada robô móvel não influencie no desempenho dos demais, o meio social é indiferente. A dinâmica de um ambiente está relacionada ao seus eventos. A geração de um número finito de eventos, todos conhecidos e previsíveis, determina um ambiente controlado. Por outro lado, a ausência de restrições quanto a ocorrência de eventos, determina um ambiente não-controlado. Os tipos de configuração e dinâmica estabelecem o grau de complexidade do ambiente. Os ambientes com configuração estática e controlados são considerados menos complexos que os ambientes com configuração dinâmica e não-controlados. Dessa maneira é aconselhável que robôs móveis atuando em ambientes complexos sejam dotados de capacidade de maior potencial.

Robôs móveis devem ser projetados de acordo com as necessidades impostas pelo ambiente, habilidades para eles definidas e critérios de desempenho. Considerando esses fatores, alguns parâmetros são de maior relevância para a definição do modelo de robô, tais como: atuadores, sensores, variáveis de decisão e restrições. Os atuadores são os dispositivos através dos quais os robôs interferem no ambiente em que atuam. Para o problema de navegação, os atuadores estão associados aos recursos que permitem o robô a se locomover e controlar seu deslocamento para a determinação de uma trajetória. Alguns exemplos de atuadores são, rodas, articulações, esteiras, garras, etc.. Os sensores têm como objetivo detectar informações do ambiente que são utilizadas pelo robô para a tomada de decisão. A viabilidade de utilização deles torna-se possível através de recursos de laser, ultra-som, infravermelho, câmeras, etc. visando detectar informações sobre a distância, aproximação e de detecção de objetos (Bianchi e Romero, 2003), (Quiles, 2005). A partir dos sinais detectados pelos sensores e do processamento desses sinais pelo sistema de navegação, os atuadores são acionados segundo a atuação de alguns comandos, denominados variáveis de decisão. O grau de flexibilidade do robô no que diz respeito às suas habilidades é proporcional ao número de variáveis de decisão, ou seja, quanto maior o número de variáveis maiores serão as habilidades do robô, porém o número elevado de variáveis implica no aumento de complexidade do projeto. Como exemplo de variáveis de decisão, pode-se citar a direção do robô, velocidade, força, etc.. Associadas às variáveis de decisão estão suas respectivas restrições limitadas por intervalos impostos por decisão de projeto ou por natureza física. Como exemplo de uma restrição para a variável velocidade, pode-se citar o caso em que a velocidade do robô não deve assumir valores negativos, ou seja, o robô não deve se deslocar na direção oposta à sua direção de movimento. Outra restrição, considerando a variável direção pode ser o caso em que o eixo de rotação do robô não permite que sua direção de movimento ultrapasse $30^{\circ}$. 
Robôs móveis são aplicados a um grande número de tarefas diversificadas, como limpeza de superfícies (assoalhos, tanques industriais, dutos, etc.), transporte de documentos (Bianchi e Romero, 2003), produtos agrícolas e sistemas de segurança. No entanto, muito dessas tarefas envolvem comportamentos básicos de navegação (Colombetti et al., 1996). Por exemplo, considere a tarefa de seguir objetos de uma determinada cor (Quiles, 2005) e captura de objetos em um mesmo ambiente. Neste caso, o robô necessita apresentar comportamentos de reconhecimento de cores e de busca de alvos. Outros tipos de comportamentos podem ser apresentados por robôs móveis, tais como: desvio de obstáculos, exploração, fuga, etc.. Sistemas de navegação desta natureza, baseado em comportamento, é uma das linhas de pesquisa em torno da navegação de robôs.

A avaliação do desempenho dos robôs móveis em um sistema de navegação pode ser realizada sob diversos critérios, tais como: extensão da trajetória para executar uma tarefa, tempo de busca ao alvo, número de alvos alcançados, número de colisões por alvos alcançados, etc.. Entretanto, os critérios de desempenhos mais exigentes não são relatados em resultados de pesquisa do que somente o cumprimento da tarefa estabelecidos para os robôs (Figueiredo, 1999). Um fator de grande importância para avaliar o desempenho de um sistema de navegação autônomo é a capacidade do sistema em aprender e se adaptar a novas situações. Enquanto o robô navega pelo ambiente, este está sujeito a se deparar com situações inéditas e imprevisíveis. Para ambas as situações o sistema deve ser capaz de tomar a decisão correta sem a interferência de agentes externos. O processo de aprendizagem e adaptação ocorre pelo aprimoramento da estratégia de navegação por meio da aquisição de conhecimento (obtido com as experiências passadas) e do ajuste de parâmetros. Um sistema com as capacidades de aprendizagem e adaptação já evoluídas (aprimoradas) tende a guiar o robô com mais facilidade para a realizar o seu objetivo com êxito.

Algumas abordagens de sistemas de navegação consideram que o ambiente (topologia e eventos) é totalmente conhecido, ou seja, o sistema de navegação tem o conhecimento do mapa do ambiente e todos os possíveis eventos pertencem a um número finito de classes conhecidas (ambientes estáticos e controlados). Neste caso, o sistema de navegação pode ser programado com antecedência, com poucos ou nenhum parâmetro adaptável. Há grandes expectativas para aplicações da robótica onde o ambiente é totalmente desconhecido. Pelo menos, neste caso, a autonomia é uma característica essencial para sistemas de navegação, em particular, e para sistemas de controle em geral (Crestani et al., 2002) (Antsaklis, 1995). A aprendizagem de sistemas de navegação autônoma inteligente é baseada nas iterações com os ambientes de navegação tornando o conhecimento prévio da topologia do ambiente desnecessário. A aprendizagem ocorre se o sistema de navegação não exibe um desempenho aceitável ou se novas experiências ocorrem. Essas premissas são investigadas em uma simples classe de problemas de navegação: o ambiente é desconhecido, há somente um alvo no ambiente e o robô precisa alcançá-lo evitando colisões contra obstáculos (Colombetti et al., 1996) (Vershure, 1998). 
Muitos sistemas autônomos inteligentes mostram resultados considerando esse problema de navegação. Um sistema autônomo constituído por uma arquitetura hierárquica baseada em redes neurais artificiais é proposto em (Tani, 2000). Uma rede neural do tipo Kohonen processa as informações dos sensores de entradas e uma rede multicamadas recorrente processa a saída. O robô nesse sistema é capaz de alcançar o alvo sem colisões através de trajetórias eficientes encontradas.

Em (Crestani, 2001) redes neurais são adotadas para projetar um sistema autônomo que aprende controlar variáveis de controle de navegação: velocidade e direção. Este sistema proporciona duas classes de campos sensoriais: direção do alvo e distância aos obstáculos. Um sistema mais complexo de navegação é baseado em técnicas evolucionárias (sistema de classificação). Resultados de simulação mostram que o sistema aprende, simultaneamente, a desviar de obstáculos, capturar alvos e coordenar esses comportamentos quando são conflitantes (Cazangi e Figueiredo, 2002). Em (Vershure, 1998) são utilizados conceitos da Teoria de Seleção de Grupos Neurais (TSGN) (Edelman, 1987) no desenvolvimento de sistemas autônomos.

Um sistema autônomo de navegação baseado em redes neurais hierárquicas modulares capaz de estabelecer sua estratégia de navegação de robôs é proposto em (Antonelo et al., 2005). A estratégia de navegação é baseada em experiências anteriores de navegação segundo o o mecanismo de aprendizado por reforço. Inicialmente, o desempenho do sistema é degradado devido à sequente ocorrências de colisões. Simulações computacionais mostram que após um período de aprendizagem, o sistema autônomo de navegação gera comportamentos de desvio de obstáculos e busca a alvos eficientemente. Além disso, os experimentos permitem concluir que o sistema autônomo de navegação desenvolve diversas habilidades para a discrminação de objetos e conceitos espaciais.

Recursos computacionais disponíveis atualmente permitem realizar simulações de sistemas de navegação com o emprego de modelos matemáticos e processamento computacional que reproduzem condições de operações em ambientes reais. Devido a falta de disponibilidade de recursos e aptidão técnica por parte de muitos pesquisadores, a opção mais viável para a avaliação de desempenho de um sistema de navegação ocorre via simulações computacionais. Nolfi e Floriano (2000) constatam que experiementos que envolvem ambientes com grau de complexidade alto demandam tempo demasiado além de testes exaustivos. Porém, o uso da simulação não pode substituir completamente as investigações de experiementos em ambientes reais, já que as características do mundo real são extremamente difíceis de serem modeladas computacionalmente com exatidão (Cazangi, 2004).

Sistemas de navegação são propostos utilizando robôs móveis, adicionando a estes capacidade de mobilidade e autonomia para interagir adequadamente com diversos ambientes ampliando o campo de novas aplicações. Em (Medeiros e Romero, 2004) uma rede neural do tipo multicamadas foi utilizada para controle de um robô móvel em um chão de fábrica. Métodos prob- 
abilísticos de mapeamento e localização são utilizados para a navegação do robô móvel Pioneer I, capacitando-o a transportar documentos entre locais distantes (Bianchi e Romero, 2003). Um sistema remoto para controle de robôs é proposto em (Barbosa, 2005) por meio de uma interface web, o robô móvel Pioneer I pode ser controlado a partir de qualquer ponto no mundo. Em (Quiles, 2005), um sistema de visão computacional é proposto baseado em redes neurais multi-camadas para capacitar um robô móvel a seguir um objeto de determinada cor e forma evitando colisões com obstáculos.

Fracasso e Reali (2005) descrevem um sistema de navegação reativo comportamental de robôs móveis autônomos utilizando lógica nebulosa combinada com uma ponderação entre as regras de inferência possibilitando a redução das regras necesárias para a modelagem do sistema, resultando em respostas rápidas. A partir dos sinais de distância dectados e a diferença angular entre a direção de movimento do robô e a direção desejada, o sistema nebuloso de navegação gera um valor indicando a intensidade dos movimentos de rotação e translaçãodo robô. Os resultados experimentais obtidos demonstram que o sistema de navegação proposto é factível para situações e implementações reais.

\subsection{Robôs Cooperativos}

A pesquisa em torno do desenvolvimento de sistemas autônomos inteligentes nos últimos anos teve seu foco em ambientes com obstáculos estáticos e onde apenas um único robô era considerado nas simulações e testes. Os experimentos realizados em sistemas como os descritos acima trouxeram novas metodologias e perspectivas para o desenvolvimento de um controlador autônomo. Os resultados obtidos a partir da avaliação de desempenho motivaram o início das pesquisas de desenvolvimento de sistemas autônomos em que os ambientes apresentam características dinâmicas, sujeitos à modificação durante as simulações, além de considerar a presença de múltiplos robôs nos ambientes.

Nesse sentido, os estudos envolvendo vários robôs podem levar à observação de comportamentos ainda não considerados em pesquisas anteriores (Crestani, 2001). Em simulações de sistemas autônomos inteligentes com múltiplos robôs, pode ser desejável que os robôs atuem simultaneamente de forma cooperativa ou de forma competitiva para a realização de uma determinada tarefa.

A motivação para o uso de sistemas com múltiplos robôs vem do fato de esses sistemas apresentarem várias vantagens contrapondo-se aos sistemas com um único robô (Arai et al., 2002) (Parker, 2002) (Arkin, 1999). Tais vantagens são: melhor desempenho, decréscimo da complexidade individual, possibilidade de permitir o compartilhamento remoto de informações e tolerância 
a falhas através de agentes redundantes. Por outro lado, o uso de sistemas com múltiplos robôs defronta com situações de difícil solução como as colisões entre os robôs durante a navegação, coordenação dos mesmos e a confiabilidade das informações transmitidas entre os robôs (Parker, 2002).

Por se tratar de um campo em ascensão, as áreas do domínio de robôs cooperativos autônomos não são, ainda, considerados maduros. Dessa maneira, algumas áreas estão sendo largamente exploradas, iniciando o processo de entendimento de como controlar e desenvolver aspectos envolvendo múltiplos robôs. Por esse motivo Arai et al. (2002) apresentam alguns tópicos de sistemas com múltiplos robôs que contribuíram para um crescimento significante das pesquisas. São eles:

- Inspiração biológica;

- Comunicação;

- Arquiteturas, alocação de tarefas e controle;

- Localização, mapeamento e exploração;

- Transporte de objetos e manipulação;

- Coordenação;

- Robôs reconfiguráveis;

A pesquisa em torno de sistemas com múltiplos robôs cooperativos teve forte influência do paradigma baseado em comportamento para robôs móveis. Pelo fato desse paradigma ser fundamentado em sistemas bioinspirados, houve um grande impulso dos pesquisadores em investigar o comportamento social de insetos e animais aplicando-o em sistemas com múltiplos robôs. Dessa maneira diversos trabalhos têm sido propostos nesta linha de pesquisa.

Grande parte das aplicações referentes a este conhecimento são destinadas ao controle de sociedades de objetos biológicos, principalmente pássaros e colônias de formigas (Parpinelli et al., 2002) para o desenvolvimento de robôs cooperativos dotados de capacidade para simular os comportamentos semelhantes aos dos agentes biológicos. Sistemas de robôs cooperativos apresentaram resultados promissores para a tarefa de explorar ambientes, procurar objetos e seguir trilha (Denenbourg et al., 1990) (Drogoul e Ferber, 1992) (Mataric, 1992).

Sistemas baseados em propriedades de insetos são apresentados em (Theraulaz e Bonabeu, 1999) e (Campos et al., 2000) e modelos predador-presa em (Nishimura e Ikegami, 1997) (Nolfi e Floriano, 1999) (Jim e Giles, 2001) para simular comportamentos sociais em agentes artificiais. Castelfranchi (1998) apresenta um trabalho voltado para a formalização de alguns fundamentos de 
relacionamentos sociais em agentes artificiais, descrevendo relações mais complexas, como organização e estrutura social.

No campo da robótica baseada em comportamento, M. J. Mataric, em (Mataric, 2001), apresenta um estudo de desenvolvimento de mecanismo de cooperação em robôs móveis através da aplicação da teoria de aprendizagem por reforço em Processos de Decisão de Markov em arquitetura de robôs baseada em comportamentos. Os robôs recebem reforço por atingir objetivos e sub-objetivos e ainda por colaborarem na obtenção dos objetivos de outros robôs, através do compartilhamento do reforço. Segundo M. J. Mataric, isto estimula o aparecimento de comportamento social.

Em (Alur et al., 2000) é apresentado um grupo de robôs móveis com capacidade de desempenhar diversas tarefas tais como localização e mapeamento cooperativo em um ambiente desestruturado. Uma câmera em cada robô é responsável por captar imagens possibilitando estimar as posições dos robôs próximos a obstáculos. Um método de mapeamento é descrito em (Fregene et al., 2002) associando a estimativa de profundidade baseado em visão com o perfil do terreno a ser mapeado. Nos experimentos não há restrição quanto ao número de robôs. Burgard et al. (2000) detalha um mecanismo de coordenação em que um grupo de robôs explora um ambiente eficientemente usando um grid construída a partir de dados captados pelos sensores de cada robô.

\subsection{Metodologia a ser estendida}

Este trabalho considera o problema de navegação definido na Seção 3.4, capturar alvos em ambientes desconhecidos evitando colisões, e propõe uma nova abordagem para navegação autônoma de robôs móveis estendendo a metodologia apresentada em (Calvo e Figueiredo, 2003b). Tal metodologia apresentada é inicialmente proposta em (Figueiredo, 1997).

Em (Figueiredo, 1997), o sistema de navegação autônomo é baseado em técnicas de redes neurais e sistemas nebulosos. A arquitetura do sistema é hierárquica e modular Figura 1.1. Dois dos módulos do sistema são responsáveis por gerar comportamentos inatos de desvio de obstáculo e de busca ao alvo, são eles Sistema Nebuloso de Desvio de Obstáculos (SDO) e Sistema Nebulosos de Busca ao Alvo (SBA), respectivamente. O outro módulo, denominado Repertório de Coordenação (RC), é responsável pela coordenação dos dois primeiros. O RC é constituído por duas redes neurais, Rede Neural Nebulosa de Desvio de Obstáculos (RDO) e Rede Neural Nebulosa de Busca a Alvo (RBA) As redes citadas são responsáveis pelo balanceamento dos comportamentos gerados pelos sistemas SDO e SBA, respectivamente. 
A aprendizagem é desenvolvida a partir de interações com o ambiente. Baseado na Teoria de Seleção de Grupos Neurais (Edelman, 1987), o processo de aprendizagem ocorre à medida que o robô recebe estímulos do ambiente de atuação (captura e colisão). A estratégia de aprendizagem adotada para o módulo de coordenação obedece à teoria do condicionamento operante, observada em sistemas biológicos (Catania, 1999).

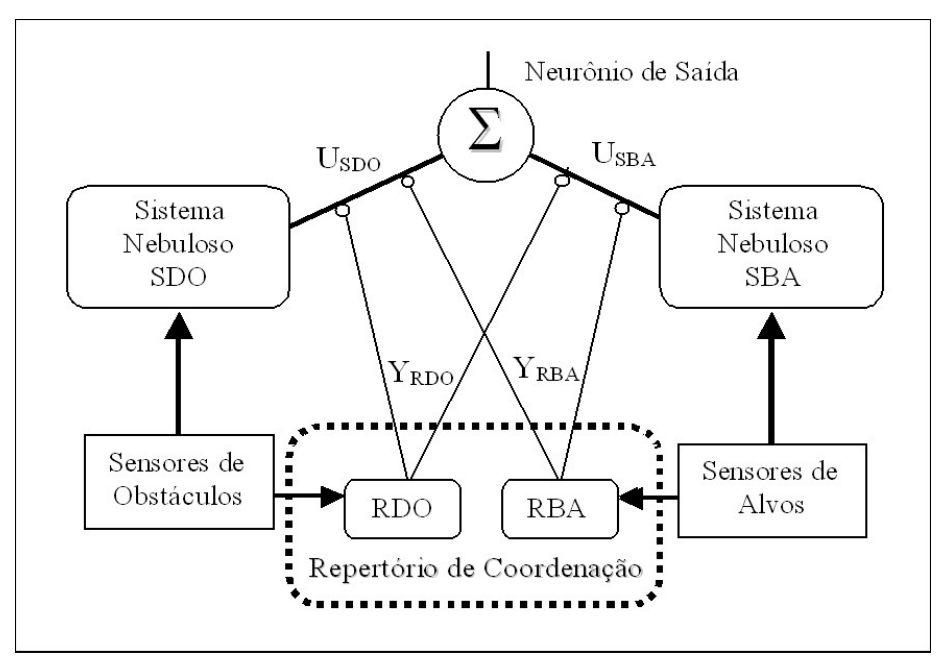

Figura 1.1: Arquitetura do sistema de navegação autônomo baseado em redes neurais nebulosas

No modelo apresentado em (Figueiredo, 1997), a estratégia de aprendizagem adotada é utilizada somente quando o robô sofre uma colisão ou quando o robô captura um alvo. Nos instantes em que ocorrem colisões, os neurônios da rede RDO são punidos e nos instantes em que ocorre uma captura os neurônios da rede RBA são recompensados. Dessa maneira, o número elevado de colisões leva o robô a desenvolver uma espécie de aversão excessiva a obstáculos. O mesmo ocorre com o número elevado de capturas, dificultando o desvio de obstáculos, principalmente quando um alvo está em suas proximidades.

De acordo com as características citadas e após inúmeras simulações e testes realizados, foi constatada uma deficiência no modelo de (Figueiredo, 1997). Este sistema não permite que o robô capture alvos em ambientes com configuração de risco, ou seja, em ambientes em que o(s) alvo(s) está(ão) posicionado(s) próximo(s) a obstáculos. Normalmente, nas simulações de robôs móveis, a primeira captura ocorre após ocorrerem várias colisões. Desse modo, é provável que o comportamento de desvio esteja fortalecido enquanto que o comportamento de busca ainda não está aprimorado.

Para eliminar esta deficiência, é apresentado em (Calvo e Figueiredo, 2003b) um mecanismo de aprendizagem que distribui de maneira mais apropriada, tanto as punições quanto as recompensas. Este mecanismo fundamenta-se na teoria de redes neurais e redes neurais nebulosas, inspirado 
em processos biológicos e em princípios da psicologia do comportamento (reflexo condicionado) baseados na aprendizagem por condicionamento (Catania, 1999).

A aprendizagem por condicionamento está baseada nos estímulos condicionados e não condicionados, presentes nos comportamentos inatos. Em conseqüência da aprendizagem, o sistema autônomo adquire capacidade de coordenação destes comportamentos. Em (Calvo e Figueiredo, 2003b), a aprendizagem por condicionamento se manifesta tanto segundo sinais de reforço quanto de punição, além de serem negativos ou positivos. Tanto para o reforço quanto para a punição, o sinal positivo determina o aumento da freqüência de um estímulo não-condicionado e o sinal negativo determina sua redução (Catania, 1999). Estes sinais ocorrem em momentos de colisão ou captura. O mecanismo de aprendizagem utilizado para as redes neurais nebulosas do RC é a aprendizagem por reforço, baseado na lei de Hebb (Hebb, 1949), ou seja, a região sináptica entre dois neurônios que disparam (de forma correlacionada) é reforçada. Ainda nesse sistema, é proposta uma extensão da lei de Hebb, na qual um neurônio pré-sináptico pode participar da intensificação ou redução de sinapses para um mesmo evento.

Outra característica do sistema descrito em (Calvo e Figueiredo, 2003b) é a presença de um módulo capaz de modificar a arquitetura das redes neurais nebulosas do RC (Calvo, 2003) (Calvo et al., 2004). Em (Figueiredo, 1997), a rede responsável pelo comportamento de desvio de obstáculos (RDO) recebe um neurônio a cada instante em que o robô sofre uma colisão. O módulo é construído de acordo com a teoria dos conjuntos nebulosos para modelar um sistema neural. Sua função é monitorar o estado atual das redes e dependendo de seu valor gerado, as redes podem ter suas arquiteturas modificadas ou permanecer no estado atual.

\subsection{Objetivos e Justificativas}

Este trabalho considera o mesmo problema de navegação definido anteriormente e propõe uma arquitetura híbrida inteligente para a navegação para robôs móveis baseada em redes neurais modular e sistemas nebulosos, considerando obstáculos e uma posição meta pré-definida em ambientes desconhecidos a priori e abordando o mecanismo de aprendizado por reforço. A partir do momento em que o robô é lançado em um ambiente, seu objetivo é atingir outra posição do ambiente previamente definida. Esta arquitetura está, em teoria, parcialmente definida, como pode ser visto em (Calvo e Figueiredo, 2003a) e (Calvo e Figueiredo, 2003b). No entanto, existe a necessidade de validar esta arquitetura usando um robô real e adaptá-la aos recursos disponíveis neste robô. O robô utilizado neste trabalho é o Pioneer I, existente no Laboratório de Inteligência Computacional (LABIC) do Instituto de Ciências Matemáticas e de Computação (ICMC) da Universidade de São 
Paulo (USP).

Desta forma, propõe-se a validação dos experimentos apresentados em (Calvo e Figueiredo, 2003a) e (Calvo e Figueiredo, 2003b) aplicando o mecanismo de aprendizado no robô móvel Pioneer 1 do LABIC-ICMC-USP. Para a aplicação do mecanismo de aprendizado no robô móvel devem ser consideradas dificuldades tais como a localização do robô em um ambiente real e dinâmico, mapeamento do ambiente (Borenstein e Koren, 2001), erro de odometria e ruídos captados pelos sensores de obstáculos. Para os experimentos realizados em ambientes reais, são analisados, a fim de comparação, o desempenho do sistema quando utilizado o sensor a laser de alta precisão (SICK PLS - laser range finder).

O presente trabalho se justifica no contexto das pesquisas em desenvolvimento no LABIC, relacionadas à área de Robótica Inteligente. Trabalhos existentes nesta área objetivam o desenvolvimento de um controlador inteligente que possa interagir com o meio ambiente tomando decisões adequadas em função de tarefas que lhe são apresentadas. É nesta direção que se enquadra o presente projeto, pois uma arquitetura híbrida inteligente é proposta, através da qual o robô deve tomar decisões entre desviar de obstáculos e seguir a direção de uma meta pré-definida de forma autônoma, segundo comportamentos inatos (desvio de obstáculos de busca a alvos).

\subsection{Contribuições}

O presente trabalho pertence ao projeto ARMOSH do grupo de Robótica do ICMC-USP, contribuindo para o objetivo maior deste projeto, o desenvolvimento de um controlador inteligente citado anteriormente. Outra contribuição está no fato de que uma arquitetura híbrida inteligente com aspectos originais, baseada em redes neurais modulares e sistemas nebulosos é proposta e será testada em tempo real no robô móvel Pioneer I existente no LABIC.

Além disto, no que diz respeito às avaliações feitas sobre o mecanismo adotado de aprendizagem por reforço, os experimentos realizados com um robô móvel possibilitam a discussão sobre a eficiência do sistema e, então, a implantação desse mecanismo de aprendizagem em outros projetos em desenvolvimento, tais como, em robôs cooperativos, onde a aplicação deste seja adequada, melhorando os resultados anteriormente obtidos. 


\subsection{Organização do texto}

A apresentação dessa dissertação inicia-se no Capítulo 2 com a descrição das técnicas inteligentes presentes na arquitetura híbrida. O sistema neural nebuloso assim como os componentes da arquitetura híbrida do sistema autônomo e o método de aprendizagem utilizado são descritos com detalhes no Capítulo 3. No Capítulo 4 são apresentadas duas linhas des pesquisa da robótica e seus paradigmas, responsáveis pelo desenvolvimento de aplições da robótica inteligente. Ainda nesse capítulo é descrito o ambiente Saphira utilizado como sistema suporte para a implantação do sistema neural nebuloso possibilitando a execução de testes em tempo real no robô móvel Pionner I que também é brevemente descrito juntamente com os dispositivos que o acompanham necessários para a realização dos experimentos. As adaptações necessárias na arquitetura do controlador autônomo para a execução de experimentos em ambientes reais e a descrição dos testes do sistema de navegação realizados em tempo real e a análise comparativa do desempenho destes em relação às simulações efetuadas no simulador de robô móvel são apresentados no Capítulo 5. Finalmente, no Capítulo 6, são apresentadas as conclusões do trabalho e sugestões para futuras investigações. 


\section{Fundamentação Teórica}

\subsection{Introdução}

A aplicação de robôs em diversos tipos de tarefas vem aumentando, fruto de intensas pesquisas e estudos. A pesquisa sobre navegação autônoma se encontra em um estágio em ascensão e tem se mostrado um importante suporte (de experimentos) no auxílio das investigações e avaliações de sistemas inteligentes. A complexidade envolvida na tarefa de geração de trajetórias eficientes em um ambiente de navegação é reconhecidamente alta. Em muitos casos exige-se que o sistema autônomo, não considerando conhecimento incorporado a priori, seja capaz de aprender uma estratégia de navegação integralmente a partir da interação com o ambiente (Calvo e Romero, 2006).

Uma fonte de inspiração para a concepção de métodos de otimização é a capacidade com que os sistemas biológicos têm de encontrar soluções eficientes para problemas complexos. Esta capacidade é, geralmente, associada à capacidade de aquisição de conhecimento extraído do próprio problema para desempenhar tarefas ou resolvê-los. Os métodos dotados desta capacidade são denominados Sistemas Inteligentes. Entre as habilidades inteligentes, está o armazenamento e recuperação de grande quantidade de informação para a resolução de problemas, tomada de decisão e conexão do conhecimento humano de modo associativo. Este tipo de comportamento está relacionado à habilidade organizacional complexa e à habilidade de adaptar e modificar o conhecimento baseado na racionalidade e aplicar essas habilidades em uma dada situação. Tais habilidades juntamente com a capacidade de modelar tarefas específicas implicam na classificação de um sistema ser "inteligente" (Rezende, 2003). 
O comportamento inteligente de um sistema é resultado de múltiplas e encadeadas decisões escolhidas segundo critérios de desempenho e risco. Os sistemas inteligentes podem ser desenvolvidos usando-se algumas técnicas isoladamente ou em conjunto para auxiliar o processo de decisão. Entre essas técnicas, destaca-se as utlizadas para a concepção do método de aprendizagem do sistema proposto, Redes Neurais e Lógica Nebulosa. Cada uma dessas técnicas oferece uma variedade de habilidades para representar o conhecimento humano. Além dessas técnicas o sistema proposto aborda conceitos da Teoria de Seleção dos Grupos Neurais (TSGN) (Edelman, 1987) e da psicologia do comportamento para delinear o processo de aprendizagem do sistema.

Este capítulo é organizado como segue. Os conceitos básicos que envolvem a teoria de Redes Neurais Artificiais e Lógica Nebulosa são apresentados na Seções 2.2 e 2.3, respectivamente. A relevância da junção dessas teorias para a aplicação são mostrados na Seção 2.4 além de ser apresentados os conceitos de sistemas híbridos. Os fundamentos de condicionamento que envolve a psicologia do comportamento é brevemente descrito na Seção 2.5.

\subsection{Redes Neurais Artificiais}

A maneira como o cérebro humano processa as informações é distinta daquela realizada por uma máquina digital construída a partir de uma arquitetura do tipo Von Neumann (von Neumann, 1993), em que a memória e a unidade de processamento de dados são duas entidades distintas e o processamento é realizado serialmente. O cérebro humano processa as informações de forma paralela, distribuindo a tarefa para as células nervosas. O cérebro é constituído por vários tipos de células. As células responsáveis pela reação aos estímulos externos são os neurônios. O número de neurônios presentes em um cérebro é estimado na ordem de $10^{11}$.

A célula nervosa tem como função tratar estímulos, ou seja, processar sinais provenientes de outros neurônios ou de outros ambientes. Em geral, um neurônio apresenta as seguintes características (Figura 2.1): 1) dentritos; 2) axônio; 3) corpo celular (soma); 4) sinapses. Os neurônios recebem os sinais de entrada provenientes de outras células através dos dentritos, processa-os no corpo celular (ou soma) e gera sinais de saída que são transmitidos para outros neurônios por meio do axônio e suas ramificações. A região por onde os sinais são transmitidos, ou seja, o local onde há o encontro do axônio de um neurônio e o dentrito de outro, é denominada de sinapse. A sinapse é uma região preenchida por um líquido iônico por onde fluem moléculas neurotransmissoras que estabelecem a comunicação entre neurônios. As sinapses podem alterar os sinais transmitidos pelo axônio ou mesmo impedí-lo que estes cheguem aos dentritos. Além disso, podem ser alteradas devido à passagem de sinais ou às atividades dos neurônios. Assim, pode-se afirmar que esta região 
está relacionada à capacidade de memória e aprendizagem (Haykin, 1994).

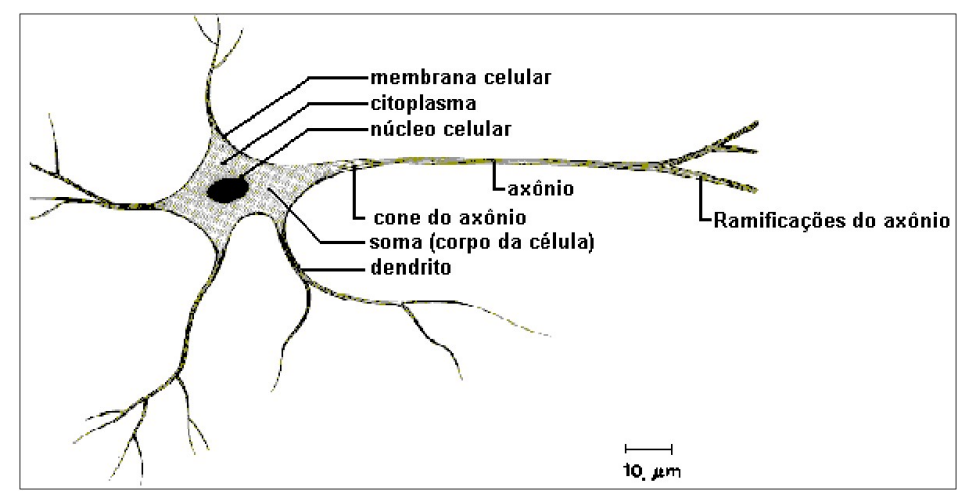

Figura 2.1: Neurônio Biológico

As redes neurais surgiram do esforço de reproduzir em dispositivos artificiais as capacidades inteligentes de que o homem é dotado, proporcionadas pelo seu cérebro. Na tentativa de entender o mecanismo de raciocínio do cérebro, emergiram duas linhas de pesquisas. A primeira delas consiste no estudo de redes neurais que representam modelos bastante simplificados do sistema nervoso biológico. Em particular para este trabalho, a arquitetura híbrida inteligente está relacionada às classes de redes neurais artificiais computacionalmente viáveis. As redes neurais artificiais são modelos computacionais constituídos por dois componentes básicos: uma arquitetura computacional paralela e distribuída (também denominada estrutura da rede neural) e um método de aprendizagem. A arquitetura da rede neural é formada por um grande número de neurônios, que operam em paralelo e que apresentam características adaptativas. Os neurônios conectam entre si por meio de ligações sinápticas (ou sinapses). A função das sinapses, relacionada à aprendizagem e à memória, é representada por parâmetros numéricos denominados pesos sinápticos. O modelo de aprendizagem determina os pesos sinápticos adequados às exigências do problema. A segunda linha de pesquisa, conhecida como neurociência computacional, baseia-se em modelos de redes neurais bastante complexos (realistas) cuja função é a simulação de fenômenos biológicos como por exemplo a modelagem da visão computacional (Deco et al., 2005), (Itti e Koch, 2001), (Quiles, 2005).

Análogo ao sistema nervoso biológico, as redes neurais apresentam redundância, neurônios semelhantes, ou até mesmo idênticos. Esta característica torna as redes neurais robustas a perturbações e tolerantes à falhas. Na ocorrência de uma falha do processador, o desempenho de uma rede neural não é prejudicado justamente por apresentar esta característica. O conhecimento de células nervosas, neurônios, que constituem o sistema nervoso biológico é relatado somente a partir do final do século XIX pelo histoligista, considerado o pai da neurociência, Santiago Ramón y Cajal em 1899 (y Cajal, 1899). Muito embora a idéia de reproduzir capacidades inteligentes em sistemas artificiais remonta a antiguidade, a descoberta de tais células trouxe maior expectativa 
neste sentido. Um primeiro modelo computacional de neurônio (neurônio artificial) foi elaborado em 1943 por McCulloch e Pitts. A respectiva publicação científica marca a criação da área de pesquisa em redes neurais. O modelo apresentado em (McCulloch e Pitts, 1943) é tal qual o ilustrado na Figura 2.2:

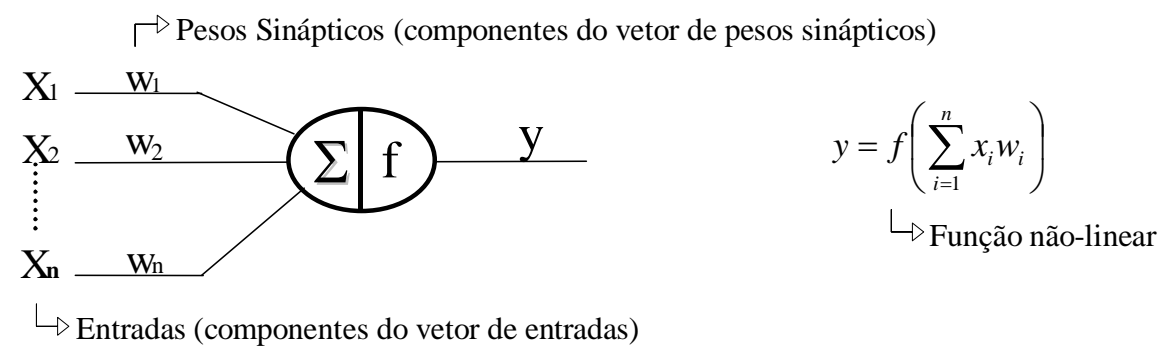

Figura 2.2: Neurônio Artificial

O neurônio artificial é um processador com capacidades simplificadas para tratamento dos sinais de entrada, em que estes possuem uma relação não linear com a saída. Além disso, possuem capacidade de adaptação de parâmetros. De acordo com o modelo da Figura 2.2, o vetor $\mathbf{x}=\left[x_{1}, x_{2}, \ldots, x_{n}\right]$ corresponde às entradas ou estímulos externos apresentados ao neurônio. $\mathrm{O}$ vetor $\mathbf{w}=\left[w_{1}, w_{2}, \ldots, w_{n}\right]$ equivale aos pesos sinápticos, que correspondem à memória do neurônio.

Porém, o modelo de McCulloch e Pitts, apesar de capturar algumas características típicas do processamento neural biológico, era incapaz de executar o aprendizado que viabilizasse a aquisição de conhecimento e a melhoria no desempenho da rede. Um modo de proporcionar capacidade de aprendizado as redes neurais foi concebido por Donald Hebb em 1949 (Hebb, 1949). Em seu livro, Hebb perseguia a idéia de que o condicionamento psicológico clássico está presente em qualquer parte dos animais pelo fato de que esta é uma propriedade de neurônios individuais. Suas idéias não eram completamente novas, mas Hebb foi o primeiro a propor uma lei de aprendizagem concreta e específica para as sinapses dos neurônios. Este passo fez crescer a intenção em buscar inspiração na própria natureza para fazer emergir comportamentos inteligentes.

Em 1951, Marvin Minsky construiu o primeiro neuro computador denominado Snark. A partir de um ponto de partida determinado, Snark ajustava seus pesos automaticamente executando com sucesso sua tarefa. Sua contribuição para a comunidade científica deve-se pela inspiração para as estruturas que o sucederam, mesmo não sendo utilizado para processar informações úteis. Um passo realmente importante na pesquisa em redes neurais foi a concepção de um modelo denominado perceptron, juntamente com um método de aprendizagem proposto por Rosenblatt (Rosemblatt, 1958). O perceptron é considerado uma rede neural com apenas um neurônio capaz de aprender de acordo com o mecanismo de aprendizagem proposto por Hebb (Hebb, 1949). Seu propósito é a resolução de problemas relacionados ao reconhecimento de padrões. Minsky e Papert, em seu 
livro Perceptrons (Minsky e Papert, 1969), analisaram e demonstraram matematicamente que os modelos de redes neurais baseados no perceptron não eram capazes de solucionar o problema do tipo Ou Exclusivo (Exclusive Or - XOR). Concluíram que os modelos baseados no perceptron não são capazes de distinguir padrões não-linearmente separáveis assumindo que as redes neurais são restritas a essa limitação.

Após a hipótese de limitação dos modelos baseados no perceptron em (Minsky e Papert, 1969), a pesquisa em torno das redes neurais desacelerou até os anos 80 quando foram impulsionadas novamente motivadas pelo surgimento de novos modelos de redes neurais que ofereceram contribuições para a área. Hopfield (1982) propôs um modelo de redes em que as conexões dos neurônios são recorrentes garantino que a rede obtivesse um estado estável na ausência de entradas externas. Para tanto, Hopfield associou o estado da rede à uma função de energia. A obtenção de um estado estável ocorre pela minumização da função de energia, atE alcançar um estado em que esta seja mínima (estável). Possuindo um comportamento baseado na competição entre os neurônios, em que o aprendizado é não-supervisionado, o modelo proposto é capaz de armazenar padrões e posteriormente recuperá-los independente da presença de ruídos. Kohonen (1982) apresentou um modelo em que os neurônios estão conectados com aqueles posicionados mais próximos a eles estabelecendo um método de aprendizagem competitivo chamado de mapas auto-organizáveis (Self-Organizing Maps - SOM).

Gail Carpenter e Stephen Grossberg criaram o modelo ART (Adaptive Ressonance Theory) em 1987 (Carpenter e Grossberg, 1987b). Este modelo utiliza um mecanismo de aprendizado nãosupervisionado e competitivo criando protótipos (clusters) dos padrões aprendidos. A Teoria da Ressonância Adaptativa foi desenvolvida para modelar uma rede neural SOM para reconhecimento de padrões baseada em dados biológicos e comportamentais. Existem redes ART dos mais diversos tipos, utilizando paradigmas de aprendizado tanto supervisionado como não supervisionado. Entre os mais utilizados são: ART 1 (Carpenter e Grossberg, 1987b) (Carpenter e Grossberg, 1988) (Moore, 1988) (Fausett, 1994); ART 2 (Carpenter e Grossberg, 1987a) (Fausett, 1994); ARTMAP (Carpenter et al., 1991a); Fuzzy ART (Carpenter et al., 1991b).

Tendo em vista o problema apontado por Minsky e Papert, um modelo de rede neural de múltiplas camadas dotado de um novo mecanismo de aprendizagem denominado Backpropagation (Retropropagação) foi proposto por Rumelhart, Hinton e Willians (Rumelhart et al., 1986). A rede proposta é composta por neurônios baseados no modelo do perceptron distribuídos em várias camadas (chamada de Multi-Layer Perceptron - MLP) que exerce um método de aprendizagem para tratar os perceptrons baseado na retropropagação do erro do sinal de saída através das camadas da rede. Este algoritmo permite realizar o aprendizado por correção de erros em uma rede com múltiplas camadas (níveis) e, conseqüentemente, resolveria o problema do XOR. 


\subsubsection{Topologia das Redes Neurais}

A topologia de uma RNA é um parâmetro importante na sua concepção, pois define o tipo de problema que pode ser tratado pela rede. Uma RNA pode ser representada por um grafo direcionado (dígrafo), em que aos vértices associam-se os subsistemas componentes (elementos de processamento) e aos arcos, associam-se as conexões entre os subsistemas. As mais interessantes potencialidades das redes neurais não são factíveis a um único neurônio. É necessário um conjunto de neurônios convenientemente agrupados (estrutura da rede neural) e conectado por meio de pesos sinápticos (conhecimento, memória) para que tais potencialidades possam ser empregadas. A decisão de como conectar os neurônios é uma das tarefas mais árduas na modelagem de uma rede neural. Os modelos de redes neurais empregados na resolução dos problemas mais diversos apresentam algumas estruturas básicas e outras particulares que desempenham funções especificas no processamento neural. Considerando as estruturas básicas, estas são estabelecidas através de conexões entre os neurônios e o arranjo entre as camadas de neurônios da rede

Os neurônios podem se conectar de maneira ascendente (acíclico) ou descendente (cíclico). A principal diferença entre essas duas formas de conexão está na ausência de realimentação da rede na primeira, ou seja, não há a presença de ciclos. Na conexão ascendente, os neurônios são conectados a outros responsáveis por desempenhar uma tarefa em uma etapa posterior do processamento (rede direta). Dessa forma o sinal da rede é propagado de maneira direta até a camada de saída. Enquanto que na conexão descendente os neurônios são conectados a outros que executam uma etapa anterior (rede recorrente), como por exemplo, na realimentação da rede pelos sinais de saída para a recuperação de memória armazenada. A seguir são citados alguns modelos de redes neurais e suas respectivas topologias. As Figuras 2.3(a) e 2.3(b) mostram uma rede neural genérica direta e recursiva, respectivamente.

O modelo Perceptron proposto por (Rosemblatt, 1958) pode ser considerado uma rede simples constituída por uma única camada com um neurônio. A entrada do neurônio equivale à entrada da rede assim como a saída do neurônio equivale à saída da rede. Além dos estímulos externos, o perceptron recebe como entrada outro fator denominado bias. Este fator determina como o mecanismo de aprendizagem explora o espaço de busca dos parâmetros do neurônio ou da rede. A topologia de um perceptron pode ser observada na Figura 2.3(c). O modelo MLP de Rumelhart, Hinton e Willians (Rumelhart et al., 1986), para sanar as limitações do perceptron, é composto por vários neurônios distribuídos em três tipos de camadas distintas: entrada - camada que recebe estímulos externos; intermediária (ou oculta) - camada que recebe como entrada o sinal de saída dos neurônios da camada anterior, podendo ser a camada de entrada ou outra camada intermediária; saída - camada que recebe como entrada o sinal de saída dos neurônios da última camada intermediária e gera a saída da rede. No modelo MLP, o sinal da rede propaga de forma ascen- 
dente, todos os neurônios de uma camada são conectados a todos os neurônios da camada seguinte.

A rede de Hopfield (Hopfield, 1982) é constituída por uma quantidade determinada de neurônios em que cada neurônio está conectado com todos os demais. O modelo de Hopfield é um modelo matricial não-linear recorrente, ou seja, as saídas estão conectadas às entradas por um atraso de tempo. Por esse motivo, este modelo é uma rede fortemente conectada. Hopfield introduziu um valor de energia em seu modelo, associado a cada estado da rede. Esta energia obedece uma função decrescente à medida que se estabelece um histórico da trajetória no espaço de estados em direção a pontos fixos (pontos estáveis com energia mínima) determinados no processo de treinamento. A dinâmica da rede é conduzida pela criação dos pontos fixos e uma regra de atualização que constituem o armazenamento e a recuperação de informação. Também conhecido como mapas de Kohonen, o modelo de Kohonen (Kohonen, 1982) apresenta uma topologia composta por uma malha de neurônios disposta em um plano na qual cada neurônio está conectado com os neurônios vizinhos (adjacentes). Pode ser considerado que o modelo de Kohonen (Kohonen, 1982) constitui de somente uma única camada em que todos os neurônios recebem estímulos externos, e a saída da rede corresponde à saída do neurônio vencedor. O neurônio vencedor é definido como sendo o neurônio que possui a maior similaridade entre o padrão dos pesos sinápticos e o padrão de entrada. As Figuras 2.3(d) e 2.3(e) ilustram a topologia das redes neurais citadas anteriormente.

Independente do modelo de rede neural, o mecanismo de como os sinais de entradas são processados no soma do neurônio é similar. O processamento neural ocorre quando o neurônio recebe estímulos externos (vetor $\mathbf{x}$ ), e juntamente com o vetor de pesos sinápticos $\mathbf{w}$, é aplicada uma função que mede a similaridade entre os vetores. Uma medida de similaridade bastante utilizada é o produto interno entre os vetores $\mathbf{x}$ e w mostrada na Figura 2.2. Após a comparação dos vetores, a saída $y$ do neurônio é obtida através da aplicação de uma função de ativação $f($.$) ao resultado$ da comparação dos vetores. A função de ativação realiza o processamento dos sinais recebidos por cada neurônio e o transforma em um estado de ativação neural. A função de ativação funciona através da aplicação de funções matemáticas gerando um valor denominado de valor de ativação. Tal valor, normalmente dentro do intervalo [0,1], é propagado através das conexões sinápticas até os neurônios de saída indicando com que grau de ativação de cada neurônio dispare. Uma maneira utilizada pra determinar se o disparo do neurônio é significativo, é estabelecer um limiar (threshold) de ativação que deve ser excedido pela função de ativação. Quatro funções de ativação são definidas a seguir. A Figura 2.4 mostra graficamente quatro funções de ativação: função linear, função rampa, função degrau e função sigmoidal.

A função linear, definida pela equação 2.1, é especificada por um valor constante que combina com a entrada do neurônio. Limitando a função linear em um intervalo especificado, os valores da função linear para qualquer entrada pertencente ao universo de discurso que excedem tanto o limite inferior quanto o superior são redefinidos por valores constantes. A restrição da linear é denomi- 


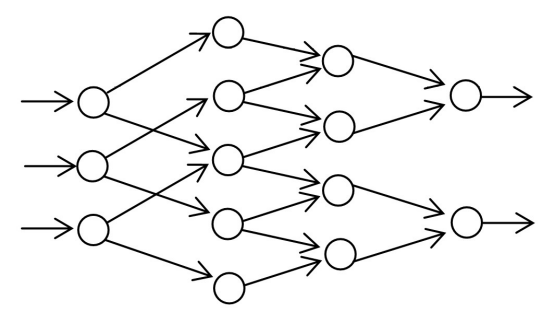

(a)

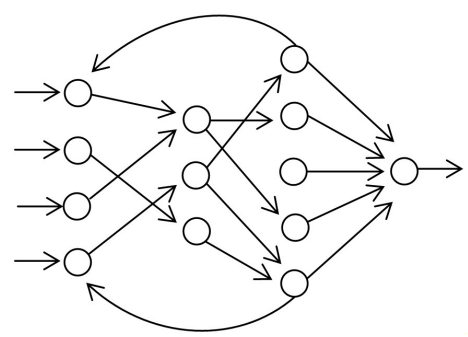

(b)

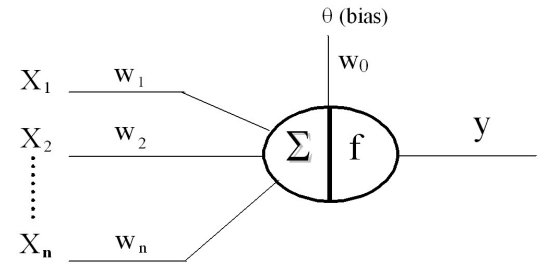

(c)

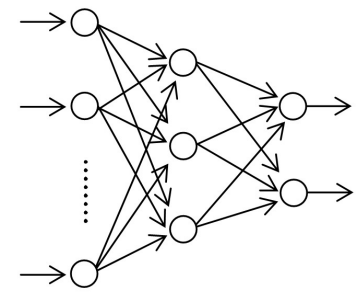

(d)

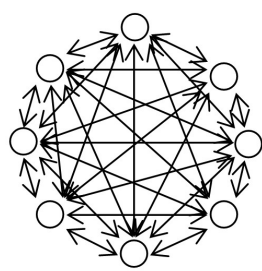

(e)

Figura 2.3: Topologias de Redes Neurais Artificiais (a) Rede Direta; (b) Rede Recorrente; (c) Topologia de um Perceptron; (d) Modelo de Rummelhart; (e) Modelo de Hopfield

nada de função rampa definida na equação 2.2. A função degrau (equação 2.3) assume valores constante para uma entrada menor que um limiar definido e outro valor constante quando a entrada é maior que esse limiar. A função sigmoidal é limitada e monotônica, definida pela equação 2.4.

$$
\begin{gathered}
f(x)=\alpha x \\
f(x)=\left\{\begin{array}{l}
0, \text { se } x<0 \\
x, \text { se } 0<x<1 \\
1, \text { se } x \geq 1
\end{array}\right. \\
f(x)=\left\{\begin{array}{l}
0, \text { se } x \leq 0 \\
1, \text { se } x>0
\end{array}\right. \\
f(x)=\frac{1}{\left(1+e^{-\beta x}\right)}
\end{gathered}
$$


em que $\alpha$ é um valor real que define a saída linear para os valores de entrada, $\beta$ determine a suavidade da curva da função sigmoidal e $x$ é a entrada para as funções de ativação.

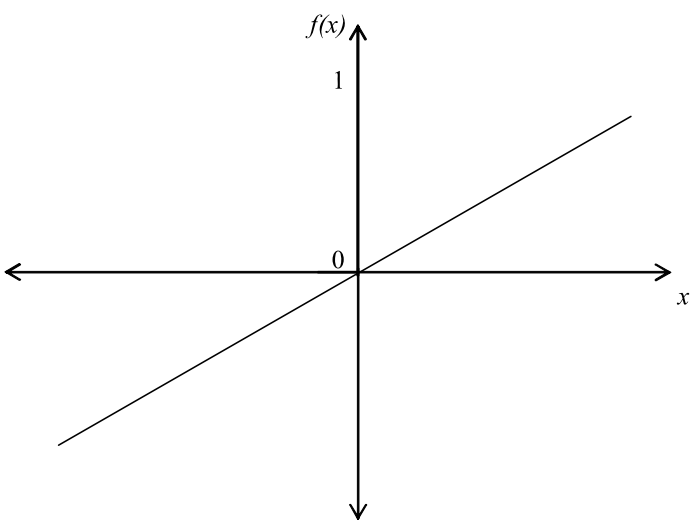

(a)

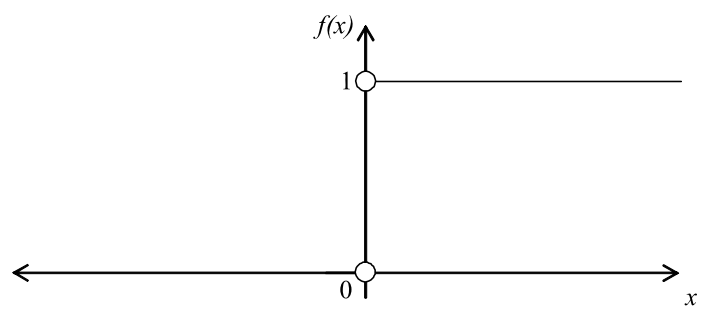

(c)

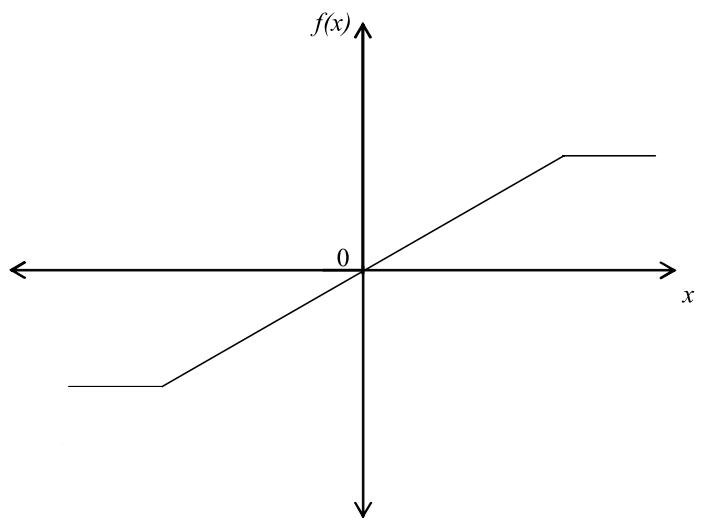

(b)

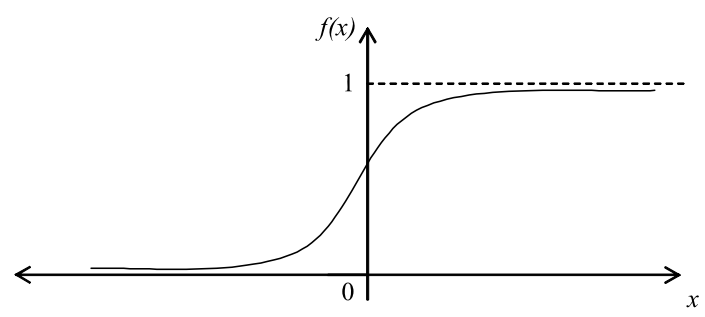

(d)

Figura 2.4: Funções de ativação não-lineares (a) função linear; (b) função rampa; (c) função degrau; (d) função sigmoidal

\subsubsection{Aprendizagem}

Uma das mais importantes propriedades das redes neurais, herdada do sistema nervoso humano, é a aprendizagem. As redes são capazes de adquirir conhecimento a partir de experiências com o ambiente que as envolve na tentativa de solucionar seus problemas. A partir destas experiências, as sinapses são alteradas de modo a adaptar-se a inúmeras situações. As sucessivas alterações das sinapses e conseqüentemente a adaptação das redes neurais caracterizam sua aprendizagem tornando capazes de generalização e reprodução do raciocínio aproximado.

O neurônio proposto por McCulloch e Pitts carecia de um mecanismo de aprendizagem que viabilizasse a incorporação de conhecimento e a melhoria no desempenho da rede, de forma automática. Esta deficiência permaneceu presente nos modelos de neurônios artificiais por um longo período, mesmo porque também não havia qualquer conhecimento sobre como o processo de aprendizagem se dava em nível celular em sistemas biológicos.

O método de aprendizagem é um dos critérios para classificar os modelos de redes neurais e se distinguem pelo conteúdo das informações trocadas durante a aprendizagem da rede neural. 
Seguindo este critério, os métodos de aprendizagem se agrupam em três classes: supervisionado, não-supervisionado, e por reforço. A seguir, estes métodos de apredizagem são brevemente descritos assim como exemplos de redes neurais que caracterizam por utilizar tais métodos.

\section{Aprendizado Supervisionado}

O método de aprendizado supervisionado consiste na apresentação para a rede neural de um conjunto de exemplos, cada qual formado por um par entrada/saída. Para cada exemplo, a rede neural recebe a entrada e deve aprender a gerar a saída correspondente. No caso da rede neural não gerar a saída desejada, é encontrada a diferença (erro) entre a saída obtida e a saída desejada. A partir do valor dessa diferença, os pesos sinápticos dos neurônios são atualizados para que, nas próximas iterações (ou seja, próximos instantes em que um par de entrada/saída for apresentado à rede) a saída obtida se aproxime ao máximo da saída desejada. Portanto, não há necessidade de que a rede neural descubra quais saídas devem ser apresentadas como resposta às entradas. As saídas corretas são estabelecidas pelos exemplos de treinamento.

A Figura 2.5 ilustra o mecanismo do método de aprendizado supervisionado. Tanto a rede neural quanto o supervisor recebem o padrão entrada/saída. A saída obtida é comparada com a saída desejada determinada pelo supervisor. A diferença entre as saídas é enviada a rede neural para o ajuste dos pesos sinápticos.

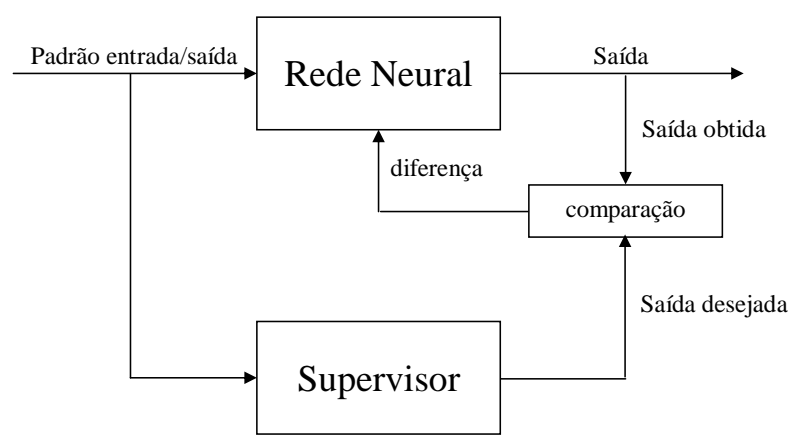

Figura 2.5: Aprendizado Supervisionado

A seguir é apresentado um dos métodos de aprendizagem mais difundidos na comunidade de redes neurais artificiais. O método de aprendizagem supervisionado denominado de Backpropagation foi proposto por Rumelhart, Hinton e Willians (Rumelhart et al., 1986). Este é o modelo mais conhecido de treinamento supervisionado sendo um dos principais responsáveis pelo ressurgimento do interesse em redes neurais artificiais. O algoritmo Backpropagation é constituído por dois passos: passo para frente (forward) e passo para trás (backward). O passo forward consiste na propagação dos sinais aplicados à camada de entrada até a camada de saída da rede, passando pelas camadas intermediárias, gerando uma resposta. O erro encontrado entre a saída obtida pela rede e a saída desejada é propagado no sentido inverso (da camada de saída para a camada de entrada) 
para o ajuste dos pesos sinápticos. Tal propagação do sinal de erro determina o passo backward do método de aprendizagem. Baseado na regra delta proposta por Widrow e Hoff (Widrow e Hoff., 1960), este algoritmo apresenta uma forma de definir o erro dos neurônios das camadas intermediárias, possibilitando o ajuste de seus pesos. Estes ajustes são realizados utilzando-se o método do gradiente.

Os passos para frente e para trás são repetidos por diversas iterações com o objetivo de minimizar o erro segundo a saída desejada. O sinal de erro $e$ da saída $y$ do neurônio $i$ é definido por:

$$
e_{i}(t)=d_{i}(t)-y_{i}(t)
$$

em que $d_{i}(t)$ é a saída desejada para o $i$-ésimo neurônio da camada de saída na iteração $t$.

Agregando os sinais emitdos pelos neurônios da camada de saída na iteração $t$ com a apresentação de todos os padrões de entrada, obtêm-se a função erro a ser minimizada mostrada na equação 2.6:

$$
E=\frac{1}{2} \sum_{k=1}^{P} \sum_{i=1}^{N} e_{i}(t)^{2}=\frac{1}{2} \sum_{i=1}^{N}\left(d_{i}(t)-y_{i}(t)\right)^{2},
$$

em que $E$ é a medida de erro total, $P$ é o número de padrões de entrada e $N$ é o número de neurônios na camada de saída da rede.

Embora o erro total (equação 2.6) seja definido pela soma dos erros dos neurônios de saída para todos os padrões, a função de erro a ser minimizada é o erro individual (equação 2.7)de cada padrão, assumindo que esta simplificação não ocasiona na perda de generalidade. A minimização dessa função corresponde, então, na minimização do erro total.

$$
E=\frac{1}{2} \sum_{i=1}^{N} e_{i}(t)^{2}=\frac{1}{2} \sum_{i=1}^{N}\left(d_{i}(t)-y_{i}(t)\right)^{2},
$$

em que $N$ é o número de neurônios na camada de saída da rede.

O método mais utilizado para o ajuste dos pesos sinápticos de uma rede neural multicamada é o do gradiente. Este método necessita da informação das derivadas parciais de primeira ordem de erro com relação aos pesos de cada neurônio e das funções de ativação dos neurônios da rede. Para as conexões entre a camada intermediária e a camada de saída, a regra do gradiente é definida por:

$$
\Delta_{w_{i j}}=-\eta \frac{\partial E\left(w_{i j}\right)}{\partial w_{i j}}=\eta . \delta_{i} \cdot y_{j}
$$


em que $w_{i j}$ é peso sináptico correspondente à sinpase $j$ do neurônio $i, \eta$ é a taxa de aprendizagem do algoritmo backpropagation e $\delta_{i}$ é o gradiente local definido por:

$$
\delta_{i}=\varphi^{\prime}\left(c_{i}\right) \cdot\left(d_{i}-y_{i}\right)
$$

em que $c_{i}$ é o sinal de entrada dos pesos aplicado ao neurônio $y_{i}$ e $\varphi($.) é a função de ativação do neurônio. As conexões $w_{i j}$ são ajustadas aplicando a equação 2.10:

$$
w_{i j}(t+1)=w_{i j}(t)+\Delta_{w_{i j}}
$$

Para as sinpases entre a camada de entrada e a camada intermediária, a função erro é diferenciada com o respectivo peso $w_{j k}$ usando a regra da cadeia, definida por:

$$
\Delta_{w_{j k}}=-\eta \frac{\partial E\left(w_{j k}\right)}{\partial w_{j k}}=-\eta \cdot \sum \frac{\partial E\left(w_{j k}\right)}{\partial y_{j}} \cdot \frac{\partial y_{j}}{\partial w_{j k}}=\eta \cdot \delta_{j} \cdot x_{k},
$$

em que $w_{j k}$ corresponde à sinpase $k$ do neurônio $j$ e $\delta_{j}$ é o gradiente local em relação à $w_{j k}$ expresso por:

$$
\delta_{j}=\varphi^{\prime}\left(h_{i}\right) \sum w_{i j} . \delta_{j}
$$

em que $h_{i}$ é o peso do sinal de entrada aplicado ao neurônio $y_{j}$.

O ajuste dos pesos sinápticos $w_{j k}$ é definido pela seguinte equação:

$$
w_{j k}(t+1)=w_{j k}(t)+\Delta_{w_{j k}},
$$

A frequiência de atualização (ajuste) dos pesos influencia o desempenho da rede durante o treinamento. Há duas abordagens que estabelecem os instantes de atualização dos pesos para o algoritmo Backpropagation: por padrão e por ciclo (batch). Na abordagem por padrão, os pesos sinápticos são ajustados após a apresentação de cada padrão de entrada para a rede durante o treinamento. Porém com taxas elevadas de aprendizagem para o ajuste dos pesos, a rede tornase instável, pois os pesos sofrem um grande passo para minimizar o erro gerado pelo padrão de entrada corrente ocasionando na perda de generalidade quanto aos demais padrões. Dessa forma, esta abordagem requer taxa de aprendizagem baixa. A abordagem por padrão se sobressai sobre a abordagem por ciclo por demandar menos tempo e, principalmente, se o conjunto de treinamento for grande e redundante. $\mathrm{Na}$ abordagem por ciclo, o ajuste dos pesos sinápticos ocorre após a apresentação de todos os padrões de entrada pertencentes ao conjunto de treinamento. Assim, o erro propagado no passo para trás corresponde ao erro gerado por todos os padrões caracterizando a estabilidade da rede após a atualização dos pesos. Em contraste com a abordagem por padrão, esta técnica requer mais tempo caso o conjunto de treinamento seja grande e redundante. 
Para o método Backpropagation, o processo de aprendizagem deve prosseguir até que o critério de parada seja alcançado. Tal critério implica o estabelecimento de um erro mínimo $\epsilon$. Ao longo do período de treinamento, deseja-se que o erro gerado pela rede seja reduzido. O processo de aprendizagem é interrompido quando o erro gerado alcança $\epsilon$. Valores para o erro menores que $\epsilon$ são considerados admissíveis.

Deve ser observado que quando o treinamento se estende por um período muito longo, há o risco de a rede perder sua característica de generalização (Geman et al., 1992) por se especializar somente nos padrões do conjunto de treinamento. Generalização é uma das mais importantes características das redes neurais artificais. O conjunto de treinamento da rede é o principal fator que determina sua capacidade de generalização. Tal conjunto, portanto, deve expressar as características gerais do Universo de Discurso. Isto implica, em dispor de vários padrões de cada classe a ser treinada, o que seria considerado o conjutno de treinamento ideal. A escolha dos padrões deve estar sempre bem fundamentada na caracterização do Universo de Discurso. A não generalização pode ser caracterizada pela escolha centrada de padrões particularizando o universo.

\section{Aprendizado Não-Supervisionado}

Nos métodos não-supervisionados, a aprendizagem se processa sem que saídas corretas sejam fornecidas. Ao contrário do método supervisionado, somente o padrão de entrada é fornecido a rede. Este método capacita as redes neurais extrairem correlações presentes nos dados de entrada, ou seja, permite a formação de representações internas para codificar características da entrada e criar novas classes automaticamente. Após a aprendizagem, a rede neural torna-se capaz de classificar suas entradas de acordo com as correlações aprendidas. A Figura 2.6 ilustra o processamento neural do aprendizado não-supervisionado.

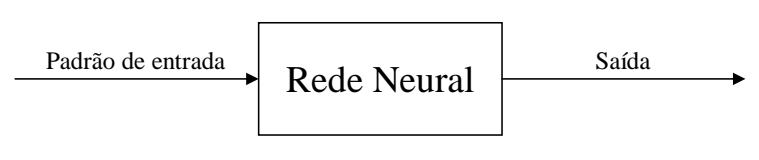

Figura 2.6: Aprendizado Não-Supervisionado

A primeira proposta concreta, e bem sucedida, de um método de aprendizagem para estruturas neurais foi apresentada por Hebb (1949). Em seu trabalho, apresenta uma lei denominada lei de Hebb (Hebb, 1949), que rege ajustes dos pesos sinápticos com o seguinte texto: "Dado dois neurônios diretamente conectados entre si, a sinapse correspondente é intensificada sempre que o neurônio pré-sináptico participa do disparo do neurônio pós-sináptico". A intensificação das sinapses corresponde a uma variação nos pesos sinápticos. Vale ressaltar que o disparo do 
neurônio ocorre quando seu sinal emitido é diferente de zero. Desse modo, a lei de Hebb pode ser formalizada através da equação 2.14:

$$
w_{i j}(t+1)=w_{i j}(t)+\eta y_{i}(t) y_{j}(t)
$$

em que $w_{i j}$ é a sinapse corresponde à sinapse $j$ do neurônio $i, y_{i}$ e $y_{j}$ são as saídas dos neurônios pré-sináptico $i$ e pós-sinpático $j$, respectivamente, $\eta$ é o fator de aprendizagem.

A lei de Hebb é um método de aprendizagem que independe do desempenho da rede, pois o ajuste dos pesos sinápticos ocorre devido ao sincronismo entre os disparos dos neurônios. $\mathrm{O}$ ajuste dos pesos se baseia em informações locais, ou seja, é importante considerar somente o sincronismo de disparo entre os neurônios envolvidos.

\section{Aprendizado por Reforço}

Para o Aprendizado por Reforço, um agente é aquele que, a partir da iterção com o ambiente em que atua, aprende de maneira autônoma uma política ótima de atuação, por experimentação direta, sem ser ensinado por meio de exemplos fornecidos por um supervisor, como ocorre com o aprendizado supervisioando. Um agente iterage com o ambiente em intervalos de tempo discreto em um ciclo de percepção-ação (Figura 2.7), e observa (a cada iteração do ciclo) o estado atual $s$ e escolhe a ação $a$ para realizar, alterando o estado atual do ambiente. Ao executar a ação, o agente recebe um sinal de reforço escalar $r_{s, a}$ indicando o quão desejável é o estado resultante. Tal sinal de reforço corresponde a uma penalização ou recompensa como conseqüência da ação realizada pelo agente. $\mathrm{O}$ comportamento do agente deve-se restringir a escolha de ações que tendem a aumentar, ao longo do tempo, a soma dos valores do sinal de reforço. Dessa maneira, o agente torna apto para realizar uma determinada tarefa ao longo das iterações através da sistemática tentativa-e-erro, guiado por uma grande variedade de algoritmos.

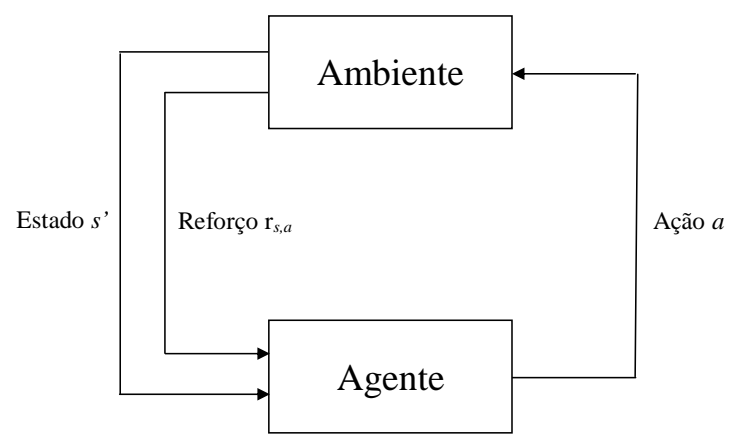

Figura 2.7: Aprendizado por Reforço 
O Aprendizado por Reforço não é definido pela caracterização de algoritmos de aprendizagem, mas por caracterizar uma classe de problemas de aprendizagem. Todo o algoritmo capaz de resolver esse problema é considerado um algoritmo de aprendizado por reforço. O aprendizado por reforço fundamenta-se no acréscimo da tendência para produzir uma ação, caso esta ação seja seguida de estados satisfatórios ou pela melhoria destes. Dessa forma, considera-se que tal tendência é reforçada. Estendendo esta idéia, ações podem ser selecionadas em função da informação sobre os estados que elas podem produzir, o que introduz aspectos de controle com realimentação.

A tarefa do agente baseia-se na busca por uma política $p$, mapeando estados $(s \in S)$ em ações ( $a \in A(s)$ ) em uma probabilidade $p(s, a)$ de se escolher uma ação $a$ em um estado $s$, para maximizar a medida de reforço ao longo das iterações. Formalmente, o modelo consiste de três conjuntos: 1) conjunto discreto de estados de ambiente $S ; 2)$ conjunto discreto de ações de agente, $A$; 3 ) conjunto de sinais de reforço representado, geralmente, pelo conjunto $\{0,1\}$ ou números reais. Uma forma bastante conhecida utilizada, atualmente, para modelar problemas de aprendizagem por reforço é o Processo de Decisão de Markov (MDP) (Bellman, 1957) (Puterman, 1994) (Howard, 1960) (Bertsekas, 1987). Este processo consiste na definição de estados (denominados de Markov)que contenham todas as informções relevantes do ambiente, necessárias para a tomada de decisão de um agente. A partir da descrição de um estado, o agente tem a capacidade de escolher uma ação segundo uma probabilidade de transição de estado associada aos mesmos. Considerando que o a gente perceba o estado $s$ e execute a ação $a$, a probabilidade do agente passar para o estado $s^{\prime}$ é designada por $P\left(s^{\prime} \mid s, a\right)$ e a recompensa esperada pela ação tomada por $R\left(s^{\prime} \mid s, a\right)$.

Os métodos de aprendizagem por reforço podem ser vistos como um meio termo entre o aprendizado supervisionado e o não-supervisionado, prescindindo da supervisão. A principal diferença entre o aprendizado supervisionado e o aprendizado por reforço é a medida de desempenho usada em cada um dos métodos. No aprendizado supervisionado, a medida de desempenho é baseada no conjunto de respostas desejadas usando um critério de erro conhecido, enquanto no aprendizado por reforço o desemepnho é baseadao em qualquer medida que possa ser fornecida ao sistema. $\mathrm{O}$ conjunto de treinamento de uma rede neural utilizando o aprendizado por reforço consiste somente no padrão de entrada, porém há um módulo externo que visa avaliar, de acordo com algum critério de desemepenho estabelecido, a resposta gerada pela rede se é satisfatória. As redes neurais aprendem sem que disponham da informação a respeito das respostas desejadas para as respectivas entradas apresentadas. Dessa forma, a única informação de realimentação fornecida à rede é se uma determinada saída está correta ou não. Considerando que o desemepenho da rede é degradado por conseqüência de uma ação, então esta é penalizada, caso contrário a ação é reforçada. O resultado da avaliação é retornado à rede como um sinal de reforço ou punição para a última ação da rede para que esta utilize-o visando o ajuste de seus pesos sinápticos. A utilização do método de aprendizagem por reforço tem como meta habilitar as redes neurais em encontrar as respostas que 
melhorem seu desempenho, maximizando o reforço (Haykin, 1994).

\subsection{Introdução aos Conjuntos Nebulosos}

O conceito de conjuntos nebulosos vem da intenção de agrupar, organizar, generalizar conhecimentos a respeito de uma certa variável (Delgado, 2002). Considerando que U seja o universo de discurso contendo diversas características da variável $x$, a função de pertinência $\rho($.$) aplicada$ a variável indica com que grau esta pertence ao conjunto $A$ definido por um conjunto de pares ordenados.

$$
A=\left\{\left(x, p_{A}(x)\right) \mid x \in \mathbf{U}\right\}
$$

Enquanto que em conjuntos clássicos o grau de pertinência da variável pode assumir somente dois valores (pertence ou não pertence ao conjunto $A$ ) na teoria dos conjuntos nebulosos, a função de pertinência para uma variável pode assumir qualquer valor dentro de um intervalo determinado. No caso da avaliação de uma variável pertencer ou não a um conjunto, os limites para os possíveis valores assumidos pela função de pertinência $\rho($.$) são pertence e não pertence. Dessa forma, a$ função de pertinência aplicada a variável pode não indicar com exatidão se a variável pertence ou não ao conjunto $A$, fornecendo uma informação imprecisa, uma das principais características dos conjuntos nebulosos (Zadeh, 1965).

\subsubsection{Funções de Pertinência}

Um dos conceitos associados à teoria de conjuntos nebulosos é a pertinência. Um conjunto nebuloso $A$ é definido pela função de pertinência $\rho_{A}($.$) que estabelece para cada variável x$ um grau de pertinência ao conjunto $A$. A função de pertinência assume valores dentro do intervalo $[0,1]$ enquanto que na teoria dos conjuntos clássicos o intervalo é restringindo em somente aos limites dos intervalo, $\{0,1\}$. A importante característica das funções de pertinência é permitir que a progressão e regressão do grau de pertinência ocorram de forma gradual não se retendo às limitações impostas pela teoria dos conjuntos clássicos.

Existem vários formatos para as funções de pertinência. A escolha do formato ideal para um determinado propósito assim como seu perfil é uma tarefa árdua. O projetista, no entanto, seguindo seus conhecimentos pode determinar um perfil que considera adequado para a aplicação. Porém, em aplicações onde a determinação do perfil torna-se uma tarefa extremamente complexa é frequiente o uso de técnicas de inteligência artificial, como redes neurais (Figueiredo e Gomide, 1996) e algoritmos genéticos (Calvo et al., 2004) (Hoffmann, 2001) para auxiliar na definição das 
funções de pertinência. Os formatos de funções de pertinência mais utilizados são: triangular, trapezoidal, gaussiana e o conjunto unitário (singleton). A Figura 2.8 mostra os formatos citados, seus respectivos modelos matemáticos são apresentados nas Equações 2.16 - 2.19

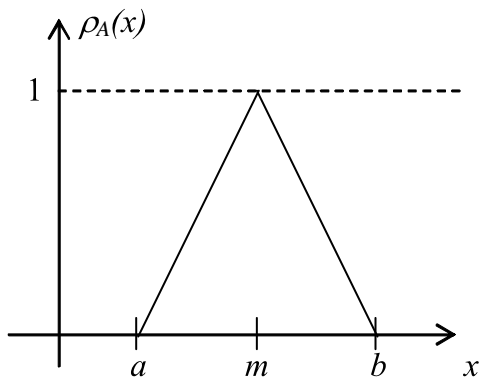

(a)

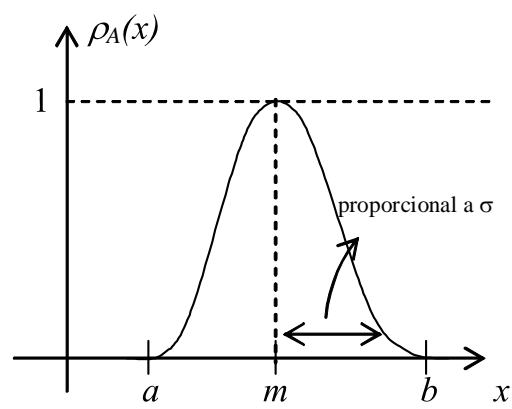

(c)

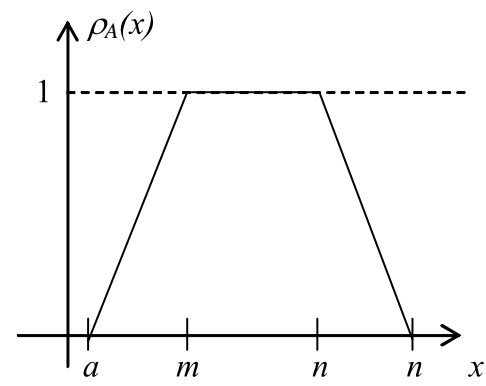

(b)

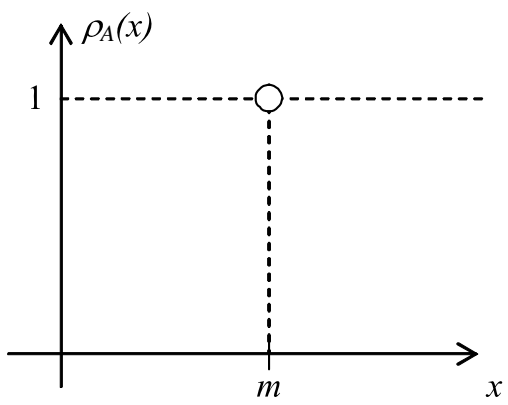

(d)

Figura 2.8: Função de pertinência de conjuntos nebulosos (a) triangular; (b) trapezoidal; (c) gaussiana; (d) singleton.

$$
\begin{gathered}
\rho_{A}(x)=\left\{\begin{array}{l}
0, \text { se } x<\mathrm{a} \\
\frac{x-a}{m-a}, \text { se } a<x \leq m \\
\frac{b-x}{b-m}, \text { se } m<x \leq b \\
0, \text { se } x \geq b
\end{array}\right. \\
\rho_{A}(x)=\left\{\begin{array}{l}
0, \text { se } x<a \\
\frac{x-a}{m-a}, \text { se } a<x \leq m \\
1, \text { se } m<x \leq n \\
\frac{b-x}{b-n}, \text { se } n<x \leq b \\
0, \text { se } x>b
\end{array}\right. \\
\rho_{A}(x)=e x p^{-\sigma(x-m)^{2}} \\
\rho_{A}(x)=\left\{\begin{array}{l}
\mathrm{h}, \text { se } x=m \\
0, \text { caso contrário }
\end{array}\right.
\end{gathered}
$$




\subsubsection{Operadores sobre Conjuntos Nebulosos}

Existem várias operações que podem ser aplicadas a conjuntos nebulosos. Há operações com argumento único, que modificam o formato da função de pertinência, por exemplo, a normalização. Tal operação converte um conjunto nebuloso subnormal em um normal. Um conjunto nebuloso é normal se sua altura é igual a 1, ou seja, se o valor máximo da função de pertinência (para qualquer argumento pertencente ao universo de discurso) for 1. Enquanto que um conjunto nebuloso é dito subnormal se sua altura é menor que 1 (Figura 2.9). Além da normalização há outras operações de um argumento, a concentração (que diminui os valores da função de pertinência), a dilatação (que aumenta os valores da função de pertinência) e a intensificação de contraste (que dilata o conjunto para valores de pertinência acima de 0,5 e concentra o conjunto para valores abaixo de 0,5$)($ Gomide e Pedrycz, 1998).

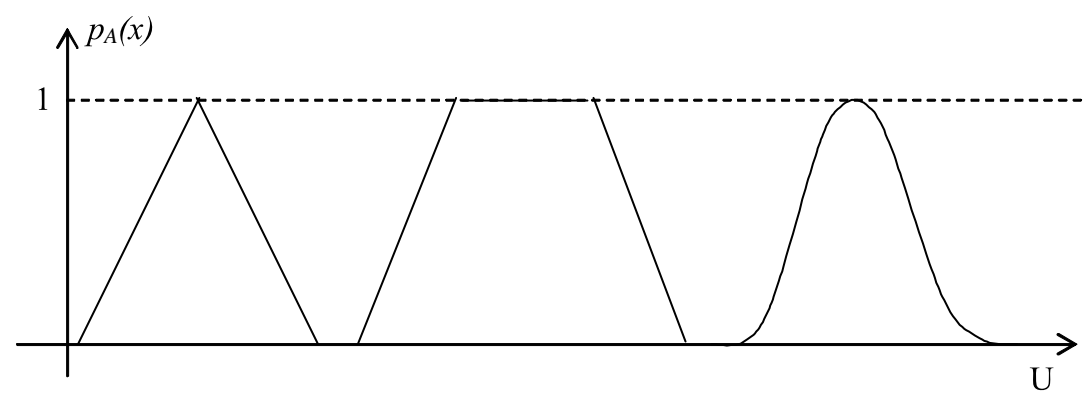

(a)

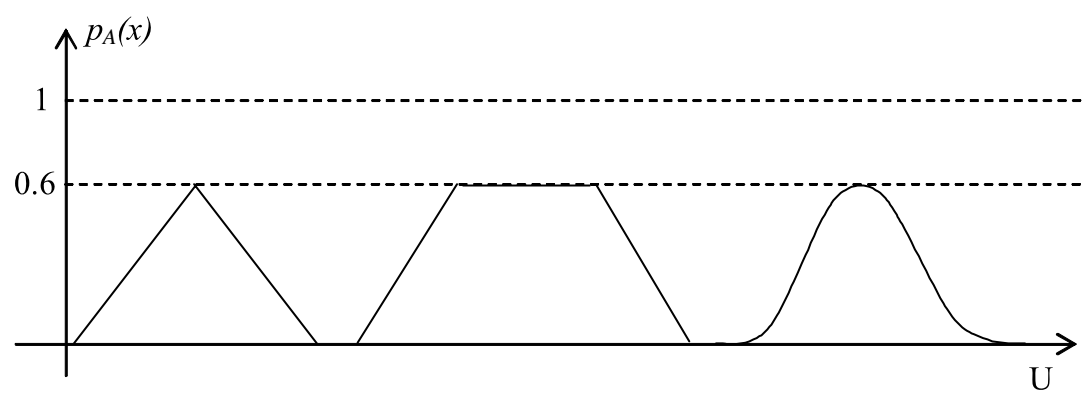

(b)

Figura 2.9: Normalidade (a) conjunto nebuloso normal; (b) conjunto nebuloso subnormal.

$\mathrm{Na}$ teoria clássica, os operadores de união, interseção e complemento são fundamentais na aplicação de conjuntos clássicos. Com base nesses conjuntos, Zadeh (1965) definiu as operações básicas para conjuntos nebulosos através da função de pertinência:

- União: $\rho_{(A \cup B)}=\max \left[\rho_{A}(x), \rho_{B}(x)\right]=\rho_{A}(x) \vee \rho_{B}(x)$;

- Interseção: $\rho_{(A \cap B)}=\min \left[\rho_{A}(x), \rho_{B}(x)\right]=\rho_{A}(x) \wedge \rho_{B}(x)$;

- Complemento: $\rho_{(\bar{A})}=1-\rho_{(A)}$. 
A interseção e a união são identificadas pela conjunção E e disjunção OU, respectivamente, devido ao isomofismo e a lógica proposicional bi-valores (Delgado, 2002). Dessa forma, as operações de conjunção e disjunção podem ser reprensentadas pelos operadores $\vee$ e $\wedge$, respectivamente (Gomide e Pedrycz, 1998). A Figura $2.10^{1}$ ilustra as operações citadas, aplicadas aos conjuntos nebulosos $A$ e $B$.

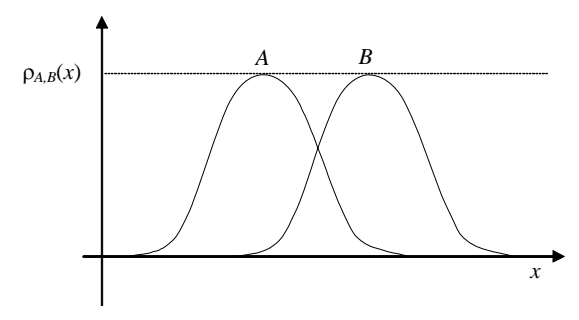

(a)

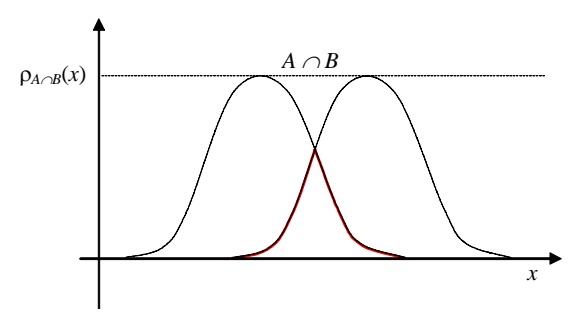

(c)

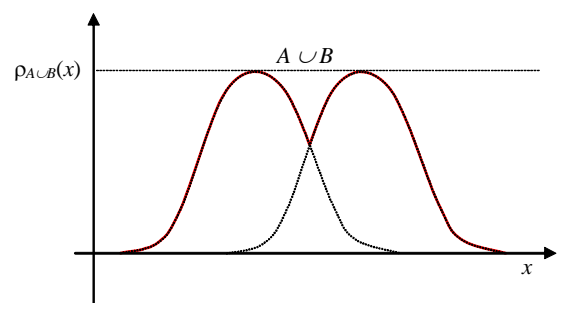

(b)

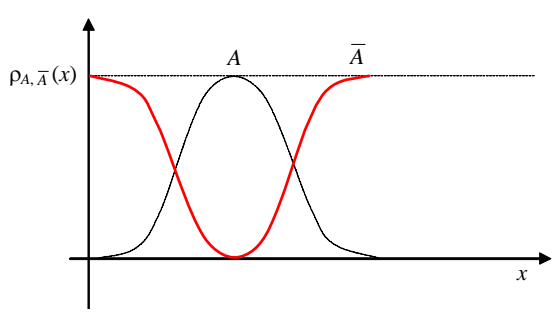

(d)

Figura 2.10: Operações com conjuntos nebulosos: (a) Conjuntos $A$ e $B$; (b) união; (c) interseção; (d) complemento.

$\mathrm{Na}$ teoria dos conjuntos nebulosos, os operadores básicos surgem distribuídos em duas classes de funções de duas variáveis, denominadas t-norma (t) e s-norma (s) com características de comutatividade, associatividade, monotonicidade e condições de contorno. As operações baseadas nessas classes atuam em conjuntos nebulosos situados em universos distintos, diferente da união e interseção que operam em conjuntos definidos em um mesmo universo. Considere os operadores $S(),. T($.$) e R($.) da classe s-norma , t-norma e das duas, respectivamente e $x, y, w, z$ elementos do universo de discurso $\mathbf{U}$ (pertencente a $[0,1]$ ), as propriedades da Tabela 2.1 se aplicam a esses operadores (Yager e Filev, 1994) (Gomide e Pedrycz, 1998).

Tabela 2.1: Propriedades dos operadores nebulosos.

\begin{tabular}{|c|c|}
\hline Comutatividade & $R(x, y)=R(y, x)$ \\
\hline Associatividade & $R(x, T(y, z))=R(T(x, y), z)$ \\
\hline Monotonicidade & $s e x \leq u e y \leq v \rightarrow R(x, y) \leq R(u, v)$ \\
\hline Condições de contorno & $S(0, z)=z, S(1, z)=1 ; T(0, z)=0, T(1, z)=z$ \\
\hline
\end{tabular}

Além dos operadores apresentados anteriormente, existem também operadores específicos que envolvem comparações que resultam em medidas de distância, igualdade, possibilidade e compatibilidade entre conjuntos nebulosos (Gomide e Pedrycz, 1998). Dentre essas medidas, os operadores de medida de possibilidade e de necessidade relacionam dois conjuntos nebulosos $A$ e $B$. $\mathrm{O}$

\footnotetext{
${ }^{1}$ Versão colorida disponível no site www.saber.usp.br
} 
operador de medida de possibilidade avalia o quanto os dois conjuntos são semelhantes, ou seja, indica o grau de sobreposição entre eles. O operador de necessidade avalia o quanto um conjunto está incluso no outro. Dada a função $\sup [A(x)]$ definida como o valor verdade máximo de um conjunto nebuloso, a função inf $[A(x)]$ como o valor verdade mínimo e $x$ pertencente ao universo de discurso $\mathbf{U}$, os operadores de medida de possibilidade e de necessidade são definidos como segue:

- Possibilidade: $\operatorname{Poss}(A, B)=\sup _{x \in U}\left[\min \left(\rho_{A}(x), \rho_{B}(x)\right)\right]$;

- Necessidade: $N e c(A, B)=i n f_{x \in U}\left[\max \left(\rho_{A}(x), 1-\rho_{B}(x)\right)\right]$.

\subsubsection{Computação com Regras Nebulosas: Raciocínio Aproximado}

Os conjuntos nebulosos têm como uma das principais funções dentro da área da inteligência artificial, a de representar conceitos poucos precisos, relacionados a uma determinada grandeza. A necessidade de tal representação surge da idéia de se implementar em sistemas computacionais tais conceitos. Neste sentido, a lógica construída no contexto dos conjuntos nebulosos corresponde a uma poderosa ferramenta. Para tanto as regras nebulosas permitem que o raciocínio aproximado represente a lógica nebulosa de maneira conveniente para a implementação de sistemas computacionais. Esta representação consiste de procedimentos de inferência baseados no conceito de regra composicional de inferência utilizados para derivar conclusões a partir de um conjunto de regras nebulosas e fatos conhecidos. A partir da definição de variáveis lingüísticas e regras composicional de inferência, as regras nebulosas são associadas ao raciocínio aproximado.

\subsubsection{Variáveis Lingüísticas}

Uma variável lingüística é definida como a cobertura do domínio da variável com uma série de conjuntos nebulosos e a definição do significado de cada conjunto (Berthold e Hand, 1999). Com outras palavras, pode-se dizer que uma variável lingüística é uma variável que assume palavras ou sentenças como valores (Gomide e Pedrycz, 1998). Zadeh (1965) definiu uma variável lingüística como uma quíntupla:

$$
<X, T(X), X, G, M>
$$

em que, $X$ é o nome da variável lingüística cuja variável base é $x, T(X)$ é o conjunto de termos lingüísticos cujo cada elemento representa um rótulo $l$ dos termos que a variável $X$ pode assumir, $\mathbf{X}$ é o universo de discurso da variável lingüística $X, G$ é a gramática para a geração dos termos ou rótulos e $M$ é a regra que associa a cada rótulo $l$ um conjunto nebuloso no universo $\mathbf{X}$, representando seu significado $M(l)$, ou seja, é a função de pertinência para cada termo lingüístico pertencente ao conjunto $T(X)$. 
Como exemplo dessa asserção, considere a variável lingüística temperatura $(X=$ temperatura $)$ definida no universo de discurso $\mathbf{X}=\left[0^{\circ} \mathrm{C}, 100^{\circ} \mathrm{C}\right]$ com variável base $x$. Sendo que os termos línguiísticos para a variável $X$ são muito baixa, baixa, média, alta e muito alta, o conjunto $T(X)$ é definido da seguinte forma:

$$
T(X)=\text { muito baixa, baixa, média, alta, muito alta }
$$

A regra $M$ associa cada elemento de $T(X)$ a um conjunto nebuloso em $\mathbf{X}$. Tal associação pode ser vista na Figura 2.11(a). Os conjuntos nebulosos distribuídos definem a partição nebulosa do universo de discurso. É importante salientar que o número de termos lingüísticos, a configuração dos conjuntos nebulosos a cada termo assim como a distribuição dos mesmos no universo de discurso dependem da natureza do problema. Dessa maneira surge a necessidade de elaboração de técnicas que definem de forma automática a partição adequada para o problema (Figueiredo e Gomide, 1996), (Calvo et al., 2004), (Hoffmann, 2001), (Cordón et al., 2001), (Delgado et al., 2001).

Nota-se que na Figura 2.11(a) a partição nebulosa é composta por conjuntos nebulosos iguais e eqüdistantes (partição uniforme). Porém, a modelagem de uma partição pode ser definida por termos lingüísticos que apresentam configurações distintas, denominada de partição não-uniforme (Figura 2.11(b). A Figura 2.11 ilustra as duas formas de particionar o universo $\mathbf{X}$.

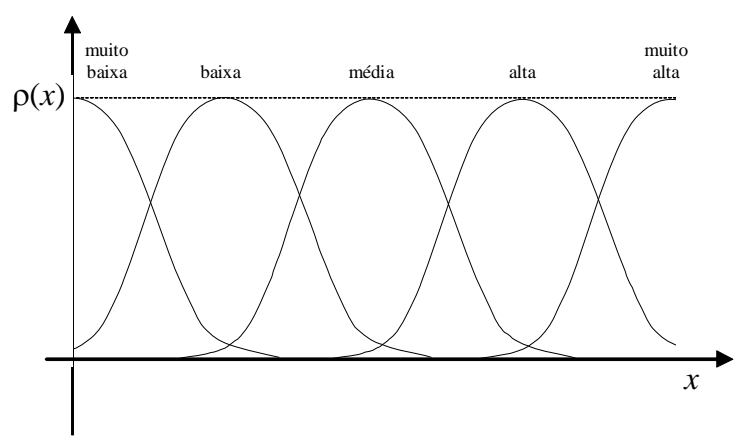

(a)

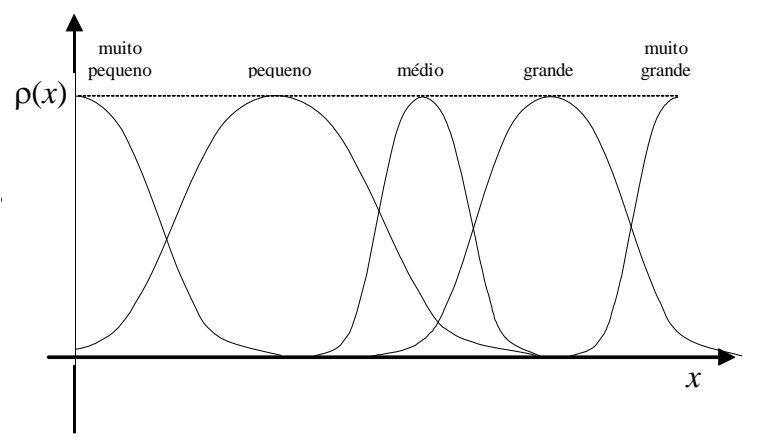

(b)

Figura 2.11: Partição Nebulosa: (a) partição uniforme; (b) partição não-uniforme

\subsubsection{Regras Nebulosas}

As regras nebulosas são ferramentas para a modelagem de sentenças em linguagem natural ou artificial (Jang et al., 1997) permitindo uma maneira formal de representar estratégias. Considerase que as regras nebulosas armazenam o conhecimento do sistema nebuloso e da aplicação. As regras nebulosas são aplicadas quando o conhecimento do problema é resultado de associações 
empíricas e experiência do ser humano, portanto a definição das regras nebulosas em um sistema nebuloso devem ser definidas por um especialista do domínio.

Utilizando da lógica nebulosa, as regras nebulosas representam o raciocínio aproximado formalmente e de maneira conveniente para implementação em sistemas computacionais através de expressões (regras) do tipo se <antecedente> então <conseqüente $>$. Uma regra nebulosa consiste em uma ou mais variáveis de entrada associadas a conjuntos nebulosos (termos lingüísticos), denominadas antecedentes e uma ou mais variáveis de saída, também associadas a conjuntos nebulosos (termos lingüísticos) e denominadas conseqüentes. Os antecedentes são conectados através de operadores lógicos nebulosos e associam-se ao conjuntos nebulosos em todo o universo de discurso através das funções de pertinência. Exemplos de regras nebulosas são, "Se velocidade é alta então o impacto é forte" ou "Se altitude é alta então a temperatura é baixa". A teoria de lógica nebulosa foi desenvolvida a partir de conjuntos nebulosos para tratar tais expressões (Figueiredo, 1997). Considere o exemplo "Se a distância é longe então a visibilidade é baixa". Tal regra pode ser simplificada da seguinte maneira:

\section{Se $X$ é $A$ então $Y$ é $B$}

em que $A$ e $B$ representam os termos lingüísticos "longe" e "baixa" e definidos por conjuntos nebulosos das variáveis lingüísticas "distância" e "visibilidade" pertencentes aos universos de discurso $\mathbf{X}$ e $\mathbf{Y}$, respectivamente.

As regras nebulosas podem ser vistas como relações nebulosas. Uma relação nebulosa $R$ é definida como um conjutno nebuloso definido nos universos de discurso envolvidos na regra tanto para as variáveis base do antecendente da regra como do conseqüente, e associa cada elemento pertencente a junção dos universos de discurso um grau de pertinência dentro do intervalo $[0,1]$. Para a simplificação da regra apresentada anteriormente, a relação nebulosa que representa esta regra é definida como: $R: X \times Y \rightarrow\{0,1\}$. Ainda para esta regra, considerando que a função de pertinência que define $R$ é denotada por $\rho_{R}($.$) , R é dada por:$

$$
R=\left\{\left((x, y), \rho_{R}(x, y)\right) \mid(x, y) \in \mathbf{X} \times \mathbf{Y}\right\}
$$

em que $x$ e $y$ são variáveis base pertencentes aos universos de discurso $\mathbf{X}$ e $\mathbf{Y}$, respectivamente.

Dessa forma, a regra nebulosa exemplificada anteriormente, pode ser definida como uma relação nebulosa $R$ no produto cartesiano $\mathbf{X} \times \mathbf{Y}$. Sendo que a regra envolve dois universos de discurso, então a função $f$ que a especifica é definida por $f:[0,1]^{2} \rightarrow[0,1]$. Dessa forma, $R$ é descrita através da função de pertinência definida no espaço bidimensional: 


$$
\rho_{R}(x, y)=f\left(\rho_{A}(x), \rho_{B}(y)\right)
$$

As relações nebulosas (e conseqüentemente as regras nebulosas) vêm de três classes de funções (Gomide e Pedrycz, 1998), são elas: conjunções nebulosas, disjunções nebulosas e implicações nebulosas através de funções t-normas (t) e s-normas (s). A representação de regras nebulosas na forma de relações nebulosas permite a associação de um grau de pertinência as regras. O grau de pertinência indica o quanto a regra em análise é considerada verdadeira. As funções que representam as relações nebulosas são mostradas a seguir:

- Conjunção nebulosa $\left(f_{c}\right): f_{c}\left(\rho_{A}(x), \rho_{B}(x)\right)=\rho_{A}(x) \mathbf{t} \rho_{B}(y)$

- Disjunção nebulosa $\left(f_{d}\right): f_{d}\left(\rho_{A}(x), \rho_{B}(x)\right)=\rho_{A}(x) \mathbf{s} \rho_{B}(y)$

- Implicação nebulosa: pode ser classificada em duas categorias básicas:

- Implicação-S: $f_{i S}\left(\rho_{A}(x), \rho_{B}(y)\right)=\rho_{\bar{A}}(x) \mathbf{s} \rho_{B}(y)$

- Implicação-R: $f_{i R}\left(\rho_{A}(x), \rho_{B}(y)\right)=\sup _{c \in[0,1]} \rho_{A}(x) \mathbf{t} c \leq \rho_{B}(y), \forall(x, y) \in \mathbf{X} \times \mathbf{Y}$

Diversas funções de t-normas e s-normas que podem ser aplicadas as relações nebulosas são encontradas em (Delgado, 2002).

Além de regras nebulosas que apresentam uma única variável (variável lingüística) tanto no antecedente como no conseqüente, são utilizadas também regras que envolvem mais de uma variável nos dois membros da regra. Essas regras são denominadas proposições multivariáveis, enquanto as regras que apresentam somente uma variával são denominadas proposições monovariáveis. Para o caso de proposições multivariáveis, a conclusão da regra é inferida com relação não apenas à um antecedente, por exemplo, Se temperatura é alta e umidade é baixa então desidratação é alta e risco de infeção é alta. A expressão que define uma proposição multiváriavel é mostrada a seguir:

Se $X_{1}$ é $A_{1}$ e $X_{2}$ é $A_{2} e \ldots X_{m}$ é $A_{m}$ então $Y_{1}$ é $B_{1}$ e $Y_{2}$ é $B_{2} e \ldots Y_{n} e ́ B_{n}$

em que $X_{1}, X_{2}, \ldots X_{m}$ e $Y_{1}, Y_{2}, \ldots Y_{n}$ são variáveis do antecedente e conseqüentemente $A_{1}, A_{2}, \ldots A_{m}$ e $B_{1}, B_{2}, \ldots B_{n}$ são conjuntos nebulosos (termos lingüísticos) definidos nos universos de discurso $\mathbf{X}_{1}, \mathbf{X}_{2}, \ldots \mathbf{X}_{m}$ e $\mathbf{Y}_{1}, \mathbf{Y}_{2}, \ldots \mathbf{Y}_{n}$, respectivamente. Os índices $m$ e $n$ indicam o número de variáveis no antecedente e conseqüente da regra, respectivamente, tal que $m, n \geq 2$. 


\subsubsection{Raciocínio Aproximado e Inferência Nebulosa}

A lógica nebulosa possibilita modelar o raciocíonio aproximado que pode ser definido como um método de inferência que produz conclusões a partir de uma ou mais regras nebulosas e fatos conhecidos. Para o raciocínio aproximado não há a necessidade de que um fato ou um conjunto de fatos concordem exatamente com a regra. Se um fato resulta em uma conclusão então fatos semelhantes devem resultar em conclusões semelhantes. O raciocínio aproximado pode ser entendido como um procedimento para computação de uma operação em que argumentos não são definidos de forma precisa.

A inferência de uma conclusão ocorre a partir de um conjunto de fatos e regras, denominados premissas. Na lógica clássica a regra de inferência utilizada é o modus ponens. Sendo que o raciocínio aproximado envolve premissas e conclusões imprecisas, a inferência nebulosas de uma conclusão ocorre da utlização da regra denominada modus ponens generalizado (MPG) que possui o seguinte mecanismo de inferência nebuloso:

$$
\begin{aligned}
& \text { premissa } 1 \text { (fato): } X \text { é } A^{\prime} \\
& \text { MPG } \frac{\text { premissa } 2(\text { regra }): \text { Se } X \text { é } A \text { então } Y e ́ B}{(\text { conclusão } B):}
\end{aligned}
$$

Seguindo o mecanismo de inferência MPG, a premissa 2 estabelece o conhecimento apenas com relação ao antecedente. Muito embora a premissa 1 apresente um fato diferente, porém muito semelhante, pode-se concluir alguma informação de $Y$. Este resultado é compatível com os mecanismos de inferência aproximado, ou seja, é possível obter conclusões para fatos que não correspondem exatamente ao conhecimento existente. Considere o exemplo em que a regra consiste em "Se uma pessoa tem 65 anos de idade então essa pessoa é idosa" e o fato em "Maria tem 63 anos". Pela inferência nebulosa, pode-se concluir que Maria é uma pessoa quase idosa pois possui quase 65 anos de idade.

O mecanismo de inferência nebulosa pode ser aplicado sobre uma regra nebulosa envolvendo várias variáveis em seu antecendente. Dessa maneira o mecanismo de inferência é definido como segue:

$$
\text { MPG } \begin{aligned}
& \text { premissa } 1(\text { fato }): X_{1} \text { é } A_{1}^{\prime} \text { e } X_{2} \text { é } A_{2}^{\prime} \text { e } \ldots X_{m} \text { é } A_{m}^{\prime} \\
& \frac{\text { premissa } 2(\text { regra }): \text { Se } X_{1} \text { é } A_{1} \text { e } X_{2} \text { é } A_{2} e \ldots X_{m} \text { é } A_{m} \text { então } Y \text { é } B}{(\text { conclusão }):} \quad Y \text { é } B^{\prime}
\end{aligned}
$$

Segundo um dos métodos de inferência mais importante (Yager e Filev, 1994), o conjunto nebuloso $C$ encontrado na conclusão é obtido através da seqüência: comparação, agregação e conclusão: 
- Comparação de proposições: Para cada variável $X_{i}$, o fato da premissa 1 é comparado com a hipótese da premissa 2 ;

- Agregação: Os resultados de cada comparação são agregados em um operador t-norma produto;

- Conclusão: Para cada regra o procedimento de inferência resulta em uma conclusão, função do conseqüente da regra e o valor de agregação das comparações.

\subsubsection{Sistemas Nebulosos}

Os sistemas nebulosos são de grande valia para a resolução de problemas a aprtir de conhecimento necessário representado através do formalismo das terorias de conjuntos nebulosos e da lógica nebulosa. $\mathrm{O}$ uso dos sistemas nebulosos são freqüentes em casos que a abordagem clássica torna-se impraticável para a modelagem de um problema. Métodos tradicionais são passíveis de alterações bruscas na solução de problemas, devido a simplificação excessiva do modelo real. Por outro lado, os sistemas nebulosos provê recursos (e.g., funções de pertinência, regras, operadores de agregação) que permite a aproximação semelhante ao modelo real, evitando que a solução gerada pelo sistema nebuloso apresente larga diferença perante a solução ideal.

Os sistemas nebulosos são uma importante ferramenta, com muitas aplicações na medida em que possuem a capacidade de inferir conclusões a partir das entradas apresentadas (Figueiredo, 1997). Os sistemas nebulosos são constituídos por quatro componentes (Figura 2.12): interface de entrada, base de conhecimento, máquina de inferência e interface de saída. A interface de entrada transforma, quando necessário, os sinais provenientes dos ambientes em conjuntos nebulosos para que sejam tratados pelo restante do sistema. O conjunto de sinais de entrada podem não pertencer ao universo de discurso dos conjuntos nebulosos do sistema, por esta razão, estes sinais passam pelo processo de "fuzzificação". Tal processo consiste na conversão dos sinais vindos do ambiente da forma aplicável ao problema em questão (forma crisp) para a forma em que o sistema nebuloso é capaz de interpretar, ou seja, normalizados dentro do intervalo $[0,1]$. A base de conhecimento consiste em dois componentes: base de regras que contém as regras nebulosas do tipo $\boldsymbol{s} \boldsymbol{e}<a n$ tecedente> então <conseqüente> representando o conhecimento do sistema e base de dados que possui informações sobre os parâmetros das funções de pertinência utilizadas nas regras nebulosas e dos operadores de agregação e inferência. A máquina de inferência realiza o procedimento de inferência (raciocínio nebuloso) para obter a saída ou conclusão. E por último, a interface de saída transforma as respostas obtidas para que sejam compatíveis com o ambiente. Este processo é denominado de "desfuzzificação" e consiste na conversão dos sinais normalizados gerados pelo sistem nebuloso em sinais que sejam interpretados pelo ambiente do problema. 
A partir dos sinais (ou estímulos) do ambiente detectados pelos sensores, estes são normalizados (se necessário) na interface de entrada em uma grandeza que os torna interpretáveis através dos conjuntos nebulosos. Os sinais já normalizados são processados pela máquina de inferência com o auxílio da base de regras que fornecem as regras nebulosas e da base de dados que contém o perfil das funções de pertinência utilizadas nas regras. Após esse processo, a saída inferida pelo sistema nebuloso sofre a ação, na interface de saída, de uma função que a transforma em um valor não-nebuloso (crisp). Em algumas aplicações faz-se necessária a transformação para que o sinal de saída do sistema nebuloso seja compreendido pelos atuadores presentes no ambiente. A transformação da saída nebulosa para uma saída não-nebulosa pode ser feita por diversos métodos. Os três métodos mais freqüentemente utilizados são: média dos máximos; centro de massa; centro de área.

- Média dos Máximos: os valores correspondentes ao máximo da função de pertinência do conjunto $C$ são identificados e a média define o valor não-nebuloso;

- Centro de Massa: o resultado da transformação de $C$ em um valor não-nebuloso é o centro de massa:

$$
\hat{z}=\frac{\int_{z} \rho_{C}(z) z d z}{\int_{z} \rho_{C}(z) d z}
$$

- Centro de Área: neste caso, $\hat{z}$ resulta do balanço entre duas áreas de $C$ determinada por $\hat{z}$ :

$$
\int_{-\infty}^{\hat{z}} \rho_{C}(z) d z=\int_{\hat{z}}^{\infty} \rho_{C}(z) d z .
$$

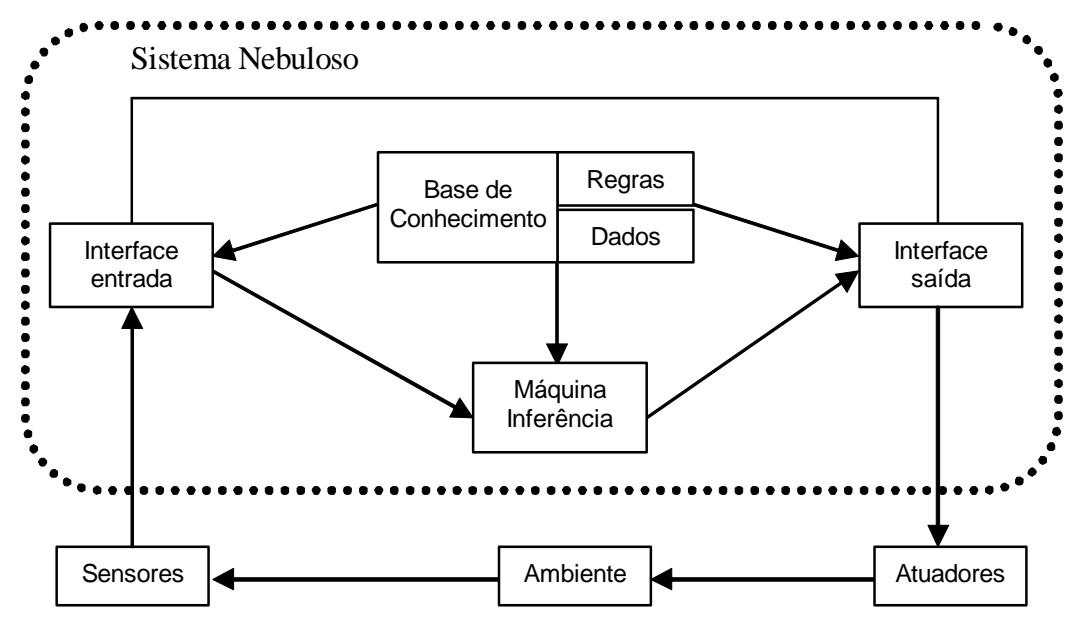

Figura 2.12: Organização modular de um sistema nebuloso 
Para a modelagem de um sistema nebuloso aplicado para resolução de um problema, é necessário a definição de vários parâmetros, por exemplo, as variáveis lingüísticas e os termos lingüísticos associados as variáveis, número de regras nebulosas, funções de pertinência associadas aos antecedentes e conseqüentes das regras, operadores que representam a semântica da regra (conjunções E, OU) e os operadores de agregação. A flexibilidde que os sistemas nebulosos fornecem para os projetistas torna esta abordagem amplamente utilizada em diversas áreas de conhecimento ..... procurar por aplicações.... Outros fatores que contribuíram para a difusão desta abordagem consitem na facilidade com que as regras nebulosas e funções de pertinências são formuladas, para tanto, não há a necessidade de definir tais parâmetros de forma ótima. Este processo é possível segundo o conhecimento do projetista sobre o problema para a definição dos parâmetros.

A computação de um sistema nebuloso envole racíocínio nebuloso e um mecanismo de inferência para a obtenção da resposta. Tais processos constituem a máquina de inferência (Figura 2.12). Há varios mecanismos de inferência utilizados por sistemas nebulosos, os mais comuns são: inferência composicional e inferência escalonada (Delgado, 2002). Os mecanismos de inferência definem os modelos de sistemas nebulosos que se distinguem nos conseqüentes das regras nebulosas. Os mais uilizados são: Mamdani (Mamdani e Assilian, 1975) e Takagi-Sugeno (Takagi e Sugeno, 1983). A seguir é descrito o modelo Mamdani, utilizado nesta pesquisa.

\section{Modelo Mamdani}

O modelo Mamdani (Mamdani e Assilian, 1975) é um sistema de inferência nebulosa que utiliza conjuntos nebulosos para definir tanto os antecendentes como os conseqüentes das regras nebulosas. O mecanismo de inferência baseia-se na inferência escalonada que consiste nos seguintes passos: comparação, agregação dos antecedentes, agregação do conseqüentes de cada regra e agregação dos conseqüentes das regras.

Para a descrição dos passos da inferência escalonada, considere e expressão nebulosa em que o mecanismo de inferência é aplicado a $M$ variáveis $X_{i}$ em seu antecedente e uma variável em seu conseqüentente:

$$
\begin{aligned}
& \text { premissa } 1 \text { (fato): } X_{1} \text { é } A_{1}^{\prime} \text { e } X_{2} \text { é } A_{2}^{\prime} \text { e .. } X_{m} \text { é } A_{m}^{\prime} \\
& \frac{\text { premissa } 2(\text { regra }): \text { Se } X_{1} \text { é } A_{1} \text { e } X_{2} \text { é } A_{2} e \ldots X_{m} \text { é } A_{m} \text { então } Y \text { é } B}{(\text { conclusão }):}
\end{aligned}
$$

1. Comparação: Neste passo, o fato (premissa 1) descrito na expressão nebulosa é comparado com cada regra (premissa 2) nebulosa pertencente ao sistema nebuloso. Cada variável do fato descrito é comparado com a variável correspondente do antecedente da regra nebulosa. 
A comparação fornece o nível de similaridade entre o fato e o antecedente de cada regra. A operação de comparação pode ser definida pelo operador de medida de possibilidade descrito na Seção 2.3.2, dada pela equação 2.23:

$$
P_{i}\left(A_{i}, A_{i}^{\prime}\right)=S_{x \in U_{i}}\left(T\left(\rho_{A_{i}}(x), \rho_{A_{1}}^{\prime}(x)\right)\right),
$$

em que $P_{i}$ é o medidor de possibilidade para a $i$-ésima variável e avalia o quanto os conjuntos nebulosos $A_{i}$ e $A_{i}^{\prime}$ são semelhantes (ou sobrepostos), $x$ é variável base dos sistemas nebulosos no universo de discurso $\mathbf{U}_{i}$ da $i$-ésima variável, $S$ é operador s-norma, $T$ o operador t-norma. Os operadores mais utilizados para s-norma e t-norma são os operadores min e $\max$, respectivamente. O operador $S($.) deve ser entendido como a aplicação da s-norma sobre todo $x \in \mathbf{U}_{i}$.

2. Agregação dos Antecedentes: $O$ resultado da comparação de todas as variáveis são agregados de acordo com os conectivos $\mathrm{E}$ e OU presentes na regra nebulosa. O valor obtido em uma regra nebulosa é aplicado ao conjunto nebuloso do conseqüente da regra determinando a intensidade com que a regra influencia na resposta gerada pelo sistema nebuloso. A agregação do antecedente é dada por:

$$
H_{r}=T_{i=1}^{M}\left(P_{i}\left(A_{i}, A_{i}^{\prime}\right)\right)
$$

em que $H_{r}$ é o resultado da agregação dos antecedentes da regra $r$ pertencente ao sistema nebuloso, $P_{i}$ é o medidor de possibilidade para a $i$-ésima variável e avalia o quanto os conjuntos nebulosos $A_{i}$ e $A_{i}^{\prime}$ são semelhantes (ou sobrepostos), $T$ é operador t-norma, $M$ é o número de variáveis presentes no antecedente da regra $r$. O operador mais utilizado para t-norma é o operador min.

3. Agregação dos Conseqüientes: Os resultados obtidos com a aplicação da agregação dos antecedentes das regras do sistema nebuloso são agregados através de um operador t-norma gerando uma função de pertinência para o conjunto nebuloso correspondente à função da resposta gerada. A agregação dos conseqüentes é dada pela equação 2.25

$$
Q=S_{r=1}^{R}\left(H_{r}\right)
$$

em que $Q$ é o resultado da agregação dos conseqüentes das regras pertencentes ao sistema nebuloso, $H_{r}$ é o resultado da agregação dos antecedentes da regra $r, S$ é operador s-norma, $R$ é o número de regras presentes no sistema nebuloso. O operadore mais utilizado para s-norma é o operador max.

Após encontrada a função de pertinência gerada pela agregação dos conseqüentes, um dos métodos de "defuzzificação" é aplicado para encontrar a resposta não-nebulosa (crisp) caso o pro- 
blema a ser resolvido necessite desse processo para interpretar a resposta gerada pelo sistema nebuloso.

\subsection{Sistemas Híbridos}

Sistemas Híbridos Inteligentes, um dos temas de pesquisa mais recentes na área de Inteligência Artificial (Goonatilake e Khebbal, 1995), envolvem a fusão de metodologias inteligentes para o tratamento de grande quantidade de informações e a incerteza inerentes ao sistemas complexos. A utilização de sistemas híbridos permite que uma técnica complete a deficiência de outra de forma a obter melhor desempenho, ampliando a capacidade do sistema de adquirir novas informações evitando uma visão parcial limitada pelas imposições e restrições de um único método. As características de técnicas quando combinadas em um sistema híbrido torna-o mais robusto e tolerante a falhas por possuir habilidades específicas de cada ténica.

A motivação para a utilização de sistemas híbridos vem devido ao fato de serem compostos por múltiplas técnicas inteligentes que se interagem com a tentativa de reproduzir a inteligência humana. Observa-se que o ser humano emprega diversos métodos para a soluçào de problemas, tais como, soluções baseadas em experiências passadas, em conhecimentos teóricos adquiridos, em diferentes métodos de raciocínios (por inferência, por probabilidades, por deduçào, por analogia). Dessa forma, os sistemas híbridos procuram, através da integração de diferentes métodos reproduzir a inteligência humana. Apesar dos sistemas híbridos serem mais complexos para o desenvolvimento, estes sistemas tem sido muito estudados e aplicados (Kasabov, 1996).

Existem diversas possibilidades de integrar metodologias inteligentes, dentre elas, destacam-se as redes neurais nebulosas, em que as redes neurais são responsáveis por gerar regras nebulosas automaticamente, além de configurar o perfil das funções de pertinência das variáveis envolvidas no sistema (Arnauts e Romero, 2001) (Figueiredo, 1997), uma rede neural nebulosa é identificada pelo uso de operadores nebulosos nos neurônios pertencentes a sua estrutura independente do modelo (Figueiredo e Gomide, 1996). Um sistema híbrido amplamente utlizado são os sistemas neuro-genético, em que um algoritmo é aplicado para a determinação dos parâmetros de uma rede neural, tais como, o número de neurônios pertencentes a rede, número de camadas (Su e Chiang, 2002) (abd D. E. Brown e Martin, 1992). Sistema nebuloso-genético envolve técnicas de algoritmos genético para a geração de regras nebulosas assim como o perfil das funções de pertinência e operadores de agregação (Delgado, 2002), (Calvo et al., 2004).

Uma das técnicas híbridas mais utilizadas para a resolução de problemas são as redes neurais nebulosas. A seguir são descritas as características das redes neurais nebulosas e apresentados 
alguns modelos propostos na literatura.

\subsubsection{Redes Neurais Nebulosas}

As técnicas inteligentes têm propriedades computacionais particulares (capacidade para aprender, se adaptar, explicar decisões) que as tornam aceitáveis para alguns tipos de problemas e não para outros. Por exemplo, enquanto as redes neurais artificiais são adequadamente aplicadas para o reconhecimento de padrões, as mesmas não possuem a habilidade de explicar como as decisões são tomadas. Sistemas de lógica nebulosa que inferem conclusões a partir de informações imprecisas são úteis para explicar tomadas de decisões, porém não dotam de capacidade da aquisição das regras nebulosas de forma automática.

À medida que as teorias relacionadas às redes neurais e aos sistemas nebulosos se desenvolviam, observou-se que estas abordagens poderiam ser unificadas, resultando em sistemas de características mais completas no que se refere às suas capacidades inteligentes. Além destas abordagens exibirem características comuns, como tratamento de incertezas e raciocínio aproximado, cada uma apresenta propriedades exclusivas que contribuem para compensar deficiências individuais da outra. De um lado as redes neurais falham em representar o conhecimento de forma explícita, mas exibem sua inclinação para o aprendizado. Com a utilização das redes neurais não é possível se traçar a maneira pela uma solução foi encontrada, além de interpretar o comportamento da rede a partir das conexões da rede e dos valores assumidos pelos pesos. Outra dificuldade é definir uma arquitetura para a rede para que se obtenha o resultado esperado. Geralmente não é possível determinar a quantidade de camadas e quantidade de neurônios em cada camada assim como as conexões. Por outro lado os sistemas nebulosos são fracos sob o ponto de vista da aquisição automática de conhecimento, porém valem-se amplamente de seu dom com respeito à manipulação de termos lingüísticos. O resultado desta união se concretizou nas redes neurais, suas arquiteturas e seus métodos de aprendizagem. o termo rede neural nebulosa refere-se a incorporação da abordagem nebulosas em um sistema neural adquirindo dos sistemas nebulosos a capacidade de representação e processamento compreensível do conhecimento, bem como os demais recursos oferecidos pelas teorias de conjuntos nebulosos e lógica nebulosa.

\subsection{Fundamentos de Condicionamento}

O aprendizado dos indivíduos de uma espécie assim como os comportamentos inatos são determinados pela história evolutiva (filogênese) dessa espécie. Neste sentido, os reflexos são produto da seleção natural e, portanto, características inatas da espécie. Associados à manutenção física e promoção da sobrevivência e reprodução. 
Muitas teorias que relacionam estes comportamentos inatos com a aprendizagem de novas habilidades levam em consideração dois tipos de eventos: agentes de reforço e punição (Baum, 1999). Os agentes de reforço são eventos que aumentaram a aptidão do individuo por estarem presentes, durante a filogênese, e tendem a fortalecer o comportamento a eles associados. Enquanto que os agentes de punição aumentam a aptidão por estarem ausentes e tendem a suprimir o comportamento a eles associados.

Pavlov (1927) afirma que um animal a partir de um estímulo não-condicionado é capaz de gerar uma resposta não-condicionada. Um segundo estímulo pode ser apresentado junto ao primeiro e, após um vasto treinamento, a resposta não-condicionada que era para o primeiro estímulo passa também a ser do segundo (agora condicionado).

Skinner (1953) entende o aprendizado como um conjunto de dois comportamentos: o respondente e o operante. O comportamento respondente semelhante à idéia de Pavlov significa que a relação é uma resposta ao estímulo causal fornecido ao mesmo (e.g. um sinal sonoro apresentado antes da apresentação do alimento a um cão). O comportamento operante corresponde aquele induzido pelo estado do próprio ser interagindo com o ambiente, independentemente da apresentação de um estímulo causal (e.g. o pressionar de uma alavanca por um rato libera o alimento). Ressalta que a aprendizagem é o resultado do reforço e experiência repetitiva.

A relação entre comportamento e conseqüência pode ser positiva quando o comportamento aumenta a probabilidade de ocorrência da conseqüência, ou negativa, quando o comportamento a reduz. Dessa maneira, a combinação destas duas relações aos tipos de consequiência gera quatro tipos de relações que resultam em aprendizagem operante: 1) reforço positivo, a relação tende a manter a ação que torna mais provável o reforço; 2) reforço negativo, a relação tende a manter a ação que torna menos provável a punição; 3) punição positiva, a relação tende a suprimir a ação na medida em que esta torna a punição mais provável; 4) punição negativa, a relação tende a suprimir a ação na medida em que esta torna o reforço mais provável.

\subsection{Considerações Finais}

Neste capítulo foram apresentados os principais fundamentos teóricos para o entendimento da concepção da arquitetura híbrida inteligente apresentada no capítulo seguinte. Conceitos básicos de técnicas de inteligência artificial como redes neurais e teoria dos conjuntos nebulosos foram apresentados assim como breves considerações sobre a Teoria de Seleção de Grupos Neurais (TSGN) e condicionamento. As redes neurais são poderosas para processamento paralelo de informações, reconhecimentos de padrões e adaptabilidade a mudanças em problemas dinâmicos como 
é o caso do presente trabalho. A teoria dos conjuntos nebulosos minimiza o esforço do projetista a respeito do tratamento de informações imprecisas e raciocínio aproximado. A TSGN e os conceitos do aprendizado por condicionamento formam a base para o mecanismo de aprendizagem presente no sistema neural nebuloso descrito no capítulo seguinte. 


\section{Sistema Neural Nebuloso}

\subsection{Introdução}

Como visto no capítulo introdutório, a proposta do presente trabalho está na concepção de um sistema de navegação autônoma para robôs móveis em ambientes do mundo real. A base para o sistema está na proposta de estender a metodologia apresentada em (Calvo e Figueiredo, 2003b) para a aplicação no robô Pioneer I do LABIC. Desta forma, esta metodologia torna-se peça chave para a navegação do robô, pela capacidade que esta tem em ponderar comportamentos conflitantes como o desvio de obstáculos e o alcance a pontos metas. Por esse motivo, esse capítulo destina-se a descrever o sistema de navegação para controle autônomo de veículos apresentado em (Calvo e Figueiredo, 2003b) com o intuito de fundamentar os conceitos utilizados e compreender os módulos que constituem a arquitetura híbrida do sistema, futuramente utilizada.

O sistema de navegação proposto em (Calvo e Figueiredo, 2003b) é baseado na Teoria de Seleção dos Grupos Neurais (TSGN) (Edelman, 1987). A TSGN tenta entender o fenômeno da inteligência a partir da observação e investigação de sistemas nervosos biológicos. A TSGN defende a hipótese de que o conhecimento específico é adquirido através de interações com o ambiente. Comportamentos inatos estão presentes nos modelos da TSGN gerados via evolução natural (Figueiredo, 1997).

Baseado nos seres vivos, o conceito de repertório neural, proposto pela TSGN, tem como meta modelar os sistemas neurais envolvidos. A arquitetura do controlador é hierárquica e modular, cujos módulos que a compõem o controlador são: Sistema Nebuloso de Desvio de Obstáculos 
(SDO), Sistema Nebuloso de Busca ao Alvo (SBA) e Repertório de Coordenação (RC). Os dois primeiros módulos, situados em um mesmo nível hierárquico, são responsáveis por gerar os comportamentos inatos de desvio de obstáculos e busca ao alvo, respectivamente. Por se tratarem de comportamentos conflitantes no problema de navegação autônoma, tais comportamentos necessitam ser coordenados. O RC, a um nível hierárquico superior aos sistemas nebulosos (SDO e SBA) e composto por três redes neurais nebulosas, coordena estes comportamentos.

O modelo de aprendizagem adotada para o RC é baseado na aprendizagem por reforço, inspirado na teoria clássica do condicionamento animal (Kandel et al., 1991). Em ambos os comportamentos de desvio de obstáculos e busca ao alvo, a aprendizagem por condicionamento está baseada nos estímulos condicionados e não-condicionados. A natureza da aprendizagem por condicionamento gerada pelo sistema pode ser classificada como reforço ou como uma punição, além de ser negativo ou positivo. A natureza negativa determina a retirada (ou a não produção) de um estímulo em conseqüência da resposta punida ou reforçada. Enquanto que a natureza positiva determina a adição (ou a produção) de um estímulo. Os modelos de aprendizagem por reforço são baseados na lei de Hebb, ou seja, a região sináptica entre dois neurônios correlacionados que disparam é reforçada. As interações com um ambiente desconhecido, composto por obstáculos e um alvo, geram estímulos que iniciam o processo de aprendizagem capaz de guiar o robô ao alvo sem colisões.

Este capítulo é organizado como segue. As Seções 4.5 e 3.3 apresentam o modelo do robô e do ambiente utilizados nas simulações, respectivamente. A Seção 3.4 apresenta os módulos que constituem a arquitetura do sistema neural nebuloso.

\subsection{Modelo do Robô Ideal}

O modelo do veículo utilizado para a navegação no sistema proposto em (Calvo e Figueiredo, 2003b) é apresentado na Figura 3.1. O veículo é dotado de diferentes classes de sensores com o objetivo de obter informações provenientes do ambiente. Duas dessas classes são mostradas na Figura 3.1, são elas: sensores de distância a obstáculos, sensores de direção ao alvo e sensores de distância ao alvo. A cada instante, o controlador autônomo recebe os sinais dos sensores e determina o ângulo de ajuste para a direção do movimento do robô (ângulo $\gamma$ ). Durante a navegação, a velocidade do veículo é constante ( 2 unidades de distância por iteração), assumindo ajustes em sua direção, valores dentro do intervalo $\left[-15^{\circ}, 15^{\circ}\right]$.

Cada sensor de distância a obstáculos determina a distância entre o robô e o obstáculo mais próximo situado na direção do sensor (ângulo $\alpha$ ). Os sensores de distância a obstáculos estão 


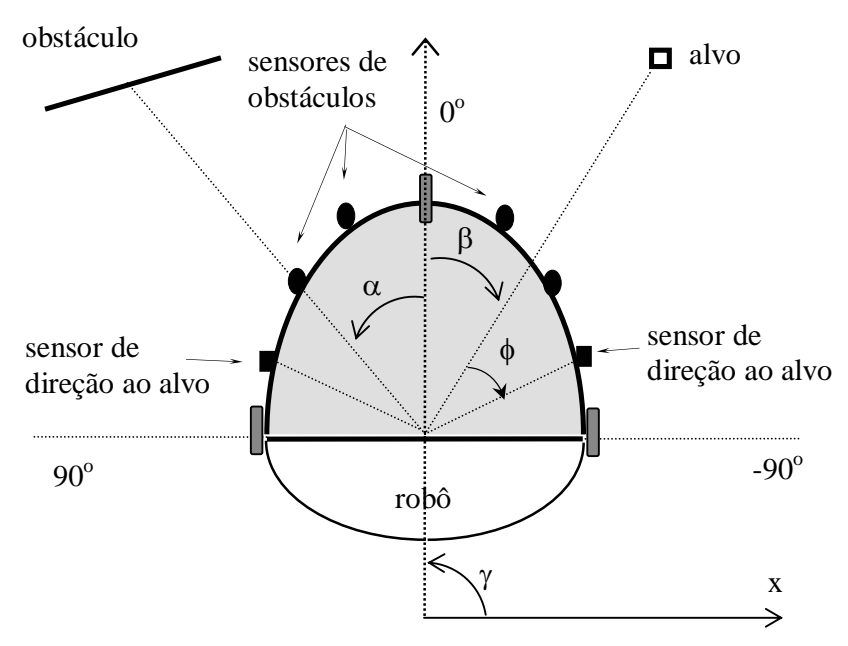

Figura 3.1: Modelo do robô e seus sensores de obstáculo e de alvo

presentes em um número de 51 sensores dispostos na parte frontal do robô, distribuindo-se no intervalo $\left[-90^{\circ}, 90^{\circ}\right]$. O valor obtido por cada sensor é normalizado para um valor dentro do intervalo $[0,1]$ obedecendo o comportamento da gaussiana descrita na equação 3.1:

$$
f(x)=\exp ^{-(x / d i s p)^{2}}
$$

em que $x$ representa o valor detectado pelo sensor e disp representa a dispersão da gaussiana. Em particular para o modelo do sensor ideal, disp $=30$.

Os sensores de direção ao alvo detectam o grau de alinhamento do robô com o alvo. Cada sensor obtém o ângulo entre sua direção e o alvo (ângulo $\phi$ ) e está associado a uma seção angular no qual sua sensibilidade é mais acentuada. Sua saída é tanto maior quanto mais próximo estiver o ângulo $\phi$ de zero, ou seja, quanto mais alinhado estiver o sensor de direção com o alvo. Os sensores de direção ao alvo estão distribuídos uniformemente ao longo do perímetro do robô em um número de 100 sensores. A Figura 3.2 apresenta o modo como os sensores de direção ao alvo obtêm suas informações. Cada sensor está situado em uma determinada posição no perímetro do robô. Para cada uma dessas posições, é traçada uma função gaussiana determinando sua seção angular, ou seja, a região onde o sensor correspondente atua. Considerando que $\theta$ seja a diferença angular entre a direção de movimento do robô (ângulo $\gamma$ ) e a direção do alvo (ângulo $\beta$ ), os sinais dos sensores são obtidos de acordo com o valor de cada gaussiana (associada a cada sensor) quando aplicada a $\theta$. Um exemplo é ilustrado na Figura 3.2, o sensor que obteve o maior sinal é o sensor posicionado a $3,6^{\circ}$ à esquerda em relação à parte frontal do robô. Portanto, a posição desse sensor é o atibuto responsável pelo ajuste da direção de movimento do robô para que este se alinhe com o alvo. 


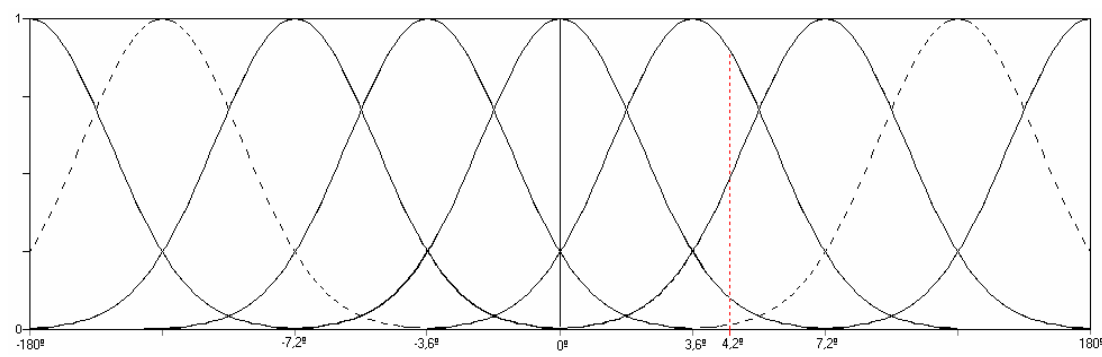

Figura 3.2: Modelo gráfico para a obtenção dos sinais dos sensores de direção ao alvo

A terceira classe de sensores consiste de sensores de distância ao alvo que detectam a distância entre o robô e o alvo. O valor encontrado é convertido em vários outros valores através de uma função gaussiana. Os campos proprietários destes valores são denominados de sensores virtuais de distância ao alvo. A Figura 3.3 apresenta o modo como os sensores de distância ao alvo obtêm suas informações. Para cada sensor é traçada uma função gaussiana determinando sua seção angular. Primeiramente é encontrada a distância entre o robô e o alvo. Este valor $(\tau)$ já normalizado entre $[0,1]$, de acordo com a equação 3.1, é transportado para o campo sensorial de distância ao alvo (Figura 3.3). Dessa maneira, os sensores obtêm seus sinais de acordo com o valor de sua gaussiana aplicada a $\tau$. Na Figura 3.3, o sensor que obteve o maior sinal é o terceiro sensor de distância ao alvo, pois sua seção angular abrange com maior intensidade o valor $\tau$.

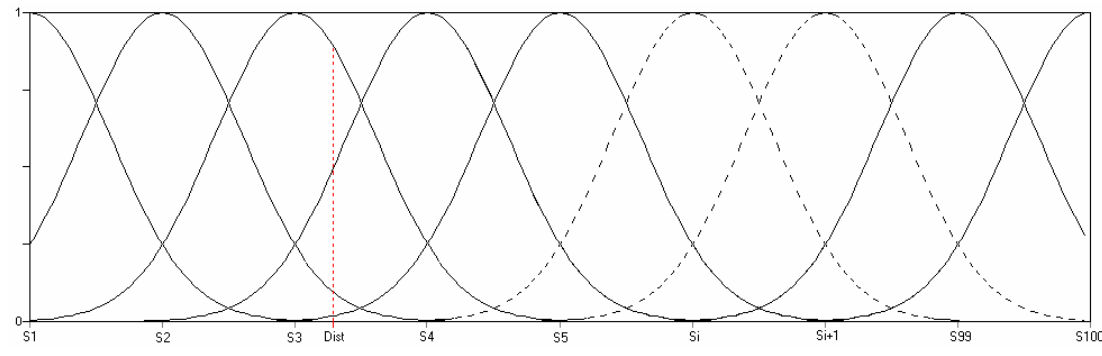

Figura 3.3: Modelo gráfico para a obtenção dos sinais dos sensores de distância ao alvo

Além disso, assume-se um sensor de captura que determina o momento em que o alvo foi alcançado e sensores de colisão que determinam o momento em que o robô sofreu colisões. Estes sensores, assim como os sensores virtuais de distância ao alvo são entidades lógicas e por isso não são mostrados na Figura 3.1.

\subsection{Modelo do Ambiente}

O ambiente no qual ocorre a navegação do robô é desconhecido. A trajetória do robô não é planejada a priori, é determinada de acordo com a navegação do robô, pois o sistema não é delibe- 
rativo. Dessa forma, o sistema não precisa do conhecimento da topologia do ambiente. O sistema de navegação autônomo é do tipo reativo, ou seja, suas decisões são consequiências das entradas instantâneas obtidas dos sensores.

O ambiente é bidimensional, podendo conter inúmeros obstáculos, de diferentes tamanhos e formas, e somente um alvo, distribuídos de forma arbitrária no ambiente. O espaço do ambiente é limitado pelas suas margens. Um exemplo de configuração do ambiente é mostrado na Figura 3.4. $\mathrm{O}$ ponto circular representa o alvo, a figura triangular representa o robô e as figuras retangulares representam os obstáculos.

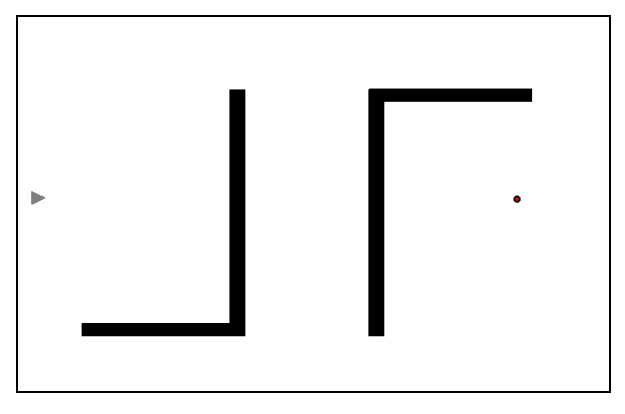

Figura 3.4: Ambiente de simulação

\subsection{Sistema de Navegação Autônomo}

O sistema de navegação autônomo proposto é inspirado nos seres vivos segundo a Teoria da Seleção de Grupos Neurais (TSGN) (Edelman, 1987). Esta teoria parte do princípio de que sistemas nervosos biológicos não comportam conhecimentos relacionados à tarefas específicas que um animal efetua antes de interagir com o ambiente. Os comportamentos relacionados a tarefas específicas são adquiridos após interações com o ambiente. A TSGN assume que o sistema nervoso biológico seja capaz de gerar comportamentos inatos desenvolvidos filogeneticamente (produto da evolução natural). Tais comportamentos não evoluem durante o processo de interação, ou seja, estes comportamentos não possuem um processo de aprendizagem ontogenética. Mesmo que os comportamentos inatos não sejam particulares a uma determinada tarefa, estes são essenciais para a vida de um animal (Kandel et al., 1991). A adaptação de um animal em ambientes e, conseqüentemente, sua aquisição de conhecimento são apoiados nos comportamentos inatos, os quais definem suas primeiras respostas aos estímulos do ambiente. 


\subsubsection{Arquitetura do Controlador Autônomo}

O sistema de navegação autônomo possui uma arquitetura modular e hierárquica (Figura 3.5), consistindo de três módulos principais, conectados a um neurônio de saída. Dois destes módulos, Sistema Nebuloso de Desvio de Obstáculos (SDO) e Sistema Nebuloso de Busca ao Alvo (SBA), situados em um mesmo nível hierárquico, geram os comportamentos inatos de desvio de obstáculos e busca ao alvo, respectivamente. Entretanto, se somente os sistemas nebulosos estivessem presentes no sistema de navegação, haveria conflito entre os dois comportamentos gerados em ambientes no qual um obstáculo se interpõe entre o alvo e o robô. Pois, enquanto o SDO objetiva desviar do obstáculo, o SBA visa capturar o alvo.

Um terceiro módulo pertencente à arquitetura do sistema autônomo é capaz de coordenar as respostas emitidas pelos módulos de comportamentos inatos. Situado em um nível hierárquico superior, o Repertório de Coordenação (RC) tem como objetivo ponderar os sinais dos dois módulos anteriores determinando a influência que cada comportamento tem sobre a tomada de decisão do sistema. Os sinais gerados pelos sistemas nebulosos são enviados para um único neurônio de saída do sistema (Figura 3.5). Os pesos sinápticos deste neurônio são determinados pelo RC. Portanto, o neurônio de saída pondera os sinais de SDO e SBA de acordo com as respostas emitidas pelo RC, gerando o ajuste adequado da direção do robô.

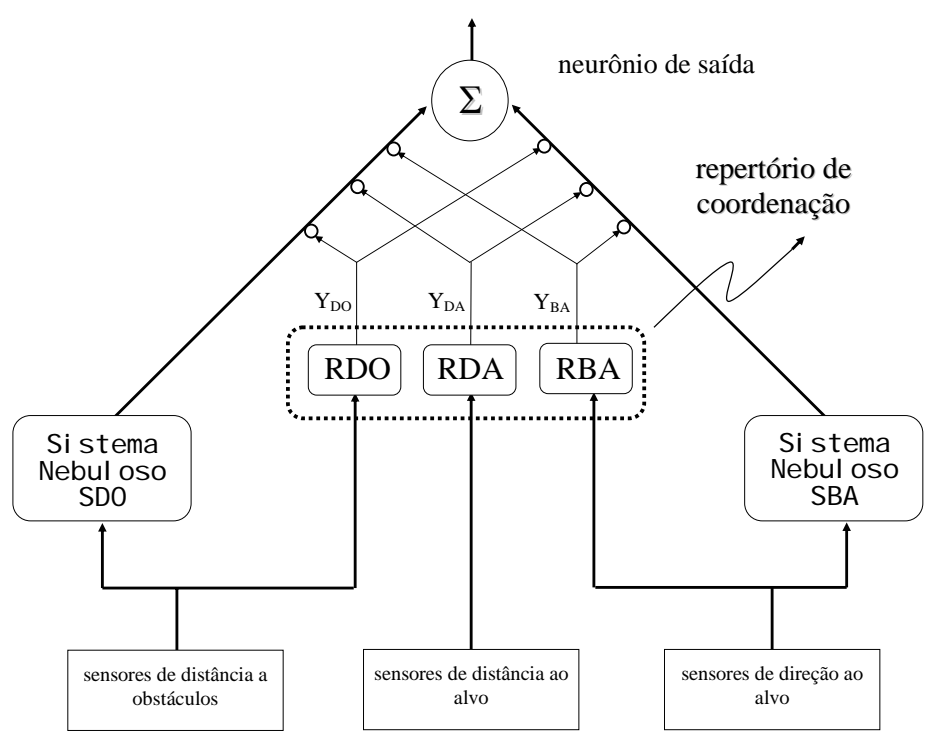

Figura 3.5: Arquitetura do sistema de navegação autônomo 


\subsubsection{Sistema Nebuloso de Desvio de Obstáculos (SDO)}

Os sistemas nebulosos são módulos desprovidos de aprendizagem e implementados utilizando métodos baseados em lógica nebulosa e regras de inferência do tipo se < antecedente $>$ então $<$ conseqüente $>$. O intuito destas técnicas é o tratamento de incertezas, informações imprecisas e conceitos mal definidos. Assim, o sistema de navegação pode gerar resultados eficientes e precisos.

O sistema SDO, em particular, gera o comportamento inato de desvio de obstáculos, ajustando a direção do robô de forma que este não colida. Se somente este módulo atuar, o robô torna-se capaz, unicamente, de desviar de obstáculos não sendo capaz de alcançar o alvo.

Para que seja efetuado o ajuste adequado da direção do robô, o sistema SDO necessita de duas entradas (antecedentes). A primeira é o sinal de distância entre o robô e o obstáculo, emitido pelo sensor de distância a obstáculos que detectou o obstáculo mais próximo, a segunda é a direção deste sensor em relação à direção do movimento do robô (ângulo $\alpha$ ). A saída deste módulo (conseqüente) é a intensidade do ajuste da direção do robô para que este não colida.

A cada instante, os sensores de distância a obstáculos obtêm seus valores, ou seja, detectam a distância do obstáculo mais próximo alinhado em sua direção. Sendo que os sinais obtidos pelos sensores assumem valores dentro do intervalo [0,1] (0 - obstáculo distante, 1 - obstáculo próximo), é encontrado o sensor que obteve o sinal mais alto, informando ao sistema a distância do obstáculo mais próximo ao robô. Portanto, o valor encontrado por este sensor, assim como a sua direção em relação à direção de movimento do robô são os responsáveis pelo sinal gerado pelo sistema SDO.

As variáveis lingüísticas (antecendentes e conseqüente) dos sistema SDO para encontrar o ajuste adequado e seus termos lingüísticos assim como as regras nebulosas são apresentados no Apêndice A.

\subsubsection{Sistema Nebuloso de Busca ao Alvo (SBA)}

O SBA gera o comportamento inato de busca ao alvo. Este sistema não torna o robô capaz de desviar de obstáculos. Somente neste modo de simulação, o robô é induzido insistentemente em buscar alvos. Mas isto pode se tornar uma tarefa impossível, caso haja um obstáculo interpondo-se entre o robô ao alvo.

É necessário somente como entrada (antecedente) o ângulo do sensor que estiver mais alinhado com o alvo. A cada iteração, os sensores de direção ao alvo obtêm seus valores. Tais valores representam a diferença angular entre a posição do sensor e a posição do alvo. Ambos os ângulos 
são encontrados de acordo com a direção de movimento do robô. A direção do sensor que apresentar a menor diferença angular será a entrada para o SBA. Assim como os sensores de distância a obstáculos, os valores para os sensores de direção ao alvo também variam dentro do intervalo [0, 1] (0 - diferença máxima de $180^{\circ}, 1$ - diferença mínima de $0^{\circ}$ ). A saída (conseqüente) gerada pelo SBA é o ajuste da direção do robô para que este se alinhe com o alvo.

As variáveis lingüísticas (antecendentes e conseqüente) dos sistema SBA para encontrar o ajuste adequado e seus termos lingüísticos assim como as regras nebulosas são apresentados no Apêndice A.

\subsubsection{Repertório de Coordenação (RC)}

Situado em um nível hierárquico superior, o papel do RC é gerar pesos sinápticos para o neurônio de saída (ver Figura 3.5) a fim de que este pondere os sinais conflitantes provenientes dos sistemas SDO e SBA, gerando o ajuste adequado para o robô.

O RC é constituído por três redes neurais nebulosas construtivas e não-recorrentes. Tais redes são: Rede Neural Nebulosa de Desvio de Obstáculos (RDO), Rede Neural Nebulosa de Distância ao Alvo (RDA) e Rede Neural Nebulosa de Busca ao Alvo (RBA). Cada rede citada está conectada ao seu respectivo campo sensorial, sensores de distância a obstáculos, sensores de distância ao alvo e sensores de direção ao alvo, respectivamente.

\subsubsection{Rede Neural Nebulosa de Desvio de Obstáculos (RDO)}

A RDO consiste de duas camadas de neurônios nebulosos. Os neurônios são modelados de acordo com a Teoria Nebulosa (Gomide e Pedrycz, 1998), ilustrado na Figura 3.6. Há dois vetores de pesos sinápticos para cada neurônio: W que representa a memória com relação a um padrão induzido e $\mathbf{S}$ que estabelece a intensidade com que a sinapse modifica a entrada. A primeira camada da rede RDO é construtiva, ou seja, nos instantes em que o ciclo de aprendizagem é acionado, alguns neurônios podem ser inseridos na primeira camada. Há somente um neurônio na segunda camada, que é conectado com todos os neurônios da primeira camada. A arquitetura da RDO é apresentada na Figura 3.7.

Cada neurônio da primeira camada conecta-se com todos os sensores do seu respectivo campo sensorial. Assim, o número de sinapses de cada neurônio é igual ao número de sensores de distância a obstáculos. O único neurônio da segunda camada possui um número de sinapses igual ao 
número de neurônios da primeira camada.

De acordo com o modelo de neurônio definido para a primeira camada, as entradas $x_{i}$ e os pesos sinápticos $w_{i}, i=1,2, \ldots N$, são valores modais para os conjuntos nebulosos (modelados de acordo com funções gaussianas) $\Omega_{x_{i}}$ e $\Phi_{w_{i}}$, respectivamente. A dispersão das funções são constantes.
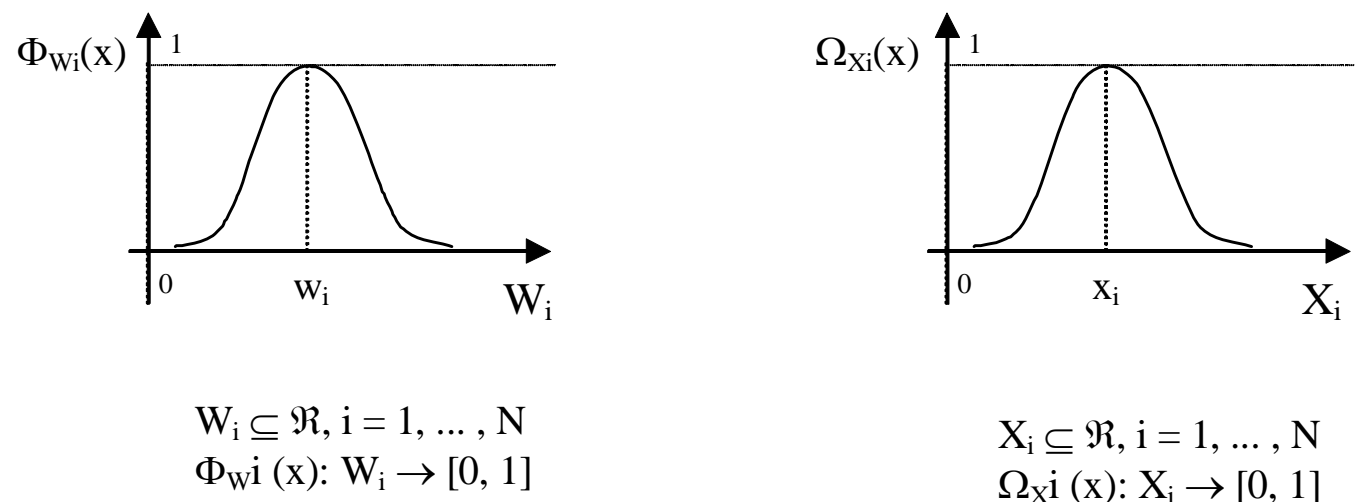

$$
\begin{aligned}
& X_{i} \subseteq \Re, i=1, \ldots, N \\
& \Omega_{X} i(x): X_{i} \rightarrow[0,1]
\end{aligned}
$$

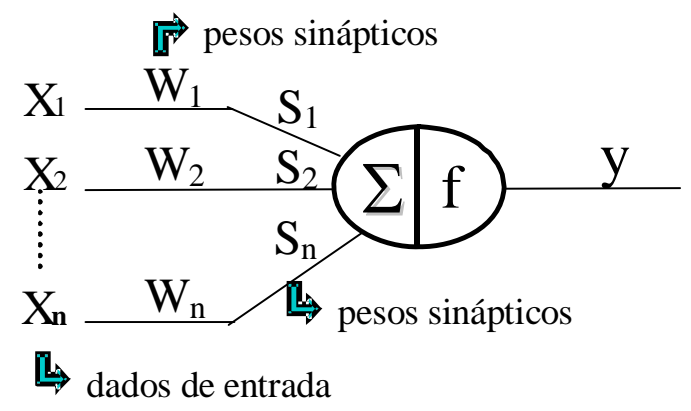

Figura 3.6: Modelo de neurônio nebuloso.

Durante o processamento neural, os conjuntos nebulosos $\Phi_{w_{i}}$ e $\Omega_{x_{i}}$ são comparados usando o operador monotônico $\Delta($.$) . Então a t-norma produto T($.$) pondera o resultado da comparação pelo$ peso sináptico $s_{i}$. Após esse processo, o operador nebuloso $A($.$) encontra o máximo sinal sináp-$ tico (o maior sinal resultante dentre todas as sinapses) e a função de ativação $f(x)=x$ determina a saída do neurônio. A equação 3.2 mostra a saída $y_{k}$ do k-ésimo neurônio da primeira camada (Figueiredo e Gomide, 1996):

$$
y_{k}=f\left(A_{i=1}^{N}\left(T\left(\Delta\left(\Phi_{w_{i}}, \Omega_{x_{i}}\right), s_{i}\right)\right)\right)
$$




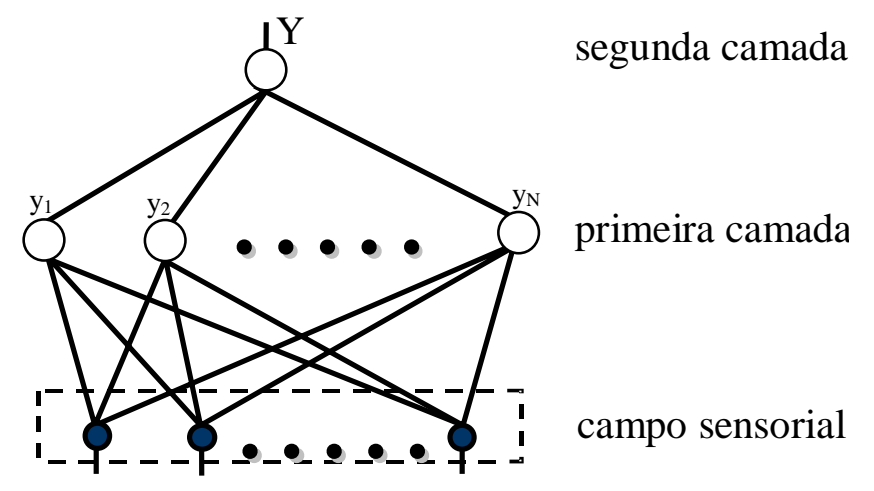

Figura 3.7: Arquitetura da Rede Neural Nebulosa para o Repertório de Coordenação.

Em particular para a equação 3.2, o operador $\Delta($.$) corresponde ao operador nebuloso de me-$ dida de possibilidade conforme a equação 3.3. Como resultado, este operador obtém o valor de intersecção entre os conjuntos nebulosos, indicando o grau de similaridade entre eles (grau de sobreposição). Esse mecanismo é mostrado na Figura 3.8. T é a t-norma produto, $A($.$) é uma$ s-norma máximo aplicada a $N$ operandos e $f($.) é a função identidade.

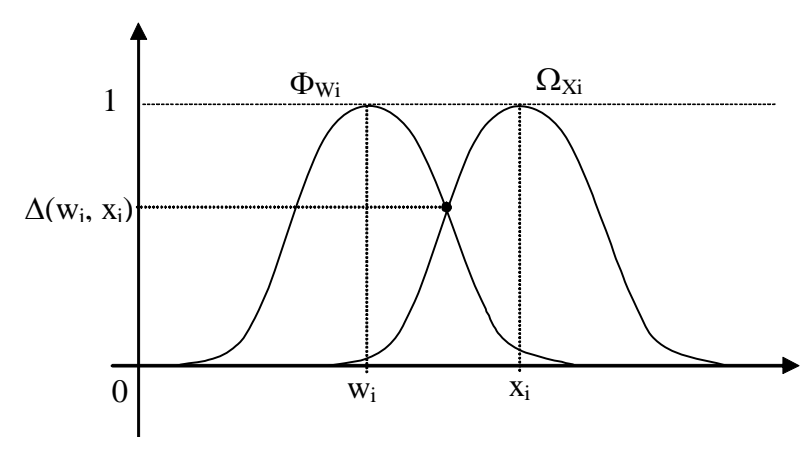

Figura 3.8: Operador de medida de possibilidade

$$
\Delta=S_{x \in U}\left(T\left(\Phi_{w_{i}}, \Omega_{x_{i}}\right)\right)
$$

O único neurônio da segunda camada da rede está conectado com todos os neurônios da primeira camada. Suas sinapses não alteram as entradas. Elas são modeladas por pesos sinápticos unitários e por um operador sináptico igual ao produto algébrico. As funções de agregação e de ativação são definidas pela s-norma máximo e pela função identidade, respectivamente. Portanto, sua saída $Y_{D O}$ (equação 3.4), e conseqüentemente a saída da rede RDO, corresponde ao valor máximo encontrado pelos neurônios da primeira camada. 


$$
Y_{D O}=S_{i=1}^{Q}\left(y_{i}\right)
$$

em que $S($.$) é a s-norma máximo e Q$ é o número de neurônios da primeira camada.

A rede RDO é responsável pela aprendizagem do comportamento de desvio de obstáculos. Os neurônios da primeira camada armazenam, através dos pesos sinápticos $w_{i}$, os padrões de colisões do robô, ou seja, cada neurônio representa uma situação de risco. A cada colisão (o sensor de colisão detecta este evento) que o robô sofre, o padrão captado pelos sensores de distância a obstáculos é avaliado pelo sistema SC que monitora o crescimento da rede para que este padrão seja armazenado em um novo neurônio da rede. Assim o número de neurônios da primeira camada da RDO é igual ou menor ao número de colisões ocorridas.

A cada iteração, os neurônios da primeira camada recebem os sinais provenientes dos sensores de distância a obstáculos. Após o processamento neural já descrito, cada neurônio emite um sinal indicando o grau de semelhança (pertencente ao intervalo $[0,1]$ ) entre o padrão armazenado no neurônio e o novo padrão de entrada apresentado na rede. A saída da rede RDO $\left(Y_{D O}\right)$ resulta da agregação dos sinais de todos os neurônios da primeira camada no único neurônio da segunda camada. O processamento desse neurônio corresponde em encontrar o sinal de maior intensidade, ou seja, o maior grau de semelhança entre o padrão de entrada e todos os que estão armazenados na rede. A saída da rede indica a intensidade da aversão a obstáculo naquele exato instante.

Como dito anteriormente, o RC é responsável por gerar os pesos sinápticos para o neurônio de saída. Observa-se na Figura 3.5 que cada rede neural nebulosa gera um peso sináptico associado aos comportamentos inato. No caso da rede RDO, o peso associado ao sistema SDO é responsável por fortalecer o comportamento de desvio enquanto que o peso associado ao sistema SBA é responsável pelo enfraquecimento do comportamento de busca ao alvo como é melhor detalhado nas seções seguintes.

Dessa forma, quanto maior for o sinal emitido pela rede RDO, maior será a aversão a obstáculos, favorecendo o comportamento de desvio, mas dificultando a captura de alvos próximos a obstáculos.

\subsubsection{Rede Neural Nebulosa de Busca ao Alvo (RBA)}

As idéias adotadas para conceber a rede RBA são similares ou análogas àquelas mencionadas para a RDO (Calvo e Figueiredo, 2001b) (Calvo e Figueiredo, 2001a). A arquitetura (modelo dos neurônios, camadas, e conexões) é idêntica a RDO. As diferenças entre as redes são mostradas 
a seguir. Cada neurônio da primeira camada da rede RBA é conectado com o campo sensorial de direção ao alvo. Dessa forma, o número de sinapses de cada neurônio é igual ao número de sensores de direção ao alvo que o robô possui. O único neurônio da segunda camada possui um número de sinapses igual ao número de neurônios da primeira camada.

A rede RBA aprende a associar as classes de sinais de direção ao alvo com o comportamento adequado de busca ao alvo. O processo de aprendizagem é ativado a todo o momento em que o robô captura um alvo (o sensor de captura detecta este tipo de evento).

Nestes instantes, os pesos sinápticos $w_{i}$ e $s_{i}$ são ajustados. Nos momentos de captura, os sinais captados pelos sensores de direção ao alvo são avaliados pelo sistema SC para que este padrão seja armazenado em um novo neurônio da rede. O número de neurônios da primeira camada da rede é igual ou menor ao número de capturas realizadas. A cada iteração, os neurônios da primeira camada recebem os sinais provenientes dos sensores de direção ao alvo. Após o processamento neural, a rede emite um sinal de saída $\left(Y_{B A} \in[0,1]\right)$ indicando a intensidade com a qual o robô está alinhado com o alvo. Quanto maior for este sinal, mais alinhado com o alvo o robô estará. A saída da RBA é dada pela equação 3.5:

$$
Y_{B A}=S_{i=1}^{Q}\left(y_{i}\right)
$$

em que $S($.$) é a s-norma máximo e Q$ é o número de neurônios da primeira camada.

\subsubsection{Rede Neural Nebulosa de Distância ao Alvo (RDA)}

A arquitetura da rede RDA (modelo dos neurônios, camadas, e conexões) e seu processamento diferem das redes RDO e RBA somente em relação às entradas da rede. Cada neurônio da primeira camada conecta-se com o campo sensorial de distância ao alvo.

A rede RDA aprende a associar classes de sinais de distância ao alvo com momentos em que o robô deve adotar o comportamento de busca ao alvo. A principal função desta rede é informar ao sistema o quão próximo o robô está do alvo. O processo de aprendizagem é ativado sempre que o robô captura um alvo. Da mesma forma que as demais redes, nos instantes em que ocorre captura, os sinais obtidos pelos sensores de distância ao alvo são avaliados pelo sistema SC para que este padrão seja ou não inserido na rede através dos pesos sinápticos $w_{i}$ de um novo neurônio, além disso, os pesos sinápticos $w_{i}$ e $s_{i}$ dos demais neurônios da rede são ajustados.

A todo instante, os neurônios da primeira camada recebem os sinais dos sensores de distância ao alvo normalizados dentro do intervalo $[0,1]$ ( 0 - alvo distante, 1 - alvo próximo). Após 
o processamento neural, a saída da rede $\left(Y_{D A} \in[0,1]\right)$ será o maior valor dentre todos os sinais sinápticos indicando o grau de proximidade com que o robô está em relação ao alvo. Quanto maior for este sinal mais próximo o robô estará do alvo. A saída da RDA é dada pela equação 3.6:

$$
Y_{D A}=S_{i=1}^{Q}\left(y_{i}\right)
$$

em que $S($.$) é a s-norma máximo e Q$ é o número de neurônios da primeira camada.

\subsubsection{Neurônio de Saída (NS)}

A segunda camada do sistema autônomo (Figura 3.5) é composta por um único neurônio de saída e, como o próprio nome sugere, é responsável por gerar a saída do sistema autônomo. Sua função é agregar os sinais correspondentes aos comportamentos inatos e juntamente com seus pesos sinápticos, gerar a saída do sistema equivalente ao ajuste angular submetido à direção de movimento do robô. Este ajuste, como citado na seção 4.5, é limitado em 15 graus assumindo, portanto, valores dentro do intervalo $[-15,15]$. A Figura 3.9 mostra o modelo do neurônio de saída que é definido de acordo com a expressão geral dada pela equação 3.7:

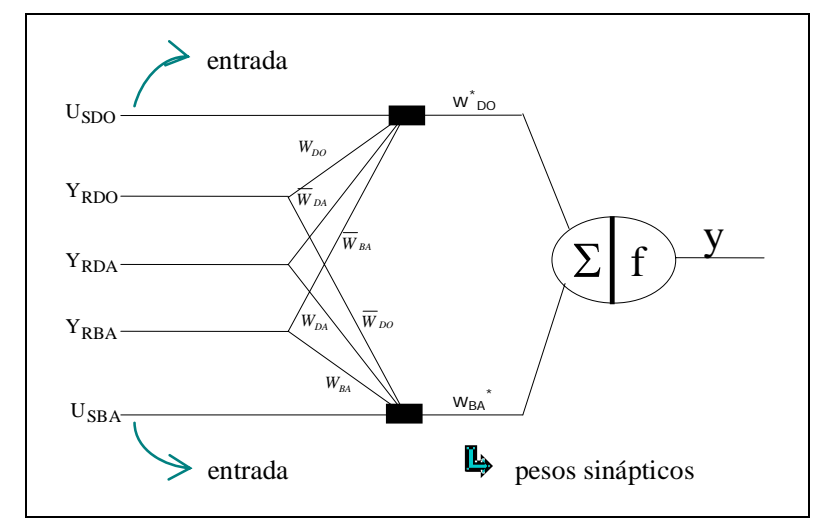

Figura 3.9: Modelo de neurônio de saída.

$$
Y=f\left(\sum_{i=1}^{N} \bar{w}_{i} x_{i}\right), \bar{w}_{i}=\frac{w_{i}}{\sum_{j=1}^{N} w_{j}}
$$

em que $x_{i}$ e $w_{i}, i=1,2, \cdots, N$, são as entradas e os pesos sinápticos, respectivamente, e $f($.$) é a$ função identidade. 
Especificamente para o caso do neurônio de saída, as entradas correspondem às saídas dos sistemas SDO e SBA e portanto, $N$ é igual a $2, x_{1}=U_{S D O}$ e $x_{2}=U_{S B A}$. Substituindo estes termos na equação 3.7, a saída do neurônio NS é dada pela equação 3.8:

$$
Y=\frac{\Phi_{D O} \times U_{S D O}+\Phi_{B A} \times U_{S B A}}{\Phi_{D O}+\Phi_{B A}}
$$

Nesta equação, $\Phi_{D O}$ corresponde ao sinal de ponderação da saída $U_{S D O}$ produzido pelo sistema SDO e $\Phi_{B A}$ corresponde ao sinal de ponderação da saída $U_{S B A}$ produzido pelo sistema SBA. As entradas e os pesos sinápticos do NS são discutidos na próxima seção.

Diferentemente do sistema apresentado em (Figueiredo, 1997), o NS, responsável por gerar a saída do sistema de navegação, é dotado de aprendizagem (Calvo e Figueiredo, 2002). Os pesos sinápticos da equação 3.8 são os responsáveis por este processo.

\subsubsection{Aprendizagem do Repertório de Coordenação}

A estratégia adotada para a aprendizagem do Repertório de Coordenação baseia-se na teoria do condicionamento animal clássico, observada em sistemas nervosos biológicos. $\mathrm{O}$ estímulo não-condicionado e o condicionado são os principais tipos de estímulos que compõem a teoria do condicionamento clássico. O estímulo não-condicionado determina uma resposta nãocondicionada, enquanto que o estímulo condicionado não está associado a nenhum comportamento em particular.

As ocorrências de colisão (instante $t_{c}$ ) e de captura (instante $t_{a}$ ) são definidas como estímulos não-condicionados que determinam os instantes de aprendizagem das redes neurais nebulosas do RC. Na ocorrência de uma colisão, um reflexo não-condicionado é induzido pelo robô. Tal reflexo leva o robô a efetuar um comportamento também não-condicionado alterando sua direção de movimento em $180^{\circ}$. Após a ocorrência de uma série de colisões, o robô passa a realizar um comportamento condicionado, o desvio de obstáculos. Outro reflexo não-condicionado é induzido, resultante da ocorrência de uma captura. Neste caso, a aproximação ao alvo aumenta, reforçando o comportamento de busca. A captura sucessiva de alvos torna o próprio ato de captura um comportamento condicionado.

Em relação ao comportamento de desvio, o estímulo não-condicionado é a colisão e o comportamento não-condicionado é o desvio (sistema SDO auxilia o sistema na execução deste comportamento). Após ser realizado o processo de aprendizagem, o estímulo condicionado é a distância 
do robô ao obstáculo e o comportamento condicionado corresponde ao desvio.

Para o comportamento de busca, o estímulo não-condicionado é a captura do alvo e o comportamento não-condicionado é a busca (procura do alvo). Em consequiência da aprendizagem, o estímulo condicionado passa a ser o alinhamento do robô com o alvo e o comportamento condicionado correspondente à captura.

Como mencionado nas seções anteriores, as redes neurais nebulosas que constituem o RC são construtivas. $\mathrm{O}$ crescimento das redes ocorre exclusivamente nos instantes $t_{c}$ e $t_{a}$ por esse motivo, no início das simulações, as redes do RC são inexistentes. Antes da ocorrência de qualquer evento, as redes não possuem neurônios em sua arquitetura. Dessa maneira, no instante em que o robô é lançado em um ambiente, os sinais emitidos pelo RC são nulos. Sendo assim, a saída do controlador (equação 3.8) determina que os pesos para os comportamentos inatos são equivalentes. Dessa forma, o comportamento que prevalecerá no início da navegação é determinado pelo comportamento inato que se apresenta em maior evidência.

Após a ocorrência da primeira colisão, são inseridos um neurônio na primeira camada e o único neurônio da segunda camada da RDO. Neste instante, os sinais obtidos pelos sensores de distância a obstáculos são transferidos para os pesos sinápticos $w_{i}$ do neurônio inserido (da primeira camada) e os pesos sinápticos $s_{i}$ são inicializados. A partir da segunda colisão, os padrões capturados pelos sensores de distância a obstáculo são avaliados pelo sistema SC para que um novo neurônio seja, ou não, inserido na rede. Após algumas colisões, a RDO associa classes de padrões capturados pelos sensores a situações de colisão iminente, influenciando, então, o aprimoramento do comportamento correspondente ao desvio de obstáculos.

De maneira análoga a rede RDO, após a primeira captura realizada pelo robô, são inseridos um neurônio na primeira camada e o único neurônio da segunda camada das redes RDA e RBA. Os padrões capturados pelos sensores de direção e pelos sensores de distância ao alvo são avaliados pelo sistema SC que decide ou não pela inserção de um novo neurônio nas redes RDA e RBA, respectivamente. Depois de uma série de capturas, a rede RDA associa classes de padrões obtidas pelos sensores de distância ao alvo a situações em que robô está próximo ao ele, e a rede RBA associa os padrões obtidos pelos sensores de direção ao alvo a situações em que o robô está alinhado com o mesmo.

Desta forma, o ciclo de aprendizagem ocorre nos instantes em que ocorre uma colisão (RDO) e uma captura (RDA e RBA). Independente da inserção de um novo neurônio, os pesos sinápticos são ajustados somente após a ocorrência do segundo evento (segunda colisão ou segunda captura). A partir da segunda ocorrência, os pesos sinápticos dos neurônios existentes nas redes são ajustados da seguinte maneira: no momento da ocorrência de um evento (ao menos que não seja o primeiro), 
o sinal de um sensor é comparado com todos os pesos sinápticos $w_{i}$ de todos os neurônios. O peso sináptico que mais se aproximar deste sinal é ajustado de forma que se aproxime do mesmo. $\mathrm{O}$ peso sináptico $s_{i}$ da mesma entrada do peso sináptico $w_{i}$ também é ajustado, representando uma média dos valores de comparação. Os ajustes nos pesos sinápticos são estudados em (Edelman, 1987) conforme o Algoritmo 1. As constantes LIMIAR e START utilizadas no algoritmo a seguir valem 0,1 e 0,5, respectivamente, de acordo com Figueiredo (1997). Para a descrição do Algoritmo 1, utiliza-se a seguinte notação:

$\mathrm{N}$ - número de sensores

e - números de eventos

Q - número de neurônios na primeira camada

$v=\left(v_{1} \cdots v_{k} \cdots v_{n}\right)$ - vetor com os valores obtidos pelos sensores

Além dos ajustes dos pesos sinápticos, em todo o instante $t_{c}$ ou $t_{a}$, a primeira camada das redes RDO, RDA e RBA pode ter sua arquitetura alterada (Calvo et al., 2004). Portanto, são redes neurais construtivas. $\mathrm{O}$ sistema que monitora o crescimento das redes neurais nebulosas determina, a partir de três parâmetros, entre duas possibilidades o estado da arquitetura das redes. Tais estados são: sem alteração e inserção de neurônio. Outros modelos de redes neurais construtivas podem ser encontradas em (Fahlman e Lebiere, 1990) e (R. Parekh, 2000).

Para a primeira camada do sistema autônomo, onde está localizado o RC, os pesos sinápticos das redes neurais nebulosas são ajustados de acordo com variações da regra de Hebb (Hebb, 1949), ou seja, a região sináptica entre dois neurônios é reforçada se eles são disparados de forma correlacionada.

Os sinais de reforço e punição são resultados da aprendizagem por condicionamento, além de serem negativos ou positivos. Estes sinais ocorrem no instante $t_{c}$ ou $t_{a}$. Os modelos de aprendizagem por reforço são baseados na lei de Hebb. Segundo Hebb, se dois neurônios disparam de forma correlacionada no tempo - o neurônio pré-sináptico influencia no disparo do pós-sináptico - então a sinapse entre eles é reforçada (Haykin, 1994) (originalmente (Hebb, 1949)).

A aprendizagem por reforço determina a execução do comportamento mais provável de ocorrer. Já a aprendizagem por punição determina o comportamento menos provável. Além disso, a natureza do condicionamento pode ser positiva ou negativa (Catania, 1999). O condicionamento positivo estabelece o aumento da frequiência do estímulo não-condicionado e o condicionamento negativo a redução de sua freqüência.

A Tabela 3.1 apresenta os tipos de aprendizagem que o sistema possui: 


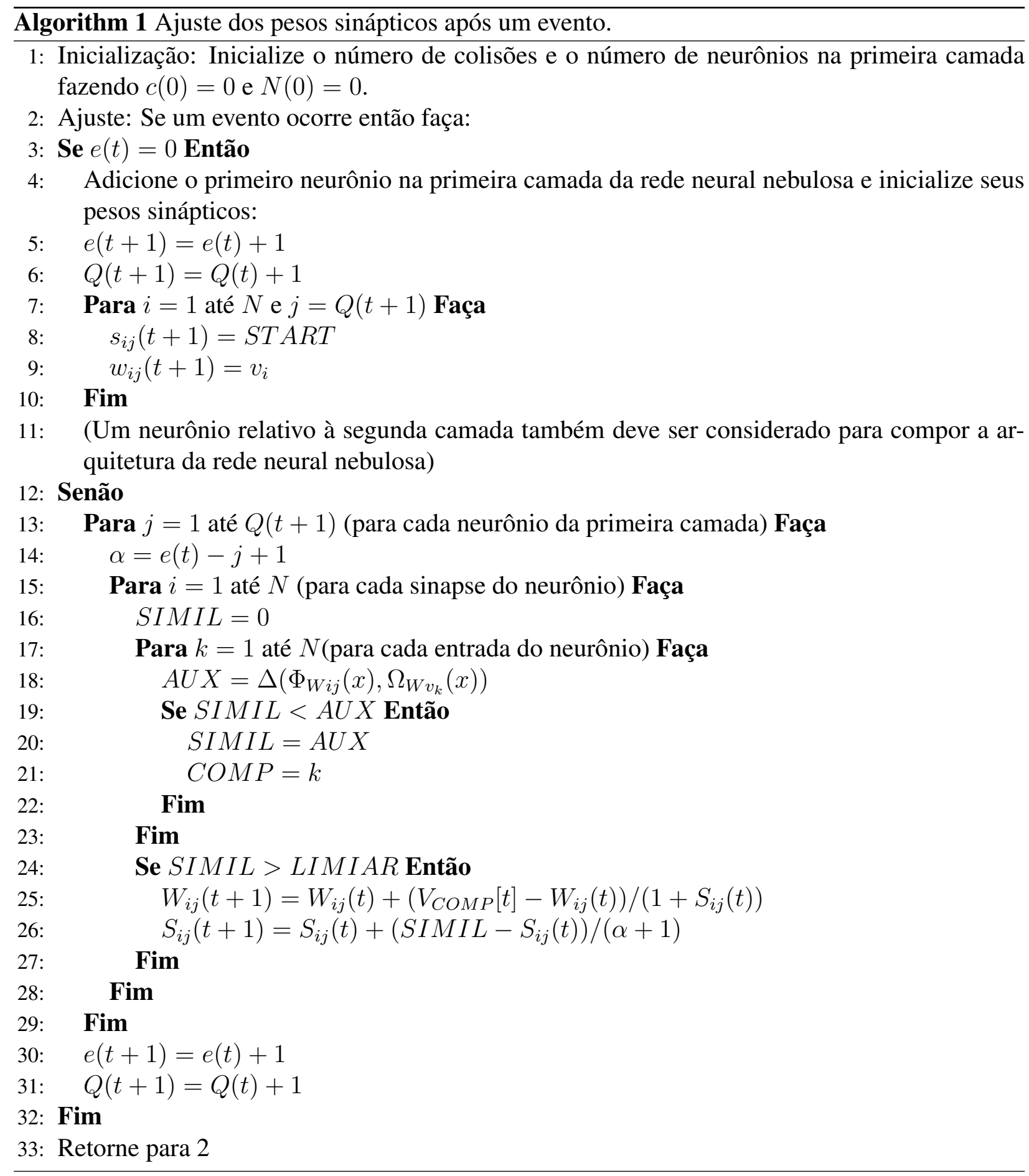


Tabela 3.1: Tipos de aprendizagem disponíveis no sistema.

\begin{tabular}{|c|c|c|}
\hline Eventos & Aprendizagem por Condicionamento & Conseqüência \\
\hline \hline \multirow{3}{*}{ Colisão } & Reforço Negativo & Aumenta o comportamento de desvio \\
\cline { 2 - 3 } & & Retira o estímulo de colisão \\
\cline { 2 - 3 } & Punição Negativa & Diminui o comportamento de busca \\
\cline { 2 - 3 } & & Retira o estímulo de captura \\
\hline \multirow{3}{*}{ Caputra } & Reforço Positivo & Aumenta o comportamento de busca \\
\cline { 3 - 3 } & & Acrescenta o estímulo de captura \\
\cline { 2 - 3 } & Punição Positiva & Diminui o comportamento de desvio \\
\cline { 3 - 3 } & & Acrescenta o estímulo de colisão \\
\hline
\end{tabular}

A teoria de aprendizagem apresentada em (Calvo e Figueiredo, 2003a), a Extensão da lei de Hebb, propõe que o disparo de um neurônio pode intensificar uma sinapse assim como reduzir a intensidade de uma outra para um mesmo evento (Calvo e Figueiredo, 2003b). O modelo de aprendizagem clássico de Hebb considera que um evento module a sinapse segundo um único padrão. Hebb demonstrou que a capacidade da aprendizagem em redes neurais vem da alteração da eficiência sináptica, isto é, a conexão somente é reforçada se tanto os neurônios pré-sinápticos quanto os pós-sinápticos estiverem excitados.

De acordo com a extensão, um sinal de reforço único, ocorrido na iteração $t$, pode determinar a intensificação (reforço) ou a redução (punição) da eficiência sináptica ou ambas as situações, em sinapses distintas. Caso o comportamento inato e o sinal de reforço apresentem naturezas opostas, e.g., reflexo repulsivo e reforço recompensador, a sinapse é reduzida. Caso as naturezas sejam concordantes, então a sinapse é intensificada.

$\mathrm{Na}$ natureza, os animais tendem a efetuar mais freqüentemente as açõess pelas quais sãoo recompensados e a deixar de realizar aquelas pelas quais são punidos. Em conseqüência disso, eles tornam-se mais aptos para realizar as ações recompensadoras e a sua habilidade para a prática das ações puníveis se reduz. Analogamente ao condicionamento animal, a ocorrência de um evento reforçador possibilita o aumento de sua frequiência, enquanto que um evento punidor reduz a frequência do mesmo.

Em particular para este trabalho e baseando-se na teoria proposta, um evento de colisão ocorrido na iteração $t$ fortalece o comportamento inato de desvio de obstáculos e enfraquece o comportamento inato de busca ao alvo. De forma contrária, um evento de captura de alvo na iteração $t$ enfraquece o comportamento de desvio de obstáculos e fortalece o comportamento de busca ao alvo. A influência da conseqüência dos eventos ocorridos nos comportamentos inatos pode ser visto na Figura 3.5, onde mostra a conexão dos sinais emitidos pelas redes neurais com a saída dos sistemas nebulosos. 
A modelagem para a extensão da lei de Hebb é aplicada à segunda camada do sistema autônomo (ver Figura 3.5). O único neurônio pertencente a esta camada possui duas entradas nas quais os pesos sinápticos estão associados a conexões axônio-axônio entre as redes neurais nebulosas e os sistemas nebulosos (Figura 3.9).

As saídas das redes que constituem o RC são associadas determinando os pesos sinápticos do NS. Os pesos $\Phi_{D O}$ e $\Phi_{B A}$ do NS (equação 3.8) são definidos de acordo com as equações 3.9 e 3.10, respectivamente:

$$
\begin{gathered}
\Phi_{D O}=w_{1}=\epsilon+W_{D O} Y_{D O}-\left(\bar{W}_{B A} Y_{B A}\right) \times\left(\bar{W}_{D A} Y_{D A}\right) \\
\Phi_{B A}=w_{2}=\epsilon+\bar{W}_{D O} Y_{D O}-\left(W_{B A} Y_{B A}\right) \times\left(W_{D A} Y_{D A}\right)
\end{gathered}
$$

Dessa forma, a equação 3.8 pode ser expressa como a equação 3.11 :

$$
Y=\frac{\left(\epsilon+W_{D O} Y_{D O}-\bar{W}_{B A} Y_{B A} \bar{W}_{D A} Y_{D A}\right) \times U_{S D O}+\left(\epsilon+W_{B A} Y_{B A} W_{D A} Y_{D A}-\bar{W}_{D O} Y_{D O}\right) \times U_{S B A}}{\left(\epsilon+W_{D O} Y_{D O}-\bar{W}_{B A} Y_{B A} \bar{W}_{D A} Y_{D A}\right)\left(\epsilon+W_{B A} Y_{B A} W_{D A} Y_{D A}-\bar{W}_{D O} Y_{D O}\right)}
$$

em que $\epsilon$ é uma constante $(\epsilon=0,05) ; \bar{W}_{D O}, W_{B A}$ e $W_{D A}$ são pesos sinápticos associados com as conexões axônio-axônio entre as redes RDO, RBA e RDA e o sistema SBA, respectivamente; $W_{D O}, \bar{W}_{B A}$ e $\bar{W}_{D A}$ são, de forma análoga, os pesos sinápticos referentes ao sistema SDO. Os pesos sinápticos são inicializados com o valor $5 \times 10^{-5}$.

No início da navegação, quando as redes neurais nebulosas são inexistentes, pode-se observar pela equação 3.11 que o comportamento do robô depende somente dos sinais dos sistemas nebulosos. Aquele sistema que possuir o maior valor em módulo torna-se o responsável pelo ajuste rotacional do robô, uma vez que a constante $\epsilon$ tem a função de não anular o ajuste do robô.

Ainda na equação 3.11, nota-se que para um mesmo evento de colisão, a intensidade das duas sinapses correspondentes ao neurônio de saída é alterada de duas formas distintas: o peso sináptico $W_{D O}$ é intensificado (associado ao comportamento de desvio), enquanto o peso sináptico $\bar{W}_{D O}$ é enfraquecido (associado ao comportamento de busca). De forma semelhante ocorre com o evento de captura ao alvo que fortalece o comportamento de busca através dos pesos $W_{B A}$ e $W_{D A}$ e enfraquece o comportamento de desvio através dos pesos $\bar{W}_{B A}$ e $\bar{W}_{D A}$. 
O fortalecimento e o enfraquecimento das sinapses são ajustados conforme as equações 3.12 e 3.13 nos instantes $t=t_{c}$ e $t=t_{a}$, respectivamente:

$$
\begin{gathered}
\left\{\begin{array}{l}
W_{D O}(t+1)=W_{D O}(t)+\zeta\left(1-W_{D O}(t)\right) f\left(Y_{R D O}\right) g\left(U_{S D O}\right) \\
\bar{W}_{D O}(t+1)=\bar{W}_{D O}(t)+\zeta\left(1-\bar{W}_{D O}(t)\right) f\left(Y_{R D O}\right) g\left(U_{S B A}\right)
\end{array}\right. \\
\left\{\begin{array}{l}
W_{B A}(t+1)=W_{B A}(t)+\zeta\left(1-W_{B A}(t)\right) f\left(Y_{R B A}\right) g\left(U_{S B A}\right) \\
\bar{W}_{B A}(t+1)=\bar{W}_{B A}(t)+\zeta\left(1-\bar{W}_{B A}(t)\right) f\left(Y_{R B A}\right) g\left(U_{S D O}\right) \\
W_{D A}(t+1)=W_{D A}(t)+\zeta\left(1-W_{D A}(t)\right) f\left(Y_{R D A}\right) g\left(U_{S B A}\right) \\
\bar{W}_{D A}(t+1)=\bar{W}_{D A}(t)+\zeta\left(1-\bar{W}_{D A}(t)\right) f\left(Y_{R D A}\right) g\left(U_{S D O}\right)
\end{array}\right.
\end{gathered}
$$

em que $\zeta=0,015, \eta=0,03$ são fatores de aprendizagem, $f($.$) é uma função sigmóide que$ normaliza a saída gerada pelas redes neurais nebulosas em um valor dentro do intervalo [0, 1] conforme a equação 3.14 e $g($.) é uma função sigmóide que normaliza a saída dos sistemas nebulosos em um valor dentro do intervalo $[0,1]$ conforme a equação 3.15 .

$$
\begin{aligned}
& f(x)=\frac{1}{1+e^{-7(x-0,5)}} \\
& g(x)=\frac{1}{1+e^{-0,5(x-0,5)}}
\end{aligned}
$$

A percepção do efeito da extensão pode ser notada rapidamente quando se observa o comportamento resultante da equação 3.11 após um estado de experiências. A ocorrência de um evento em uma quantidade maior que a do outro implica no enfraquecimento do comportamento do segundo.

O comportamento de busca a alvos pode ser prejudicado sem que ocorram capturas. Para isso é preciso que o robô tenha sofrido algumas colisões. O mesmo ocorre na ausência de estímulo de colisões, neste caso o comportamento de desvio de obstáculos é influenciado negativamente favorecendo o comportamento de busca ao alvo.

Mesmo que a ocorrência de uma colisão tenha o efeito de fortalecer o comportamento de desvio, há neste mesmo instante o enfraquecimento do comportamento de busca. Isso ocorre com o ajuste do peso sináptico $\bar{W}_{D O}$. De forma semelhante, nos instantes em que as capturas são realizadas, a intensidade do comportamento de desvio é reduzida através do ajuste dos pesos sinápticos $\bar{W}_{B A}$ e $\bar{W}_{D A}$. 


\subsection{Considerações Finais}

Neste capítulo foi apresentado o sistema neural nebuloso que serve como base para o desenvolvimento do trabalho proposto. Desde uma visão geral até a descrição em detalhes dos componentes do sistema foram apresentados. Tal sistema fundamenta-se na TSGN e engloba técnicas de redes neurais e teoria dos sistemas nebulosos. Os comportamentos inatos gerados pelos sistemas nebulosos que compõe a arquitetura híbrida são ponderados pelo Repertório de Coordenação (RC). As redes neurais constituintes do RC são responsáveis por associar os comportamentos de desvio de obstáculos e busca ao alvo. Para tanto, o processo de aprendizagem adotado está baseado no aprendizado por reforço.

O aprendizado está presente nas duas camadas da arquitetura. Na primeira, o mecanismo de aprendizagem é baseado na lei de Hebb e na segunda utiliza-se de um mecanismo baseado na extensão da lei de Hebb. Desse modo, os comportamentos conflitantes gerados pelos sistemas nebulosos são coordenados de forma que um comportamento prevalecerá sobre o outro dependendo da situação em que o robô se deparar, ou seja, no instante em que a execução de um comportamento se faz necessária com maior intensidade sobre o outro. A ponderação desses comportamentos através do RC é responsável por esta tarefa, auxiliando o sistema a tomar decisões de forma sensata.

Considerando que o sistema neural nebuloso é o sistema de navegação autônomo do robô Pioneer I, define-se neste capítulo o mecanismo pelo qual o robô tornar-se-á capaz de se locomover em ambientes reais. Diante disso, o capítulo seguinte apresenta os resultados obtidos tanto em simulação quanto em ambientes reais devido a implantação do sistema neural nebuloso no sistema Saphira, software de suporte do robô Pioneer I. 



\section{CAPÍtULO \\ 4 \\ Robô e Software de Controle}

\subsection{Introdução}

Inúmeras implementações de robôs tendem a projetá-los no formato de acordo com a função que o mesmo desempenha (carros, aviões, aspiradores de pó, etc.) e não simplesmente baseá-lo no formato de seres humanos como um dispositivo mecatrônico e antropomórfico. Além do formato espera-se que o robô seja dotado de um modelo de raciocínio semelhante ao do ser humano. No entanto não é necessário que o tal raciocíonio associado ao robô seja idêntico ao do homem para desemepenhar uma tarefa estabelecida.

Pesquisas na área de robótica sofreram uma divisão no início da década de 60. O primeiro ramo da divisão seguiu o caminho da robótica industrial onde foram concentrados projetos de braços robotizados para aplicações de manufatura. Nesta linha de pesquisa, é necessário que os robôs (braços robotizados) sejam programados por meio de técnicas precisas para aplicações em linhas de montagens em que a repetição de tarefas é uma característica essencial. A segunda linha de pesquisa resultante da divisão ocorrida no caminho evolutivo da robótica foi conduzida pela teleoperação (robôs controlados manualmente a distância) para a construção de robôs autônomos, originando uma nova subárea denominada de robótica inteligente. A "inteligência" é incorporada em robôs por meio de um conjunto de técnicas denominado de paradigma robótico. O sistema de navegação proposto em (Calvo e Figueiredo, 2003b) utiliza o paradigma reativo para o robô executar a tarefa de alcançar um ponto meta. Para tornar possível a validação do sistema neural nebuloso descrito no Capítulo 3 em experiementos reais é utilizado o robô móvel Pioneer $\mathrm{I}^{1}$ junto

\footnotetext{
${ }^{1}$ ActivMedia Robotics - http://www.activmedia.com
} 
com o simulador Saphira que provê uma interface entre o sistema de navegação e o controle dos atuadores do robô.

Neste capítulo são apresentados alguns conceitos dos robôs que são focos das duas linhas de pesquisas da robótica, robôs manipuladores e robôs móveis autônomos nas Seções 4.2 e 4.3, respectivamente. Na seção 4.4.2 são mostrados alguns paradigmas da robótica. O robô móvel utilizado para a validação do sistema de navegação é mostrado na Seção 4.5 seguido de seu software de controle, o ambiente Saphira, ferramenta pela qual tornou-se possível a aplicação do sistema de navegacão em ambientes reais na Seção 4.6.

\subsection{Robôs manipuladores}

Robôs manipuladores são comumente projetados para atuarem em ambientes altamente estruturados com configurações bem definidas. Robôs programados em ambientes desta natureza são programados para realizar uma série de movimentos bem definida com alto grau de velocidade e precisão sem a necessidade de monitoramento e representação do ambiente. Seguindo este contexto, Arkin (1999) afirma que a Associação de Robótica Industrial (RIA) define: "Um robô é um manipulador reprogramável e multifuncional projetado para mover material, peças, ferramentas, ou dispositivos especializados por meio de movimentos variáveis programados para a realização de uma variedade de tarefas.".

Os primeiros robôs manipuladores foram projetados para manipular material radioativo e auxiliar na construção de bombas atômicas. Esses robôs eram controlados remotamente (teleoperados) com o intuito de evitar que o contato dos cientistas com o material radiotivo. Atualmente, os robôs manipuladores são utilizados em diversas aplicações, tais como, limpeza de oleodutos, braços robóticos utilizados para soldar tubulações, laboratórios de ensino remoto, entretenimento, etc. Dois exemplos de robôs manipuladores controlados via Web são apresentados a seguir.

O TeleGarden ${ }^{2}$ é uma instalação artística que permite a interação dos usuários com um jardim remoto via web possiblitando-os a efeturarem atividades relacionadas ao monitoramento de um jardim, como plantar e regras as plantas além de acompanhar o crescimento das mesmas por meio de movimentos de um braço robótico. Este projeto foi desenvolvido pela Universidade da Califórnia do Sul em 1995. Outro projeto, denominado de Telelabs ${ }^{3}$ e de responsabilidade da Escola de Engenharia Mecânica da Universidade da Austrália Ocidental, tem como objetivo desenvolver e testar novas tecnologias para aprendizado pela Internet. Esse projeto consiste de um robô industrial e câmeras para permitindo o monitoramento das atividades do robô. O método de aprendizado

\footnotetext{
${ }^{2} \mathrm{http} / /$ www.ieor.berkeley.edu/goldberg/garden/Ars/

${ }^{3}$ http://telerobot.mech.uwa.edu.au/index.html
} 
aplicado aos estudantes envolve a combinação de teoria, simulações e utilização dos equipamentos de laboratório. Esse projeto consiste de um robô industrial e câmeras para permitindo o monitoramento das atividades do robô.

Instituições de ensino têm mostrado interesse no desevolvimento de robôs controlados de forma remota. A Universidade do Tennessee de Chattanooga (UTC) apresenta o uso do software LabView $^{4}$ que possiblita o controle de equipamentos através da Internet. O Instituto de Tecnologia Federal Suíço de Lausanne (EPFL) ${ }^{5}$ desenvolve projetos em que robôs e periféricos são conectados a Internet utilizando através do software de manipulação de equipamentos de laboratórios Quanser possibilitando o acesso de forma remota dos mesmos.

\subsection{Robôs móveis autônomos}

Robôs móveis são agentes artificiais ativos com capacidade de locomoção, imersos no mundo real. Os robôs são definidos como agentes por atuarem de forma racional, segundo um mecanismo de raciocínio aproximado ao raciocíono humano; artificial por serem máquinas e não criaturas da natureza; ativos por aturarem no ambiente de forma propositada e não passiva; com capacidade de locomoção por se moverem no ambiente real (Ribeiro et al., 2001). A locomoção de um robô ocorre por meio de técnicas específicas provendo ao robô funções que possibitam a realização daa tarefa de navegação. Tais funções são, desviar de obstáculos, mapear o ambiente, localizar-se no ambiente e planejar a trajetória, com o intuito de realizar de forma segura as tarefas estabelecidas ao robô.

O controle autônomo de robôs móveis para a realização de tarefas simples, tais como, entrega de documentos (Bianchi e Romero, 2003), coleta de objetos e exploração de ambientes (procurar por referências) é uma linha de pesquisa em ascensão na área de robótica. A tarefa de locomoção ainda é um dos grandes problemas encontrados na área de controle de robôs móveis, ou seja, não é um problema simples definir uma tarefa ao robô considerando a priori seu posicionamento inicial e deixando este se locomover até a a execução da tarefa seja atingida ou até o alcance de uma posição meta de forma autônoma (Ribeiro et al., 2001).

A construção de robôs móveis autônomos foi motivada pela tarefa de teleoperação em que os mesmos eram controlados manualmente a distância, originando uma nova subárea denominada de robótica inteligente. Esta nova linha de pesquisa visa o estudo e o desenvolvimento de robôs inteligentes. Murphy (2000) define robô inteligente como: "Um robô inteligente é uma criatura

\footnotetext{
${ }^{4}$ http://chem.engr.utc.edu/

${ }^{5}$ http://www.epfl.ch/
} 
mecânica que pode funcionar autonomamente. "Em contraste com os braços robotizados, um robô inteligente não realiza tarefas de modo repetitivo e pré-determinado. A autonomia aplicada na robótica significa que o robô pode operar de modo auto-contido e, sob condições razoáveis, sem recorrer a influências externas, como por exemplo, um operador humano. Em outras palavras, associa-se a um robô autônomo a capacidade de tomar decisões para realizar determinadas tarefa sem interferência externa. A grande maioria dos robôs inteligentes faz parte do grupo dos robôs móveis, dotados de capacidades de locomoção, incluindo o robô utilizado para a realização deste projeto.

\subsection{Paradigmas da Robótica}

A "inteligência" é incorporada em robôs por meio de um conjunto de técnicas denominado de paradigma robótico. Um paradigma é uma filosofia ou conjunto de concepções e/ou técnicas que caracterizam uma abordagem a uma classe de problemas. Três primitivas básicas e a forma de como elas são organizadas diferenciam os paradigmas robóticas, são elas: sentir, planejar e agir. A primitiva sentir diz respeito às tarefas relacionadas com a recupração de informações do ambiente em que o robô está inserido, por meio de seus sensores. Planejar está relacionada ao processo de receber informações e a partir delas, produzir tarefas a serem conduzidas pelo robô. A terceira primitiva, agir, produz comandos diretamente aos atuadores do robô (motores ou quaisquer dispositivos que modifiquem ativamente o ambiente). Até o momento existem três paradigmas robóticos, são eles, o hierárquico, o reativo e o híbrido reativo/deliberativo (Murphy, 2000). Cada um deles é descrito a seguir de forma sucinta.

\subsubsection{Paradigma Hierárquico}

O paradigma hierárquico foi o primeiro paradigma robótico. Neste, as primitivas robóticas estão organizadas de forma que a primeira primitiva a ser realizada é a primitiva sentir, obtendo informações detectadas pelos sensores e as integra em um modelo de mundo global. Em seguida, a primitiva planejar é executada, a qual interpreta o modelo de mundo global e fornece tarefas à primitiva agir, que por sua vez, comanda os módulos de controle de baixo nível do robô. Essa organização (Figura 4.1) é cíclica, ou seja, o robô reinicia o ciclo após a primitiva agir. Este paradigma apresenta uma deficiência a respeito do tempo de resposta. Os processos de criação de modelos de mundo complexos e de planejamento são computacionalmente custosos, e com o fato de que as primitivas estão organizadas seqüencialmente, uma nova percepção do ambiente e a análise de suas ações se foram realizadas corretamente assim como as mudanças causadas por outros agentes devem ser iniciadas após o robô agir no ambiente. 


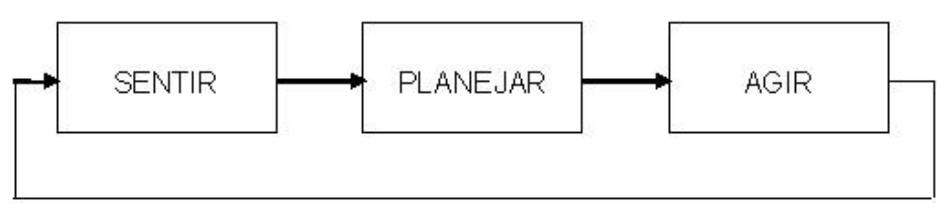

Figura 4.1: Paradigma Hierárquico

Um dos primeiros robôs móveis inteligentes desenvolvidos foi Shake (Shanahan, 2001). Este robô segue o paradigma o hierárquico de maneira que a percepção do mundo seja totalmente separada da ação. A primitiva planejar é realizada por um planejeador denominado STRIPS, o qual utiliza a análise meios-fins para inferir ações tomando como parâmetro um modelo simbólico do mundo obtido anteriormente ao planejamento.

\subsubsection{Paradigma Reativo}

Analisando estudos de psicólogos sobre o comportamento de animais, pesquisadores da área de robótica criaram um novo paradigma, o paradigma reativo. Este paradigma pode ser observado na Figura 4.2, a primitiva planejar foi completamente eliminada com intuito de fazer um mapeamento direto entre percepção e ação. O paradigma reativo é orientado a comportamentos que podem ser vistos como "elos" de ligação entre a percepção à ação. Também podem ser considerados como unidades básicas a partir das quais sistemas complexos podem ser desenvolvidos pela integração de partes simples.

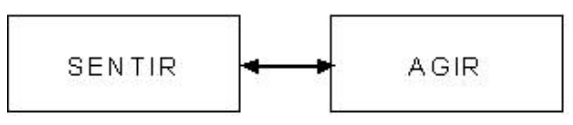

Figura 4.2: Paradigma Reativo

O comportamento geral do robô é alcançado por meio da combinação de vários comportamentos independentes. Essa independência implica em que as primitivas sentir e agir são locais a cada comportamento. Desta forma, vários comandos motores independentes são gerados e devem ser integrados de algum modo. Para o paradigma reativo, representação do ambiente em que o robô atua é desnecessário. Dessa forma, os robôs devem mapear suas ações a percepções obtidas diretamente de seus sensores. O sistema de navegação autônomo validado neste trabalho utiliza o paradigma reativo na determinação da trajetória do robô em um ambiente de atuação desconhecido. Segundo Brooks (1991), um dos mais importantes defensores da abordagem reativa: "O melhor modelo do mundo é ele próprio." 


\subsubsection{Paradigma Híbrido Reativo/Deliberativo}

Apesar do sucesso alcançado com o paradigma reativo demonstrado por implementações de comportamentos, como desviar de obstáculos e seguir metas simples usando percepção orientada à ação, muitos pesquisadores perceberam que o paradigma reativo não resolveria todos os problemas. Muitas tarefas requerem que os robôs sejam dotados de memória para a representação de mundo, como por exemplo o mapeamento e a localização, tarefas cruciais para que um robô possa navegar de forma autônoma por longas distâncias e grandes períodos de tempo.

O paradigma híbrido é capaz de combinar os paradigmas hierárquico e reativo de forma a reduzir o tempo decorrido na execução das primitivas, ou seja, não tornar os robôs lentos como no paradigma hierárquico, e ainda assim realizar planejamentos que possuem alto custo computacional. Como mostrado na Figura 4.3, a primitiva planejar está presente, porém há a sua ligação de forma seqüencial com as demais. Neste paradigma, a organização é do tipo planejar, sentir-agir. Isso significa que o planejamento é realizado em um passo e então sentir e agir são realizados simultaneamente. Portanto, o planejamento não faz parte do ciclo de percepção-ação, interagindo nessa organização somente quando tem algum resultado relevante de seus planejamentos. O planejador pode ser usado, dentre outras coisas, para definir a tarefa destinada ao ciclo percepção-reação e para estabelecer os comportamentos que devem ser ativos na próxima tarefa.

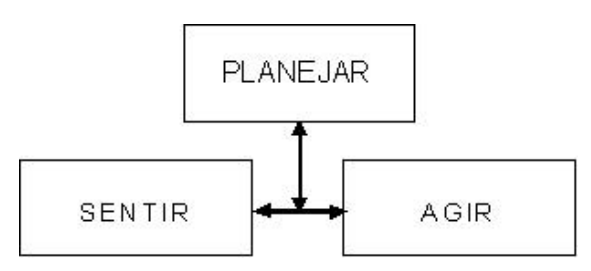

Figura 4.3: Paradigma Híbrido

\subsection{Robô Pioneer I}

Tornando possível a validação do sistem neural nebuloso descrito no Capítulo 3 em experimentos reais, todo o desenvolvimento do sistema de navegação e experimentos foram realizados sob a plataforma do robô móvel Pioneer $I^{6}$ (Figura 4.4). Este robô está montado sobre um eixo de duas rodas que lhe permite fazer rotações e movimentos para frente e para trás. Como se pode observar na Figura 4.5, o robô possui pequenas dimensões. O robô é movido por dois motores com movimentação por diferencial. Ele pode se mover a uma velocidade máxima, aproximada de $60 \mathrm{~cm} / \mathrm{s}$. Suas capacidades de odometria variam bastante dependendo da superfície por onde ele

\footnotetext{
${ }^{6}$ ActivMedia Robotics - http://www.activmedia.com
} 
está se locomovendo. O erro de distância é de aproximadamente 1 centímetro por metro, o erro de rotação é de aproximadamente 8 graus por rotação.

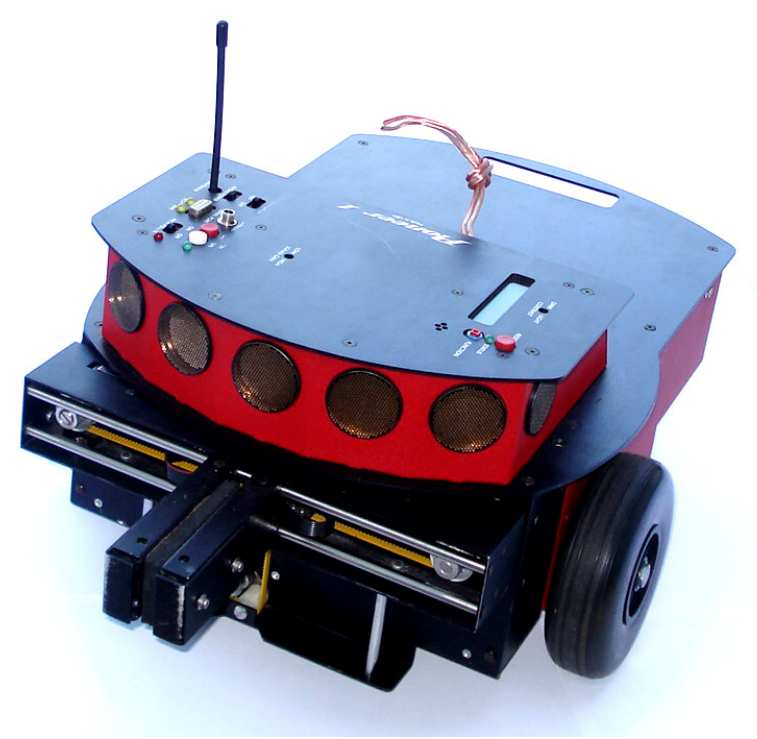

Figura 4.4: Pioneer I

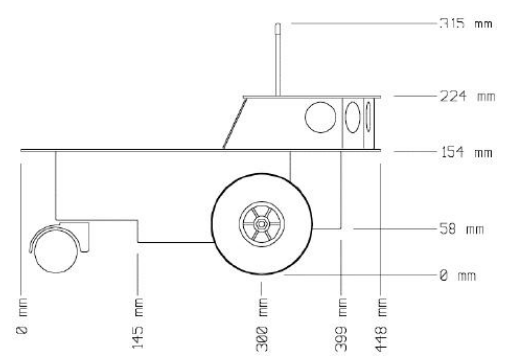

(a)

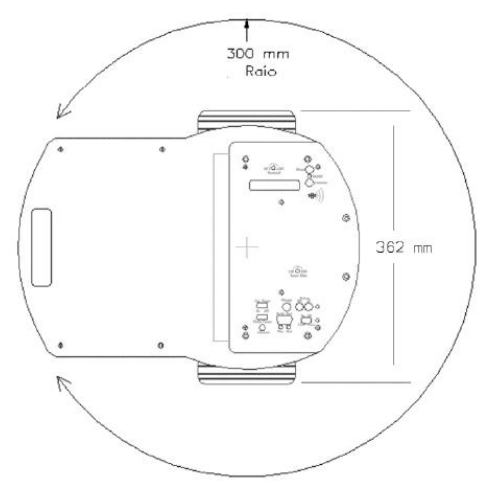

(b)

Figura 4.5: Pioneer I (a) Vista lateral; (b) Vista superior

O robô é equipado com um gripper que se movimenta para cima e para baixo com 2 graus de liberdade. O gripper opera entre dois estados: aberto/fechado. Os sensores infra-vermelhos existentes na parte frontal e traseira de cada pá podem detectar objetos entre as pás e qual pressão deve ser exercida para capturar objetos. As duas pás podem erguer objetos com no máximo 1,4 kg e um sistema de elevação vertical permite pegar objetos com no mínimo $2 \mathrm{~cm}$ de altura. Além disso, possui três habilidades de conexão com o microcomputador: via rede, porta serial ou transmissão, via ondas de rádio. Para utilizar a transmissão via ondas de rádio o transmissor é conectado à porta serial do computador. 
O robô móvel Pioneer I possui sete sonares ultra-sônicos 4.6 sendo cinco deles localizados na parte frontal, um na lateral direta e um na lateral direita. O tempo necessário para um sonar realizar uma leitura é de $40 \mathrm{~ms}$, ou seja, cada sonar possui uma taxa de disparo de $25 \mathrm{~Hz}$. Os sonares exibem características típicas de qualquer sonar. Eles raramente medem a distância do objeto mais próximo. Os sonares sempre retornam valores que são imprecisos e, não necessariamente denotam a distância correta. Os sonares medem o tempo decorrido entre a emissão e a recepção de uma onda sonora. Para objetos lisos, a chance de receber um eco depende do ângulo entre o sonar e o objeto que refletirá a onda sonora. Quando as ondas sonoram acertam a parede frontalmente, muito provavelmente elas retornam na direção dos sonares. Entretanto, quando as ondas sonoras atingem a parede em um ângulo desfavorável, provavelmente elas são refletidas para longe dos sensores e não podem ser detectadas.

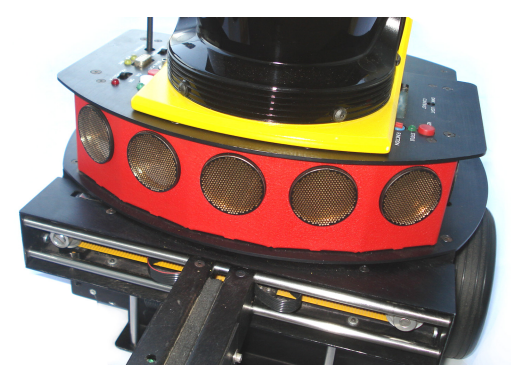

Figura 4.6: Sonares aclopados no Pioneer I

Devido aos sonares não apresentarem medições satisfatórias para as tarefas de desvio de obstáculo, foi necessário encontrar uma solução para tal problema. A solução encontrada foi a aquisição de um sensor laser denominado Proximity Laser Scanner (PLS) 4.7. O sensor é capaz de rastrear o ambiente com um ângulo de visão de 180 graus, resolução angular de 0,5 graus, distância máxima de $50 \mathrm{~m}$ e erro de $131 \mathrm{~mm}$ para distâncias menores ou iguais a $4 \mathrm{~m}$.

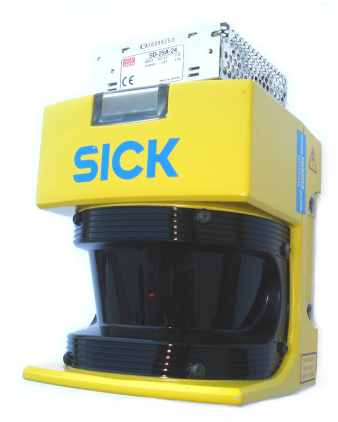

Figura 4.7: Proximity Laser Scanner

O software de controle do robô é executado off-board e é passado para o robô de forma remota, por meio de um link de rádio de 9.600 bps. O software remoto recebe as informações do 
robô e dos sonares a uma freqüência de $10 \mathrm{~Hz}$. A taxa máxima de envio de comandos para mudar a direção do robô é de apenas $2 \mathrm{~Hz}$ (ou menos) por limitações no controlador on-board do robô.

\subsection{Ambiente Saphira}

O robô dispõe de um ambiente para simulação denominado Saphira da ActivMedia, Inc., versão 6.1 permitindo que códigos em $\mathrm{C}$ sejam anexados à biblioteca deste ambiente. O ambiente Saphira apresenta um comportamento similar ao robô e assim auxilia os testes dos algoritmos implementados para o robô real.

O ambiente Saphira é uma arquitetura para o desenvolvimento de aplicações robóticas, projetado e mantido pelo Artificial Intelligence Center do Stanford Research Institute. Este ambiente vem acompanhado de uma biblioteca de funções que permite a construção de programas em linguagem $\mathrm{C} / \mathrm{C}++$ para o controle de robôs móveis como o Pioneer I, sendo compatível com Microsoft Windows 95 / NT, FreeBSD, Linux e Unix. Isso permite uma abstração de alto nível do hardware robótico provendo informações sensorias como leituras de sonares, encoders e recebendo comandos de manipulação dos movimentos do robô, como por exemplo, "gire 10 graus". O software Saphira também vem acompanhado de um simulador para robôs Pioneer, no qual é possível monitorar ambientes estáticos e observar os movimentos do robô.

\subsection{Considerações finais}

Neste capítulo foi apresentada uma revisão de vários conceitos indispensáveis a um pesquisador da área de robótica inteligente. Conceitos básicos a respeito da definição da "máquina" robô foram apresentados sob dois pontos de vista que dividiram o caminho evolutivo da robótica em dois segmentos, o primeiro seguiu o caminho da robótica industrial focalizando a pesquisa no desenvolvimento de robôs manipuladores e o segundo teve sua motivação direcionada na construção de robôs móveis autônomos. O segundo segmento foi o ponto de partida para o surgimento de uma nova subárea, a robótica inteligente. A forma como a "inteligência" é incorporada em um robô é caracterizada por um paradigma robótico. No paradigma hieráquico as primitivas estão dispostas seqüencialmente ocaisionando em um tempo de resposta alto para que o robô execute uma ação enquanto que no paradigma reativo, este tempo é reduzido com a eliminação da primitiva planejar. Dessa forma, o paradigma reativo é definido como orientado a comportamentos. O robô age segundo uma determinada percepção do estado do ambiente sem, previamente, planejar suas ações. A combinação desses dois paradigmas, resulta no paradigma híbrido reativo/deliberativo cuja a primitiva planejar está posicionada num nível hierárquico superior. Por outro lado, as primitivas, sentir e perceber são realizadas paralelamente após a etapa de planejamento, evitando que o tempo 
de resposta de ação do robô seja elevado em planejamentos altamente custosos computacionalmente.

O hardware robótico do sistema de navegação, composto pelo robô móvel Pioneer I e o software Saphira que o acompanha para manipular os movimentos do robô, utilizado para validar o sistema de navegação autônoma proposto neste trabalho quando aplicado a um robô móvel foi descrito, detalhando os principais componentes do robô necessários para a realização de experimentos em abiemtes reais. 


록

\section{Implementação e Resultados}

\subsection{Introdução}

Este capítulo é dedicado à apresentação e análise dos resultados obtidos nos testes feitos com o sistema de navegação autônomo implementado em ambientes reais com a utilização do robô móvel Pioneer I. Os testes foram realizados com o intuito de avaliar o desempenho do sistema descrito no Capítulo 3 e validá-lo quando aplicado em ambientes reais, detectando suas potencialidades e limitações.

Em (Calvo e Figueiredo, 2003b) o mecanismo de aprendizado adotado no sistema neural nebuloso é validado para experimentos realizados em simulação, em que as condições para a navegação do robô são ideais. Em simulação, os sinais dectados pelos sensores estão livres de ruídos e obtêm informações do ambiente com total exatidão. Para este caso, as simulações computacionais se deram por meio da ferramenta de simulação de navegação de robô móvel desenvolvida, que no decorrer do texto é chamada de SR. Tal simulador fornece os artifícios necessários à construção de ambientes virtuais, à navegação de robôs e à analise de parâmetros envolvidos.

O grande desafio encontra-se em validar o sistema de navegação aplicando-o em um robô móvel para atuar em ambientes reais. Para isso, algumas dificuldades devem ser superadas como os ruídos apresentados na detecção dos sinais pelos sensores, irregularidades na superfície de locomoção do robô, erro de odometria, limitações físicas, mecânicas e elétricas do robô. Para os experimentos reais, o robô dispõe do ambiente de simulação Saphira que apresenta comportamentos do robô similares ao do robô móvel, auxiliando os testes em ambientes reais. Portanto, este 
simulador (referenciado de agora em diante como SS) designa um estágio anterior aos experimentos em ambientes reais. Comportamentos observados no simulador SS são esperados também em ambientes reais (chamados de AR a partir deste ponto).

A validação do sistema de navegação adotado no sistema neural nebuloso ocorre através da análise de comparação do desempenho entre os experimentos realizados nos simuladores (SR e SS) e em AR. O sistema de navegação é validado com sucesso se este apresentar, em SS e AR, desempenho semelhante ou melhor ao desempenho apresentado no simulador SR. O desempenho do sistema caracteriza-se não somente pela proporção do número de colisões pelo número de capturas ocorridos, mas principalmente pela presença de um período de capturas consecutivas sem a ocorrência de colisões. Dessa forma, fica evidente a evolução da aprendizagem resultante da aplicação do mecanismo de aprendizado por reforço adotado. Vale ressaltar que algumas adaptações foram necessárias no sistema de navegação para que este seja aplicado em AR. O sensor laser (PLS), citado no Capítulo 4, é acoplado ao robô Pioneer I para desempenhar a tarefa dos sensores de distância a obstáculos. No robô móvel não há a presença física de sensores que detectam o alvo. Assim como ocorre no simulador SR, a posição do alvo é fornecida ao sistema e então é encontrado o sensor de direção ao alvo que se encontra mais alinhado com o alvo dentre todos os sensores posicionados, virtualmente, no perímetro do robô. Ainda com a posição do alvo fornecida e juntamente com a posição do robô (por ele conhecida), é encontrada a distância entre o robô e o alvo pelo sensor virtual de distância ao alvo.

Os experimentos reais contemplam a utilização do robô móvel Pioneer I descrito no Capítulo 4. A arena onde os ambientes reais foram montados consiste em uma área de 4,6 $\mathrm{m}$ x 4,6 $\mathrm{m}$ cercada por placas de madeiras de $1,15 \mathrm{~m}$ de comprimento e $0,4 \mathrm{~m}$ de largura, conforme pode ser visto na Figura 5.1. Os ambientes podem ser configurados de acordo com a necessidade de cada experimento. Neste sentido, placas de madeira móveis auxiliam na montagem de diversas configurações do ambiente simulando obstáculos para o robô. As placas de madeira foram, gentilmente, confeccionadas no Laboratório de Madeira e Estrutura de Madeira (LAMEM-EESC-USP). Para o monitoramento e visualização dos resultados obtidos foi utlizada a técnica de mapeamento desenvolvida em (Bianchi e Romero, 2003). Esta técnica possibilita a visualização do ambiente de atuação do robô assim como a trajetória percorrida minizando erros de odometria para a construção do mapa resultante.

Os experimentos apresentados neste capítulo são divididos em 3 etapas. A primeira consiste nos experimentos voltados para o sistema SDO, módulo responsável por gerar o comportamento inato de desvio de obstáculos, realizados nos simuladores (SR e SS) e em AR. Na segunda etapa, é observado o comportamento do sistema quando somente o sistema SBA é executado, gerando o comportamento inato de busca ao alvo. Experimentos realizados com o balanceamento dos sistemas SDO e SBA, através do módulo RC, caracteriza a terceira etapa. Os resultados são obti- 


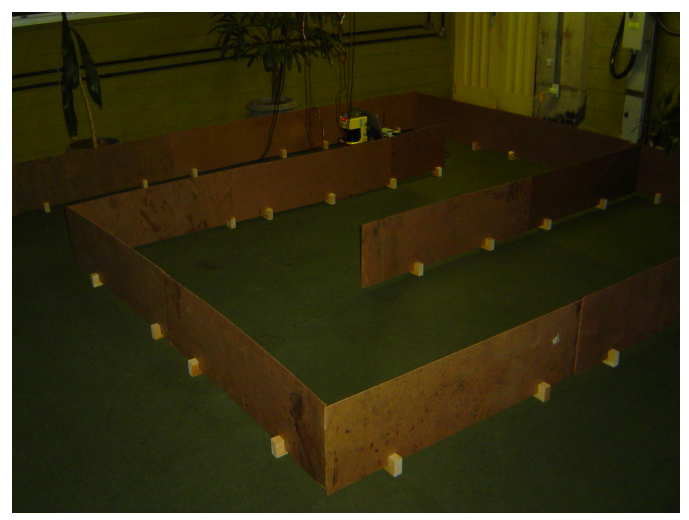

(a)

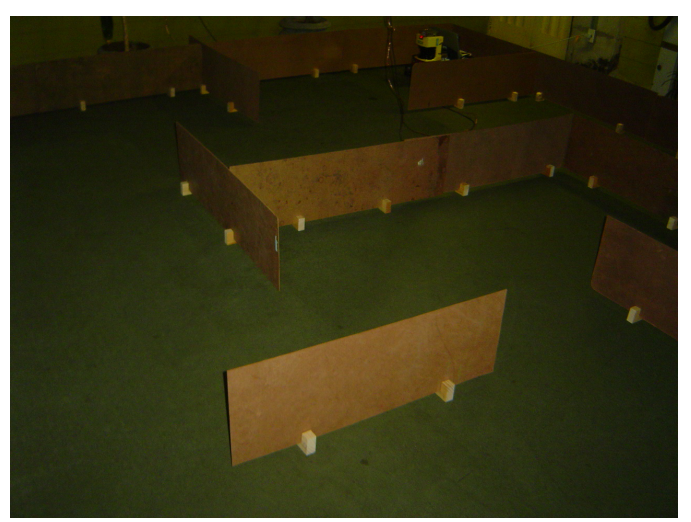

(c)

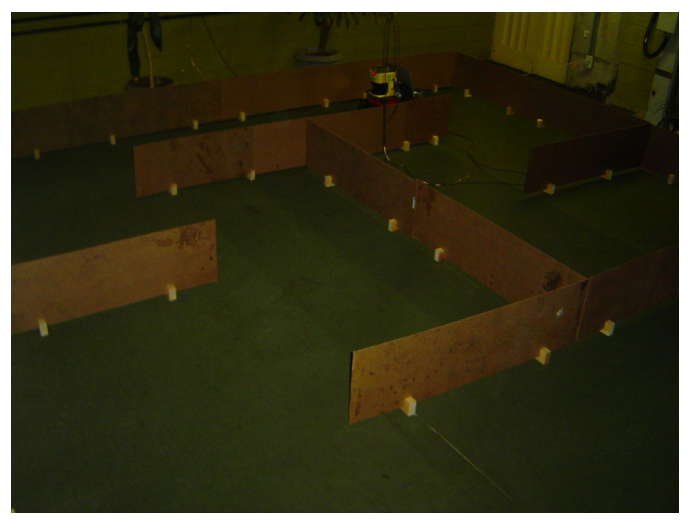

(b)

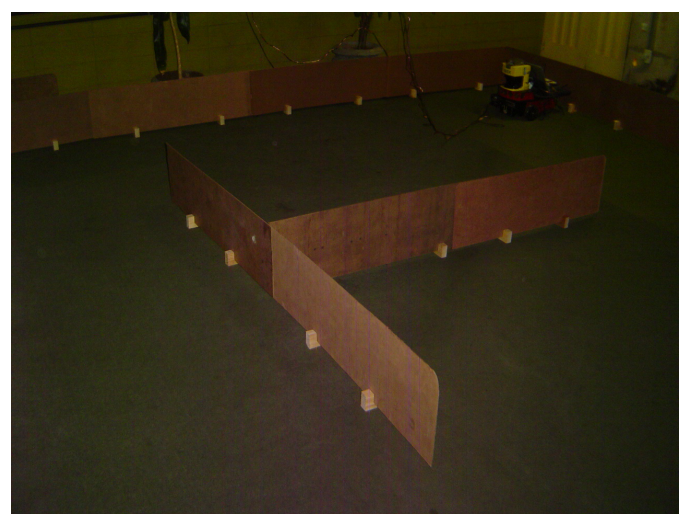

(d)

Figura 5.1: Modelo de ambientes utilizado nos experimentos reais

dos através da realização de experimentos em cada etapa. Os experimentos são caracterizados pela configuração do ambiente determinada pela disposição dos obstáculos e alvos no ambiente. Considera-se que o experimento foi executado com sucesso se o robô cumpriu sua tarefa de acordo com o módulo em avaliação (desvio de obstáculo, busca ao alvo ou ambos objetivos coordenados).

Para a análise dos resultados obtidos nas etapas citadas, recorre-se à apresentação do desempenho do sistema de navegação autônomo na forma de gráficos. Os gráficos contêm duas curvas, cada qual representante de um evento. A curva mais espessa está associada às colisões contra obstáculos ocorridas, enquanto que a segunda curva representa as capturas de alvos realizadas. As curvas são plotadas em função do número acumulado de ocorrências do evento (eixo das ordenadas) em função do número acumulado de iterações (eixo das abscissas). Em ambas as curvas, o comportamento demonstrado por uma linha vertical representa a ocorrência do evento correspondente (colisão ou captura), por outro lado, o comportamento demonstrado por uma linha horizontal representa a não ocorrência do evento.

Durante os experimentos, a inserção dos alvos é realizada pelo projetista de acordo com a necessidade de se observar determinados comportamentos do robô. Nos ambientes de atuação do 
robô são definidas regiões específicas, dentro das quais os alvos são inseridos em posição aleatória logo que o alvo anterior tenha sido capturado pelo robô. A motivação para a realização das regiões específicas para a inserção de alvos está associada à necessidade de se dispor de alvos em determinadas posições do ambiente de modo a exigir certos comportamentos do robô, como por exemplo, capturar alvos separados por um obstáculo entre eles. Tanto para as simulações quanto para os experimentos reais, os alvos consistem em pontos $(x, y)$ no espaço bidimensional que define o ambiente. Inicialmente, são definidas diversas posições de alvos em lugares estratégicos do ambiente. Porém, a ordem dos alvos a serem capturados restringe-se a ordem em que os mesmos foram definidos (inseridos) no ambiente.

De forma simplificada, os objetivos do robô durante o processo de navegação são capturar alvos continuamente e evitar colisões contra obstáculos, partindo de conhecimento inicial inexistente. Traduzindo em gráficos, espera-se que a curva associada às capturas cresça continuamente e a curva de ocolisões estabilize em algum tempo ou que haja um período suficientemente grande entre duas colisões consecutivas para a corrência de capturas, refletindo o comportamento esperado conforme o processamento do neurônio NS (Seção 3.4.8) do sistema neural nebuloso. Conforme o mecanismo de aprendizado adotado, a extensão da lei de Hebb, a ocorrência de uma colisão acarreta no fortalecimento do comportamento de desvio enfraquecendo o comportamento de busca. Já a ocorrência de uma captura fortalece o comportamento de busca e enfraquece o comportamento de desvio. Por esse motivo, é aceitável que ocorra algumas colisões após a ocorrência de inúmeras capturas. Os eventos de colisão e de captura são fundamentais à evolução do sistema, pois a ocorrência desses eventos inicia o processo de ponderação da intensidade dos comportamentos inatos, tornando o robô apto a desviar de obstáculos e capturar alvos. Para os experimentos em AR, o robô não sofre danos materiais ao colidir, uma vez que a colisão é virtual. Isto é, o evento é disparado quando é detectada uma proximidade menor que um limiar estipulado pelos sensores de distância a obstáculos. Tanto para os simuladores quanto para os experimentos em AR, a captura ocorre nos instantes em que o robô se aproxima do ponto $(x, y)$ definido como ponto meta. Neste caso, é estipulado um raio de tolerância para o que o robô não necessite alcançar exatamente o ponto meta.

Para efeito de validação do sistema de navegação autônomo, foram modificadas algumas características na arquitetura do controlador autônomo tornando possível a sua aplicação em AR. Tais modificações são descritas na Seção 5.2, e de acordo com elas, foram realizados experimentos para demonstrar o desempenho dos módulos da arquitetura neural apresentada no Capítulo 3 (vide Seção 3.4.1): SDO, SBA e RC. Em cada módulo, foram realizados experimentos nos simuladores (SR e SS) e em AR. O sistema de navegação autônomo empregado em todos os experimentos mantém as configurações descrtidas no Capítulo 3. Os resultados são divididos em várias seções, cada qual analisando características e situações específicas do problema. Experimentos utilizando somente os módulos SDO e SBA são apresentados nas Seções 5.5 e 5.4, respectivamente. O balanceamento dos comportamentos inatos (desvio de obstáculos e busca de alvos) através do RC é 
mostrado por meio dos experimentos apresentado na Seção 5.6.

Considerando que a principal proposta deste trabalho é validar a abordagem aprensentada em (Calvo e Figueiredo, 2003b) em um robô real, foram encontradas algumas dificuldades que inviabilizariam a aplicação do sistema de navegação em AR. Uma dessas dificuldades, como mencionado anteriormente, é a ausência de sensores de direção e distância ao alvo no robô Pioneer I. Dessa forma, não são detectados sinais que evidenciam a presença de um alvo no ambiente de atuação do robô. Essas informações são essenciais para o funcionamento do sistema SBA e das redes neurais nebulosas RDA e RBA pertencentes ao RC (Figura 3.5). Devido a ausência desses sensores, fez-se necessário acoplá-los ao robô móvel de maneira virtual. Assim como no simulador SR, as informações detectadas por esses sensores no simulador SS e em AR, dependem da posição do robô e do alvo. Para os simuladores SR e SS, isto é uma tarefa simples, uma vez que o sistema de navegação tem o conhecimento do mapa do ambiente e da localização do robô e do alvo, portanto, essas informações podem ser passadas para o robô.

Nos experimentos em AR, o robô possui a informação da posição do alvo que é fornecida pelo sistema de navegação para que se torne a posição meta (posição que o robô deve alcançar). Porém, em AR, a posição do robô fornecida pelo Saphira não é precisa devido ao erro de odometria que ocorre no robô móvel utilizado neste trabalho. Por esse motivo, foi integrado no sistema neural nebuloso, descrito no Capítulo 3, um módulo responsável por fornecer informações a respeito da posição do robô e do alvo, denominado nesse trabalho de Módulo de Localização de Alvos (LA) e descrito na seção seguinte.

\subsection{Método de Localização de Alvos}

O módulo LA foi originalmente desenvolvido por R. Bianchi (Bianchi e Romero, 2003) e consiste no método de mapeamento (MM) do ambiente e no método de localização (ML), com o intuito de gerar o mapa do ambiente e localizar o robô no ambiente mapeado, respectivamente. No sistema neural nebuloso, o módulo LA supre a necessidade de informação a respeito da direção e distância do alvo, pois através deste módulo a posição do robô passa a ser conhecida (com erro de odometria minimizado), e com a posição do alvo já fornecida, é possível obter informações da direção e distância do alvo. Essas informações, então, são fornecidas para os sensores virtuais de direção e de distância ao alvo, respectivamente. O módulo LA requer os sinais dos sensores de distância de obstáculos (sensor laser) para efetuar a tarefa de mapeamento do ambiente que auxilia na determinação da posição do robô. De acordo com as modificações citadas, a aquitetura do controlador autônomo sofre alterações como é mostrado na Figura 5.2. Como pode ser visto ainda nessa figura, os sinais recebidos pelo sistema SBA e pelas redes RDA e RBA são provenientes do 
módulo LA.

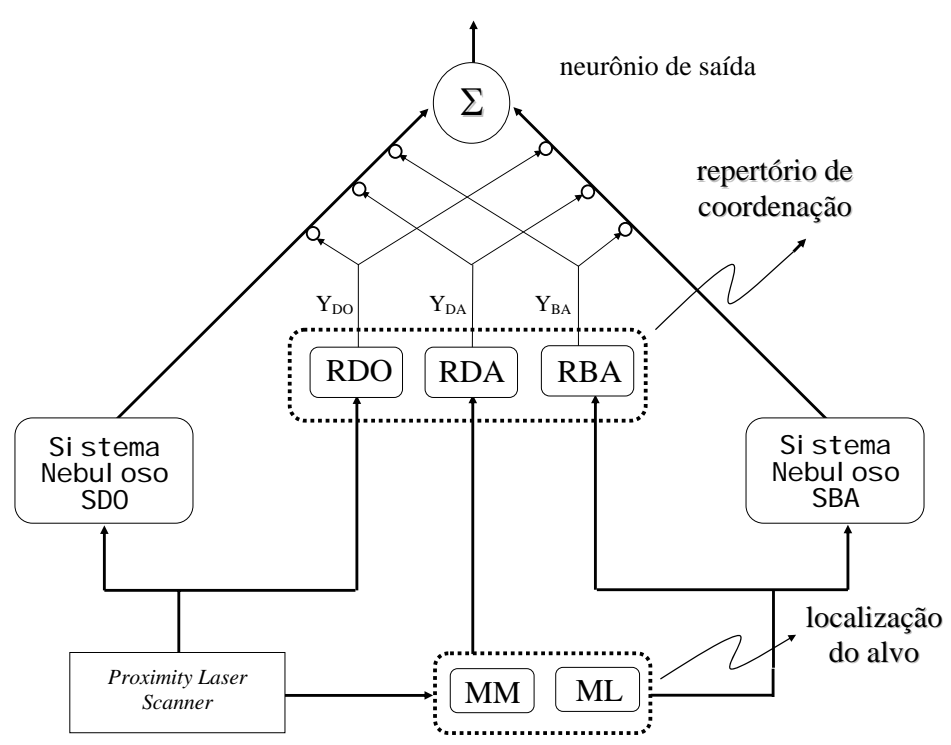

Figura 5.2: Arquitetura do sistema de navegação autônomo para ambientes reais

A localização de robôs móveis é uma tarefa que consiste em estimar a posição de um robô em seu ambiente por meio de informações de seus sensores de distância a obstáculos. Para isso, o robô deve possuir, a priori, um mapa do ambiente, o qual pode ser construído automaticamente (pelo sistema de navegacão) ou manualmente (por seres humanos). A seguir é descrito brevemente o método de localização utilizado em (Bianchi e Romero, 2003) que tem sido aplicado com êxito em diversos trabalhos (Simmons et al., 1997), (Fox et al., 1999), (Thrun et al., 2000) e incorporado ao sistema de navegação descrito neste trabalho, denominado de Localização de Markov e a extensão desse método para ambientes dinâmicos segundo a abordagem apresentada em (Fox et al., 1998).

\subsubsection{Método de Localização (ML)}

Como dito anteriormente, o método de localização incorporado neste trabalho e utilizado em (Bianchi e Romero, 2003) é a Localização de Markov (Fox et al., 1998), um método probabilístico que mantém várias hipóteses a rspeito da posição do robô. Cada hipótese possui um peso associado representando um fator probabilístico numérico. Este método de localização tem como objetivo encontrar a distribuição de probabilidades sobre todos os possíveis locais do ambiente. Seja $l=\langle x, y, \theta\rangle$ uma posição no espaço de estados, em que $x$ e $y$ são coordenadas cartesianas do robô e $\theta$ é a sua orientação, estabelece-se a distribuição $\operatorname{Bel}(l)$ sobre todos os locais $l$ que indica a probabilidade do robô estar nas posições $l$. No entanto, posições $l$ que apresentarem maior pro- 
babilidade são posições conideradas com maiores chances do robô estar. Ou seja, a distribuição $\operatorname{Bel}(l)$ expressa a crença subjetiva de que o robô possui em estar na posição $l$. Se a posição inicial do robô é conhecida, então a distribuição é $B e l(l)$ é centrada na posição correta (valor modal da distribuição), caso contrário, esta é uniformemente distribuída pra refletir tal incerteza.

A Localização de Markov aplica dois modelos probabilísticos diferentes para atualizar $\operatorname{Bel}(l)$ : 1) um modelo de ação para incorporar os movimentos do robô; 2) um modelo perceptual para atualizar a crença baseando-se na entrada sensorial. A movimentação do robô é modelada pela probabilidade condicional $p\left(l \mid l^{\prime}, a\right)$ que especifica a probabilidade de que uma ação $a$, quando executada em $l^{\prime}$, leve o robô para $l$. Dessa forma, $\operatorname{Bel}(l)$ é atualizada de acordo com a fórmula geral proveniente do domínio das cadeias de Markov, dada pela equação 5.1:

$$
\operatorname{Bel}(l)=\sum_{l^{\prime}} p\left(l \mid l^{\prime}, a\right) \operatorname{Bel}(l)
$$

em que o termo $p\left(l \mid l^{\prime}, a\right)$ representa um modelo da cinemática do robô. Na implementação proposta por Fox et al. (1998) (Fox et al., 1998), foi assumido que os erros de odometria são normalmente distribuídos.

As leituras dos sensores são integradas de acordo com uma fórmula de atualização Bayesiana. Seja $s$ uma leitura de sensor e $p(s \mid l)$ a probabilidade de se perceber $s$ dado que o robô está na posição $l$, então $B e l(l)$ é atualizada de acordo com a regra da seguinte equação:

$$
\operatorname{Bel}(l)=\alpha p(s \mid l) \operatorname{Bel}(l)
$$

em que o $\alpha$ é um fator de normalização que garante que $B e l(l)$ totalize 1 sobre todo $l$.

Ambos os passos de atualização são aplicáveis apenas se o problema for Markoviano, ou seja, se as leituras de sensores passadas forem condicionalmente independentes de leituras futuras dada a localização atual do robô. Desse modo, a hipótese de Markov assume que o mundo é estático. Apesar de na prática essa abordagem ter sido aplicada até mesmo em ambientes que continham pessoas e que desta forma violavam a hipótese de Markov, os experimentos reportados em (Fox et al., 1998) mostram que ela não se adequa bem a ambientes densamente povoados. Uma das formas de resolver esse problema consiste na aplicação de filtros que selecionam quais leituras dos sensores serão utilizadas efetivamente na localização. O intuito é eliminar as leituras influenciadas por objetos dinâmicos.

O método de Localização de Markov implementado em (Bianchi e Romero, 2003) utilizou o algoritmo de Monte Carlo que consiste na representação da distribuição (crença) $\operatorname{Bel}(l)$ por um 
conjunto de amostras $s$ associadas a um fator numérico de importância $p$. Tal fator indica a probabilidade da amostra ser relevante para a determinação da posição do robô. A crença inicial é obtida gerando-se aleatoriamente $N$ amostras da distribuição prévia $P\left(s_{o}\right)$, e atribuindo-se o fator de importância uniforme $N^{-1}$ para cada amostra. Leituras de sensores $o$ e ações $a$ são processadas em pares. Monte Carlo constrói uma nova crença repetindo a seguinte seqüência de "suposições": primeiro, um estado aleatório $s$ é gerado a partir da crença atual, sob consideração dos fatores de importância. Para aquele estado $s$, Monte Carlo supõe um novo estado $s_{o}$ de acordo com o modelo de ação $P\left(s_{o} \mid a, s, m\right)$ no qual $m$ contém os dados do mapa. O fator de importância para esse novo estado $s_{o}$ recebe um valor proporcional à consistência perceptual desse estado, como medido por $P(o \mid s, m)$. A nova amostra, juntamente com seu fator de importância, é memorizada e o laço básico é repetido. A geração de amostras é finalizada quando a soma total dos fatores de importância exceder um limite $p_{\max }$, ou quando o próximo par $\langle o, a\rangle$ for alcançado. Finalmente, os fatores de importância são normalizados e o método de Monte Carlo retorna o novo conjunto de amostras definido como a crença corrente.

\subsection{Método de Mapeamento(MM)}

O mecanismo de locomoção de um robô de maneira autônoma em ambientes não estruturados ocorre por meio conhecimento, a cada instante, da sua localização no ambiente. Em (Bianchi e Romero, 2003) isso é alcançado utilizando o algoritmo de Monte Carlo apresentado na Seção 5.2.1. Porém, esse método requer a existência de um mapa do ambiente, que pode ser de difícil construção de forma manual. No entanto, mapas gerados por métodos de mapeamento automático possuem várias vantagens sobre a geração manual quando consideradas as mudanças do ambiente, as características do ambiente que devem ser reconhecíveis aos sensores e o nível de detalhamento oferecido (Bianchi e Romero, 2003).

O método para o mapeamento de ambientes utiliza uma representação probabilística e reticulada da informação espacial chamada Occupancy Grid. A construção de mapas de ambientes é efetuado atrávés dos sensores de distância ao alvo que apresentam ruídos. As células do espaço reticulado onde o método Occupancy Grid é aplicado armazenam uma estimativa probabilística de seu estado definido como livre ou ocupado (Elfes, 1989).

As estimativas do estado das células são obtidas por meio da interpretação dos sinais de distância a obstáculos utilizando modelos probabilísticos dos sensores. Um procedimento de estimativa Bayesiano permite a atualização incremental do Occupancy Grid usando leituras realizadas por vários sensores sobre múltiplos pontos de vista. A variável de estado associada a uma célula $m_{\langle x, y\rangle}$ do Occupancy Grid é definida como uma variável aleatória discreta com dois estados, livre e ocu- 
pada, denotadas EMP e OCC, respectivamente. Dessa forma, o Occupancy Grid corresponde a um campo aleatório de estados discretos e binários. Uma vez que os estados das células são exclusivos e exaustivos, $P(\langle x, y\rangle=O C C)+P(\langle x, y\rangle=E M P)=1$.

Os dados dos sensores de distância são interpretados utilizando um modelo probabilístico do sensor $P\left(m_{\langle x, y\rangle} \mid o^{(t)}, s^{(t)}\right)$ que estabelece a probabilidade de uma célula $m_{\langle x, y\rangle}$ estar ocupada dados a observação do sensor $o^{(t)}$ e a posição do robô $s^{(t)}$. Esse modelo é utilizado em um procedimento de estimativa Bayesiano para determinar as probabilidades de estado das células do Occupancy Grid. Ao final da execução do método Occupancy Grid, obtém-se um mapa que representa a probabilidade de ocupação de cada célula.

O método Occupancy Grid não apresenta resultados satisfatórios quando operado isoladamente em ambientes amplos. Isso deve-se ao fato de que as posições do robô são conhecidas. O robô apresenta erro odométrico que é acumulado durante a sua locomoção, ocasionando no mapeamento do ambiente de maneira não eficiente. Considerando esse problema, o método de localização Monte Carlo é integrado ao método de mapeamento baseando na observação de que o sensor de distância a obstáculo (sensor laser) permite o mapeamento de parte do ambiente com o robô parado em uma única varredura. Dessa maneira, esta abordagem intercala cilcos de mapeamento com ciclos de localização.

Os detalhes dos algoritmos de localização e mapeamento são encontrados em (Bianchi e Romero, 2003).

\subsection{Sistema Nebuloso de Desvio de Obstáculos}

Nesta seção, vários experimentos foram realizados visando analisar o desempenho do robô quando somente o sistema SDO é executado. O sistema SDO é responsável por gerar o comportamento inato de desvio de obstáculo. Neste caso, os alvos são desconsiderados e a tarefa do robô é somente explorar o ambiente sem que ocorram colisões. Para que o sistema SDO opere adequadamente, ou seja, gere o ângulo de rotação do robô, são necessárias as informações do sensor de distância a obstáculo que detectar o obstáculo mais próximo do robô. Tais informações são: o sinal detectado do sensor e sua posição angular no perímetro do robô. O sistema SDO é desprovido de aprendizagem e utilizando métodos baseados em lógica nebulosa e regras de inferência, torna-se possível inferir uma conclusão (saída do sistema) que corresponde ao ajuste angular da direção de movimento do robô. Considerando as regras de inferência, as informações fundamentais citadas para o uso adequado do sistema SDO são os antecedentes das regras e o ângulo de rotação do robô 
é o conseqüiente.

Em cada iteração, ou seja, a cada passo do robô, os sensores de distância a obstáculos detectam sinais provenientes do ambiente. Estes sinais são normalizados (fuzzificados) segundo a equação 3.1 (vide Seção 4.5) de modo que sejam interpretados pelo sistema nebuloso. Nesta equação, diferentemente das simulações realizadas no simulador SR, o valor de disp é igual a 90 e 120 para o simulador SS e para os experimentos em AR, respectivamente. Considerando que o valor do parâmetro disp corresponde a sensibilidade do sensor em relação aos obstáculos e observando o comportamento da equação 3.1, nota-se que quanto maior o valor do parâmetro disp mais sensível o sensor estará do obstáculo. Uma alta sensibilidade implica na não necessidade do robô em se aproximar de um obstáculo para que este seja detectado pelos sensores. Ou seja, mesmo a uma distância não muito próxima de um obstáculo, os sensores têm a possibilidade de detectá-lo e, então, auxiliar na tomada de decisão realizada pelo sistema nebuloso neural. A pouca sensibilidade determina a capacidade dos sensores em detectar um obstáculo somente a uma distância pequena, permitindo que o robô se aproxime do obstáculo desprovido do comportamento de aversão a obstáculo durante a aproximação ao mesmo.

Os valores assumidos para o parâmetro disp nos simuladores (SR e SS) e nos experimentos em AR foram definidos empiricamente. Isto justifica-se pelo fato de que no simulador SR o robô é considerado como um ponto $(x, y)$ no ambiente, não considerando suas dimensões fisicas. Dessa maneira, é de extrema facilidade o robô executar uma curva brusca, uma vez que o ajuste da direção de movimento do robô é realizado pela plotagem do mesmo para a nova direção. Sendo assim, o modelo de robô ideal é dotado de pouca sensibilidade a obstáculo permitindo-o a explorar o ambiente mesmo quando próximo a obstáculos. Para os experimentos no simulador SS e em $\mathrm{AR}$, o valor para o parâmetro foi incrementado. No simulador SS, o tempo de giro do robô é lento quando comparado com o simulador SR e em AR. Assim, faz-se necessário que os sensores tenham sensibilidade a obstáculo maior que os sensores ideais. Isto implica que mesmo longe do obstáculo, o robô inicia o processo de giro evitando que esta ação, necessária para desviar de um obstáculo, seja realizada próximo a este, evitando também a ocorrência de uma colisão. Para os experimentos em AR, os sensores têm sensibilidade maior quando comparado com os simuladores, pois em AR, são consideradas as dimensões físicas do robô. A alta sensibilidade evita que o robô realize curvas bruscas próximo a obstáculos, permitindo que o ajuste da direção do movimento do robô seja livre de obstáculo.

De acordo com as alterações realizadas, o sistema SDO é validado para diversas configurações de ambiente. A Figura 5.3 ilustra o primeiro modelo de ambiente utilizado para a validação. Observa-se na Figura 5.4 que tanto para o simulador SR quanto para o simulador SS e em AR, não houve colisão contra obstáculos, mostrando a eficiência do sistema SDO em AR. 
De acordo com as alterações realizadas, o sistema SDO é validado para diversas configurações de ambiente. A Figura 5.3 ilustra o primeiro modelo de ambiente utilizado para a validação. A trajetória do robô nos simuladores (SR e SS) e em AR é mostrada na Figura 5.4. Observa-se que tanto para o simulador SR quanto para o simulador SS e em AR, não houve colisão contra obstáculos, mostrando a eficiência do sistema SDO em AR.

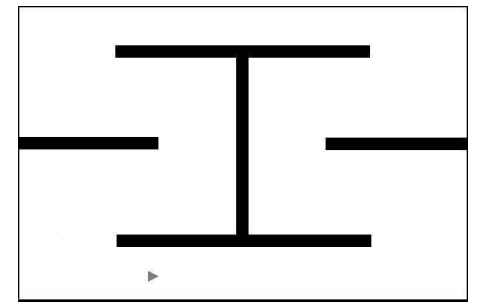

(a)

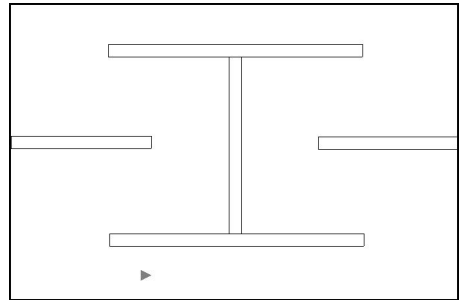

(b)

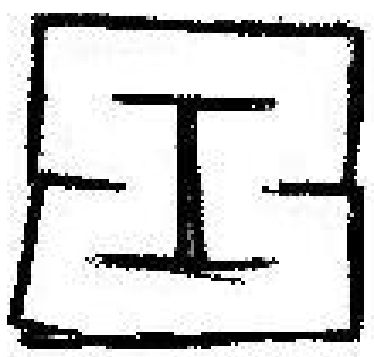

(c)

Figura 5.3: Modelo de ambiente para o experimento do sistema SDO (a) simulador SR; (b) simulador SS; (c) AR

Uma segunda configuração de ambiente é testada para comparar os experimentos. Na Figura 5.5 é mostrado o modelo do ambiente para continuar a validação do sistema SDO. Similar ao experimento anterior, nota-se que o robô esteve livre de colisão durante o percurso como pode ser visto na Figura 5.6.

\subsection{Sistema Nebuloso de Busca ao Alvo}

Os experimentos a seguir são realizados quando o sistema SBA é executado isoladamente. O sistema SBA é responsável por gerar o comportamento inato de captura de alvos. Dessa forma, o robô não torna capaz de desviar dos obstáculos presentes no mundo e sua tarefa passa a ser, somente, alcançar o(s) alvo(s). Para que o sistema SBA opere adequadamente, é necessária a informação do sensor de direção ao alvo que detectar o alvo com mais intensidade, ou seja, o sensor que estiver mais alinhado com o alvo (diferença angular mínima entre a posição do sensor e a posição do alvo). Tal informação se refere à posição angular do sensor no perímetro do robô. Assim como o sistema SDO, o sistema SBA é desprovido de aprendizagem e o valor de ajuste da 


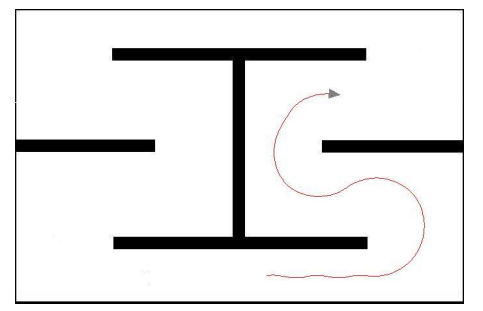

(a)

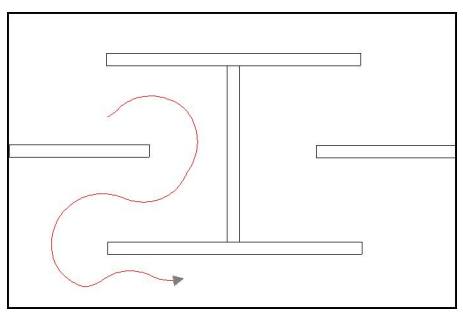

(b)

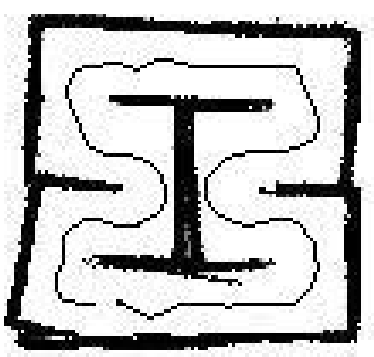

(c)

Figura 5.4: Trajetória do robô quando somente o sistema SDO é executado (a) simulador SR; (b) simulador SS; (c) AR

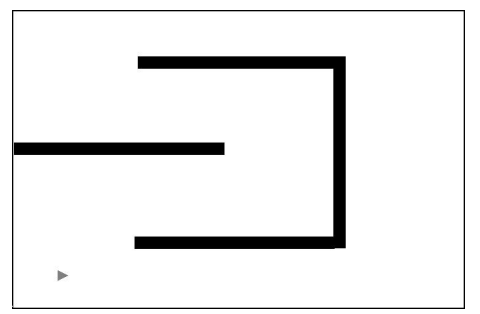

(a)

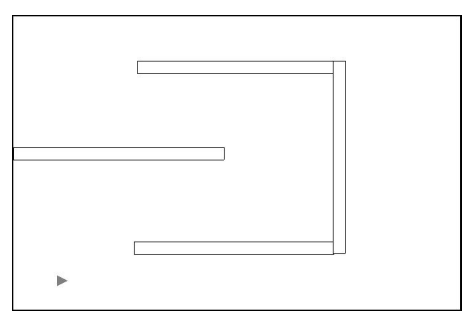

(b)

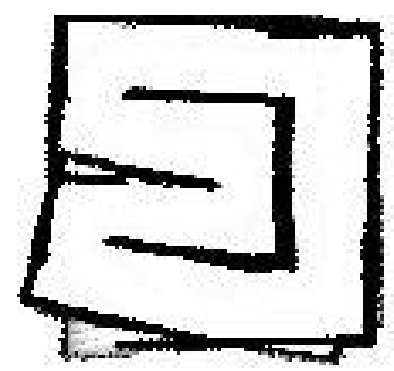

(c)

Figura 5.5: Modelo de ambiente para o experimento do sistema SDO (a) simulador SR; (b) simulador SS; (c) AR

direção de movimento do robô é inferido de acordo com métodos baseados em lógica nebulosa e regras de inferência. Dessa forma, o antecedente das regras é a informação referente a posição angular do sensor e o conseqüente é o angulo de rotação do robô. Para que uma direção de ajuste seja inferida, os sinais detectados pelos sensores são normalizados (fuzzificados) através do mecanismo 


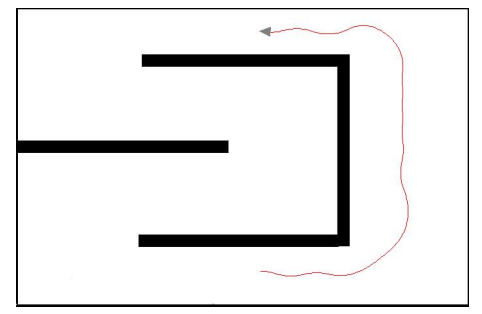

(a)

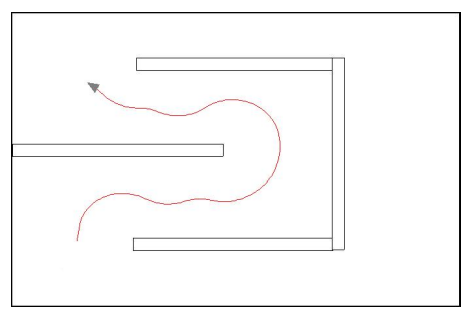

(b)

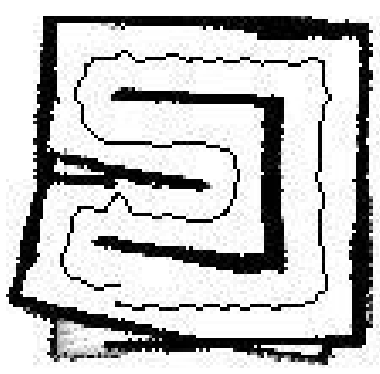

(c)

Figura 5.6: Trajetória do robô quando somente o sistema SDO é executado (a) simulador SR; (b) simulador SS; (c) AR

descrito na Seção 4.5 e, então, aplicados no sistema nebuloso.

Primeiramente, o sistema SBA é validado em ambientes desprovidos de obstáculos (Figura 5.7). Para este caso, o robô não encontra dificuldades para capturar os alvos presentes. A quantidade de alvos presentes no ambiente é igual a 15. Juntamente com o posicionamento desses alvos, esta quantidade permite que o robô navegue por todo o abiente diversas vezes mostrando a eficácia do módulo avaliado. A ordem de captura dos alvos obedece a ordem em que são inseridos no ambiente. Nota-se nas Figuras 5.8 - 5.10 e nos gráficos da Figura 5.11 que não houve colisão (contra os limites do ambiente) durante a execução da tarefa de capturar alvos. O sistema nebuloso SBA tende o robô a permanecer sempre alinhado com o alvo segundo o sensor que estiver mais alinhado com o alvo, pois, a cada iteração o ajuste angular da direção de movimento do robô é proporcional a posição angular deste sensor. Por este motivo, a cada alvo capturado, o robô se direciona rapidamente para o próximo.

O experimento a seguir consiste na execução do sistema SBA quando um obstáculo intercepta o caminho do robô ao alvo (Figura 5.12). Percebe-se neste caso, que a captura do alvo torna-se impossível, pois a tarefa do sistema SBA é somente permitir que o robô se posicione na direção do alvo sem possuir qualquer mecanismo de desvio de obstáculos. Desse modo, sucessivas colisões são inevitáveis devido à presença de um obstáculo entre o robô e o alvo, como pode ser visto na Figura 5.13. Com o auxilio dos gráficos da Figura 5.14, é possível notar o número excessivo de colisões durante a tentativa de alcançar o alvo. 


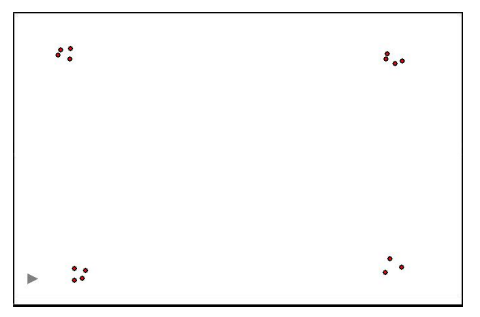

(a)

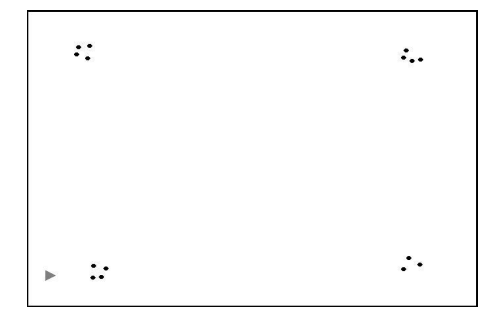

(b)

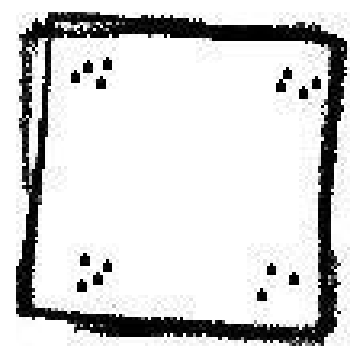

(c)

Figura 5.7: Modelo de ambiente sem obstáculos para o experimento do sistema SBA (a) simulador SR; (b) simulador SS; (c) AR

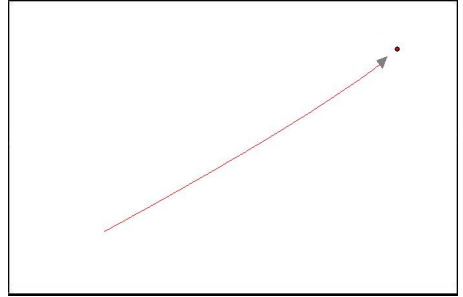

(a)

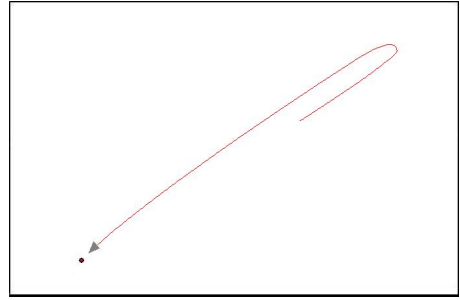

(b)

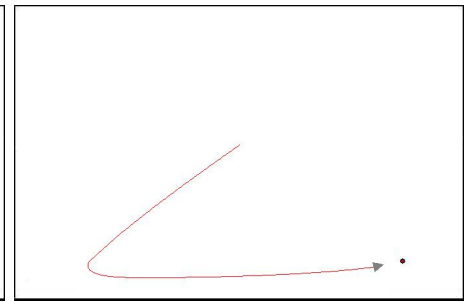

(c)

Figura 5.8: Trajetória do robô no simulador SR (a) Primeiro alvo; (b) Segundo alvo; (c) Terceiro alvo

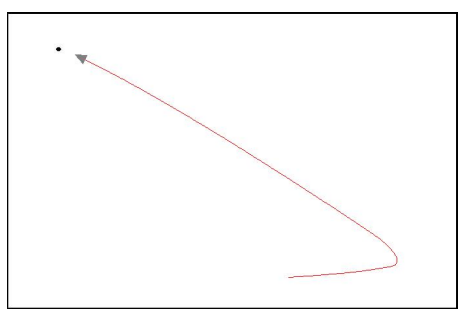

(a)

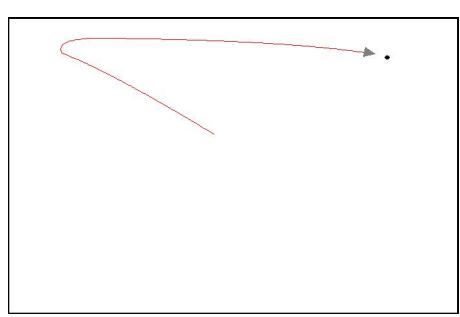

(b)

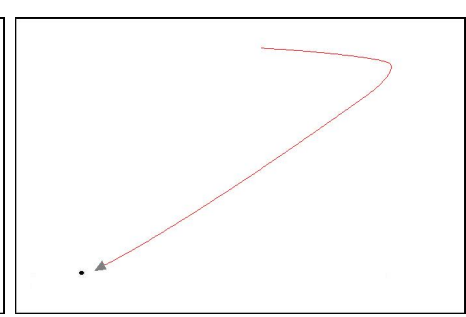

(c)

Figura 5.9: Trajetória do robô no simulador SS (a) Quarto alvo; (b) Quinto alvo; (c) Sexto alvo

Os experimentos realizados nesta seção foram satisfatórios quanto ao desempenho do sistema nos simuladores (SR e SS) e em AR. Para o primeiro experimento em um ambiente sem a presença de obstáculos 5.7, o robô foi capaz de capturar os alvos com facilidade, enquanto que no segundo 5.12, o obstáculo presente entre o robô e o alvo, o impediu de alcançar o alvo. Vale ressaltar que as curvas associadas ao evento de colisão crescem excessivamente para o segundo experimento em particular, devido a falta de um mecanismo de aprendizagem responsável pelo 


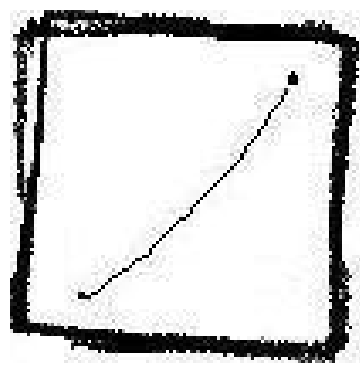

(a)

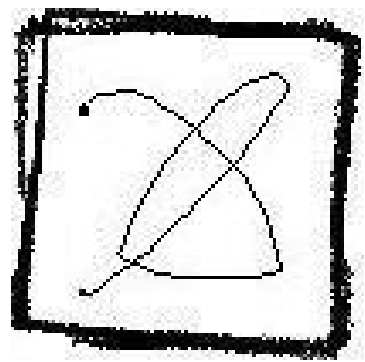

(d)

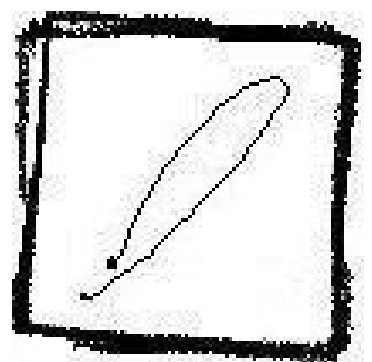

(b)

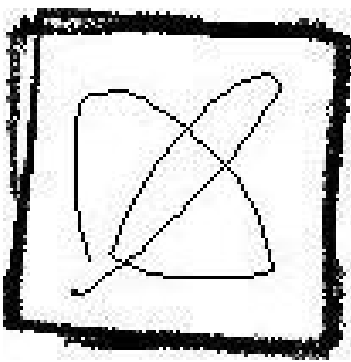

(e)

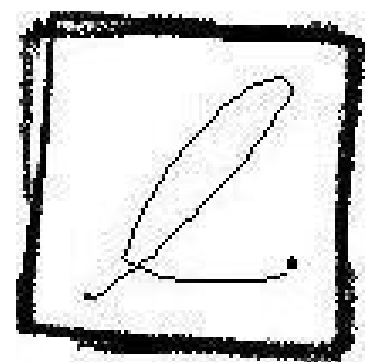

(c)

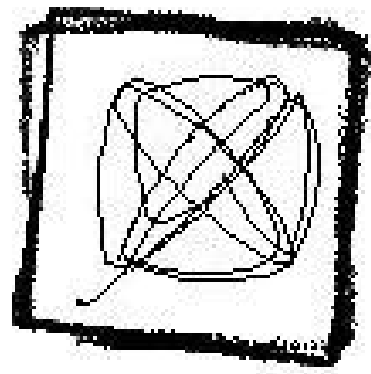

(f)

Figura 5.10: Trajetória do robô em AR (a) Primeiro alvo; (b) Segundo alvo; (c) Terceiro alvo; (d) Quarto alvo; (e) Quinto Alvo; (f) Captura de todos os alvos

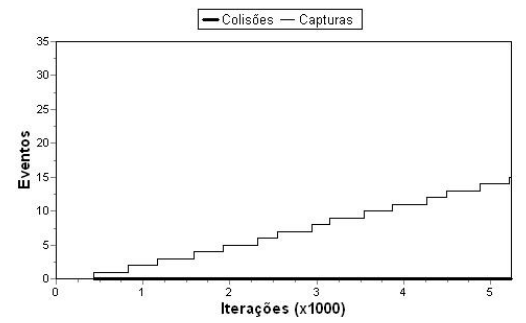

(a)

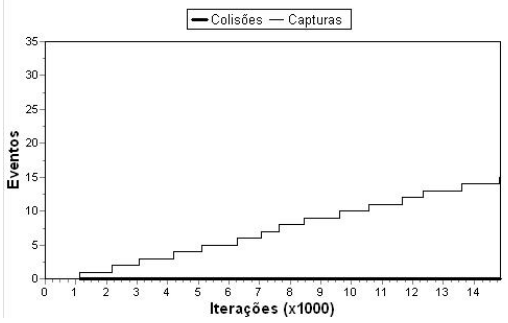

(b)

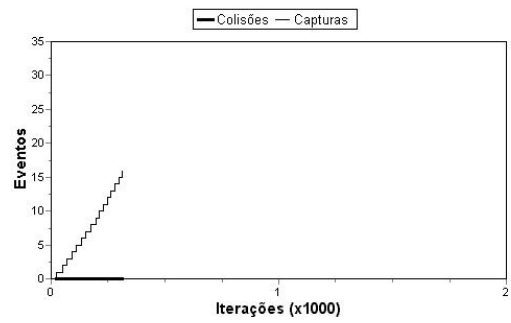

(c)

Figura 5.11: Desempenho do sistema de navegação autônomo para o sistema SBA em um ambiente sem obstáculos (a) simulador SR; (b) simulador SS; (c) AR

comportamento de desvio de obstáculos. De acordo com a funcionalidade do sistema SBA, o simulador SS e os experimentos em AR apresentaram desempenho semelhante ao desempenho do simulador SR. Isto mostra que o sistema SBA está apto para sua execução em ambientes reais.

\subsection{Repertório de Coordenação}

A validação do sistema neural nebuloso se encerra com a validação do RC. Formado por três redes neurais nebulosas construtivas e não-recorrentes (RDO, RDA e RBA), a função do RC é gerar pesos sinápticos para o neurônio NS (Figura 3.5) e, assim, ponderar os comportamentos conflitantes gerados pelos sistemas SDO e SBA, fornecendo o ajuste adequado para o robô e tornando-o 


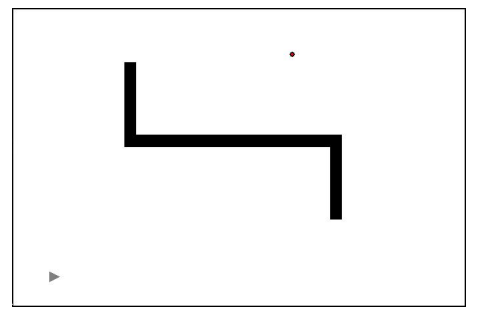

(a)

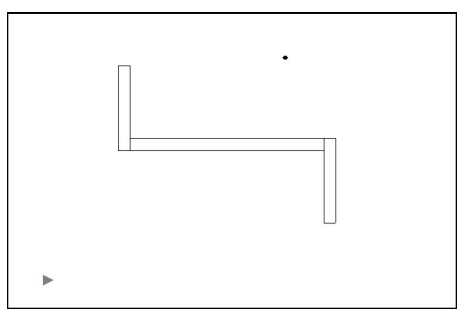

(b)

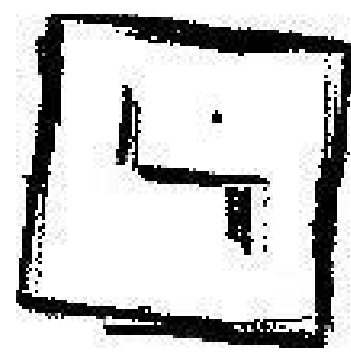

(c)

Figura 5.12: Modelo de ambiente com obstáculos para o experimento do sistema SBA (a) simulador SR; (b) simulador SS; (c) AR

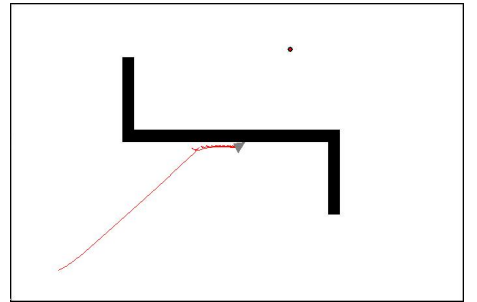

(a)

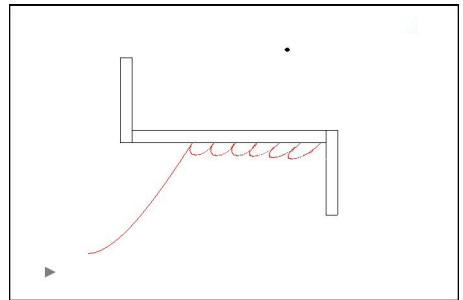

(b)

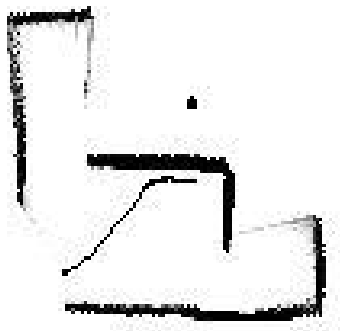

(c)

Figura 5.13: Trajetória do robô quando somente o sistema SBA é executado (a) simulador SR;

(b) simulador SS; (c) AR

capaz de adaptar a um ambiente mundo desconhecido e, após a etapa de aprendizagem, alcançar alvos evitando colisões contra obstáculos. Cada rede citada está conectada ao seu respectivo campo sensorial, sensores de distância a obstáculos, sensores de distância ao alvo e sensores de direção ao alvo, respectivamente.

Para os experimentos realizados no simulador SS, o sensor laser (PLS) é simulado para fazer o papel dos sensores de distância a obstáculo, enquanto que nos experimentos em AR o sensor 


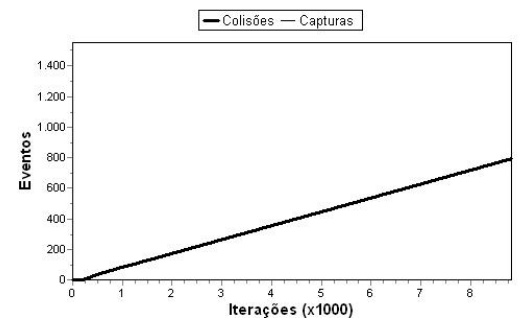

(a)

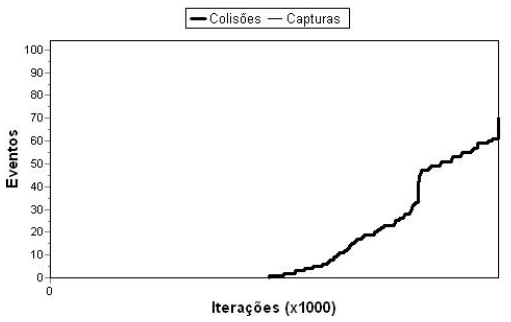

(b)

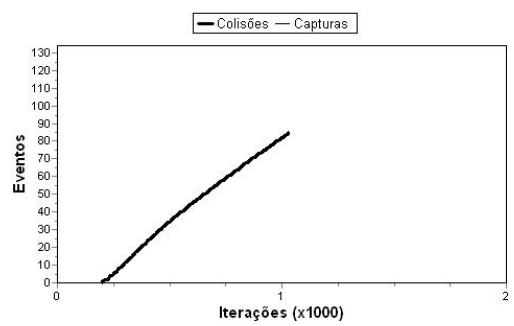

(c)

Figura 5.14: Desempenho do sistema de navegação autônomo para o sistema SBA em um ambiente com obstáculos (a) simulador SR; (b) simulador SS; (c) AR

laser é acoplado no robô Pioneer I. No simulador SS e em AR, Os sensores de direção ao alvo e de distância ao alvo são virtualmente integrados no robô atuando de maneira similar ao simulador SR como é descrito na Seção 4.5. Porém, em AR, um passo antes dos sensores de direção ao alvo e distância do alvo atuarem, é aplicado o módulo de localização (Bianchi e Romero, 2003). Pois, este método fornece ao sistema de navegação a posição do robô no ambiente real, e com base nessa posição e na posição (fornecida) do alvo é possível que tais sensores detectam sinais a respeito da direção e da distância do alvo em relação ao robô.

O primeiro experimento para o módulo RC é realizado na configuração de ambiente, para os simuladores (SR e SS) e em AR, mostrada na Figura 5.15. Nesta configuração há somente um obstáculo no centro do ambiente e estão dispostos 15 alvos em posições aleatórias desde que a ordem de inserção dos alvos seja alternada entre os lados do obstáculo. Esta distribuição dos alvos obriga o robô a se deparar com o obstáculo na caputra de dois alvos consecutivos. Durante o experimento, somente um alvo está presente no mundo. Após a captura, o alvo (capturado) é eliminado e o próximo alvo, de acordo com a ordem de inserção, aparece no ambiente. As Figruas 5.16, 5.17 e 5.18 mostram a trajetória percorrida pelo robô para a captura dos 15 alvos presentes no ambiente juntamente com o desempenho do sistema nos gráficos das Figuras 5.19(a), 5.19(b) e 5.19(c) para os experimentos realizados nos simuladores SR, SS e em AR, respectivamente.

É comum que ocorram várias colisões antes da captura do primeiro do alvo (considerando a ordem de inserção dos alvos), pois no início do experimento, as redes neurais nebulosas pertencentes ao RC são inexistentes, não havendo um balanceamento entre os comportamentos inatos. Assim, o conflito entre os comportamentos impede que o robô desvie de obstáculo para alcançar um alvo. Porém, pode ser observado no gráfico das Figuras 5.19(a) e 5.19(c) que ocorreu uma captura antes de uma colisão. Este fato ocorre em situações em que o ajuste angular gerado pelos sistemas SDO e SBA direcionam o movimento do robô para o mesmo lado (esquerda ou direita), ou seja, o ajuste angular gerado pelos sistemas possuem o mesmo sinal (sinal positivo indica rotação para a esquerda e sinal negativo indica rotação para a direita). Outro situação que possibilita a captura de um alvo ocorrer antes de uma colisão é quando o alvo está posicionado de forma que 


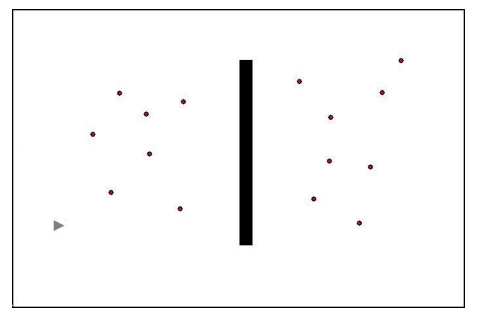

(a)

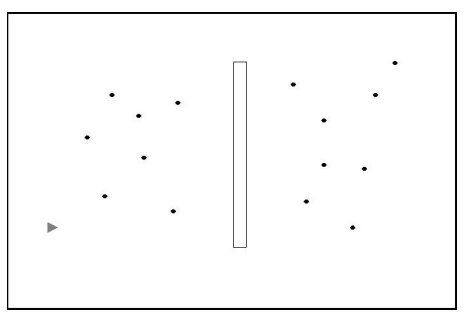

(b)

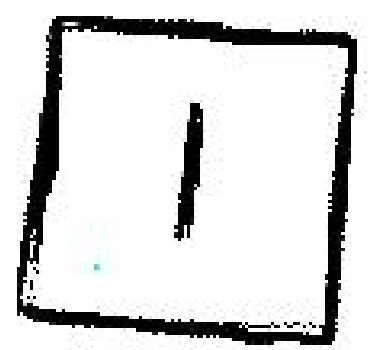

(c)

Figura 5.15: Modelo de ambiente com obstáculos para o experimento do RC (a) simulador SR;

(b) simulador SS; (c) AR

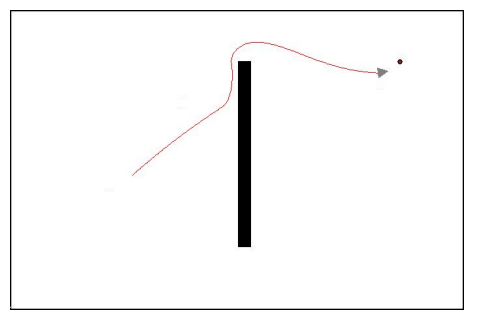

(a)

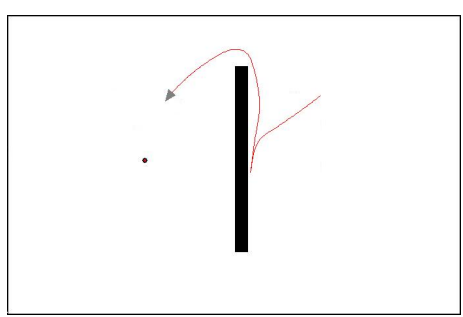

(b)

Figura 5.16: Trajetória do robô no simulador SR para o experimento do RC (a) Primeiro alvo; (b) Segundo alvo

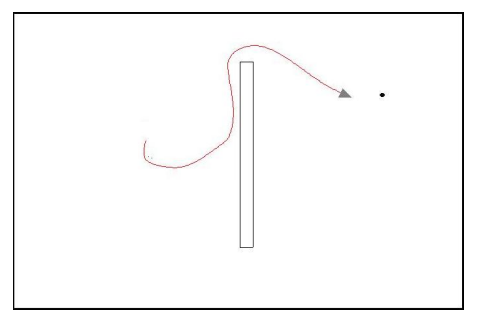

(a)

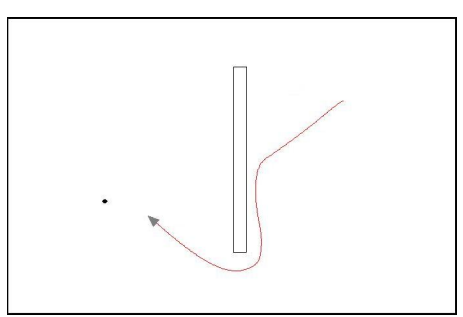

(b)

Figura 5.17: Trajetória do robô no simulador SS para o experimento do RC (a) Terceiro alvo; (b) Quarto alvo

o caminho do robô até o alvo (em linha reta) esteja livre de obstáculos.

A colisão é um evento que dispara o processo de aprendizagem do RC e do neurônio NS, portanto é essencial para que o sistema aprimore o comportamento de desvio de obstáculos. Ao mesmo tempo que aprimora o comportamento de desvio a colisão enfraquece o comportamento 


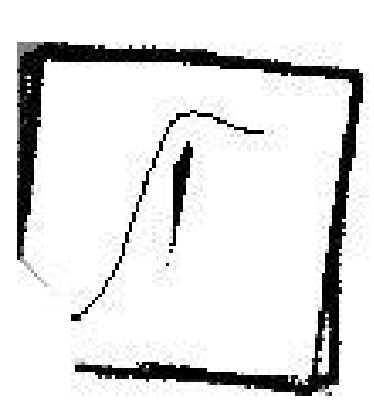

(a)

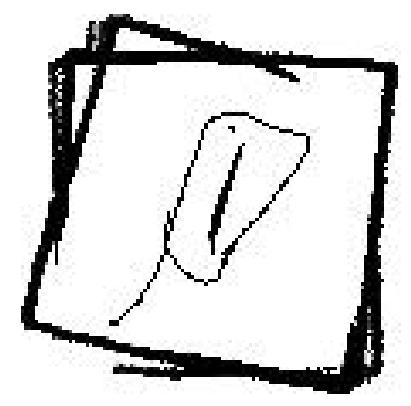

(b)

Figura 5.18: Trajetória do robô em AR no o experimento do RC (a) Primeiro alvo; (b) Segundo alvo

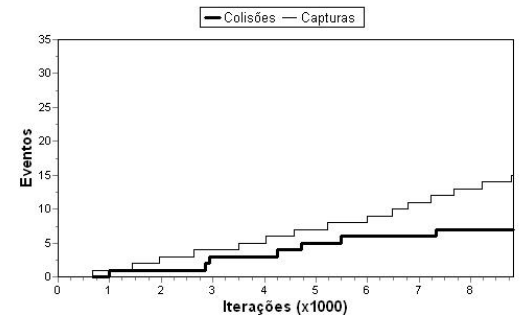

(a)

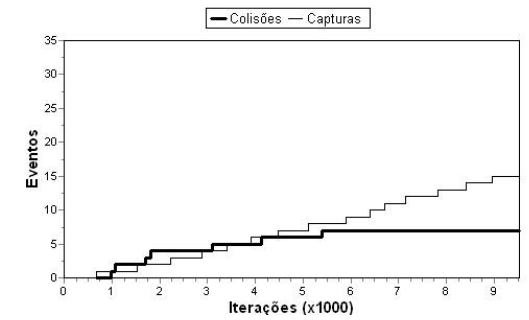

(b)

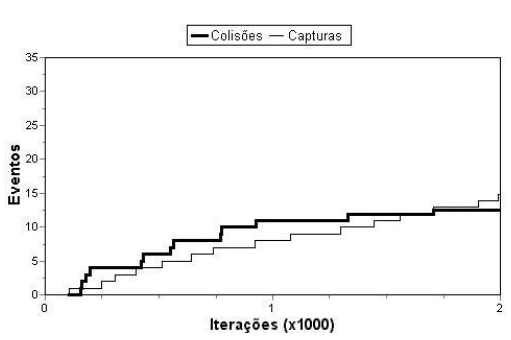

(c)

Figura 5.19: Desempenho do sistema de navegação autônomo para o sistema SBA em um ambiente com obstáculos (a) simulador SR; (b) simulador SS; (c) AR

de busca. Um número excessivo de colisões dificulta a captura de um alvo. Análogo à colisão, a captura caracteriza-se pelo disparo do processo de aprendizagem tanto no RC quanto no NS aprimorando o comportamento de busca ao alvo. A ocorrência de inúmeras capturas resulta no enfraquecimento do comportamento de desvio a obstáculos possibilitando o robô a colidir. Este comportamento pode ser visto nos gráficos que mostram o desempenho do sistema nos simuladores e em AR. Após um período em que a ocorrência de colisões e capturas se alternavam, o sistema aprendeu e vários alvos foram capturados até que o comportamento de desvio fosse enfraquecido, acarretando em novas coliões do robô contra obstáculos.

Outro experimento para a validação do módulo RC é realizado utilizando a configuração de ambiente mostrada na Figura 5.20. Do mesmo modo que o primeiro experimento, foram distribuídos 15 alvos no ambiente em posições estratégicas para que dois alvos consecutivos, segundo a ordem de inserção dos mesmos no ambiente, estejam posicionados em lados opostos de um obstáculo. Dessa maneira, é possível analisar o comportamento do sistema e validar o módulo RC.

Da mesma maneira que no experimento anterior, observa-se nas Figuras 5.21, 5.22 e 5.23 e nos gráficos da Figura 5.24 que o desempenho do sistema foi o esperado. Após um período de colisões, o sistema foi capaz de capturar uma sequiência de alvos demonstrando a atuação do mecanismo de 


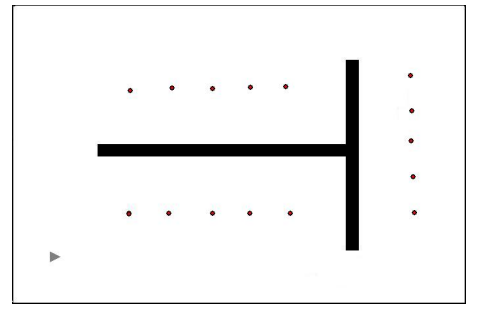

(a)

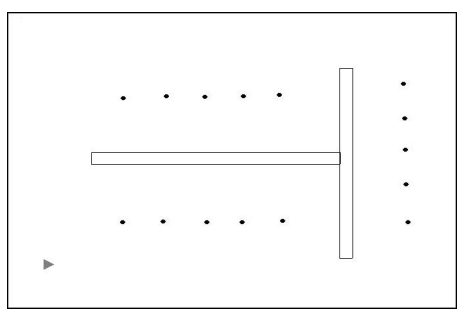

(b)

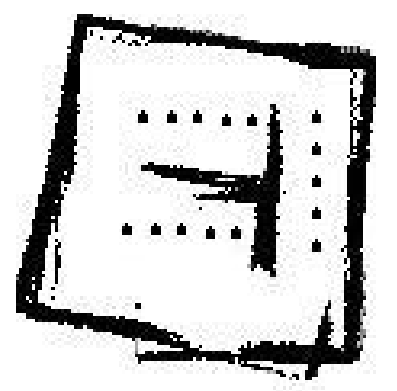

(c)

Figura 5.20: Modelo de ambiente com obstáculos para o experimento do RC (a) simulador SR;

(b) simulador SS; (c) AR

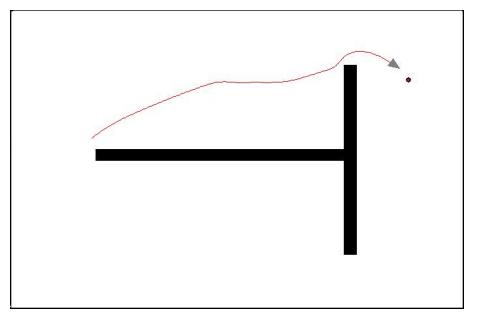

(a)

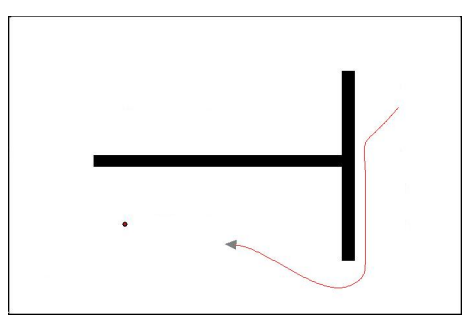

(b)

Figura 5.21: Trajetória do robô no simulador SR para o experimento do do RC (a) Primeiro alvo; (b) Segundo alvo

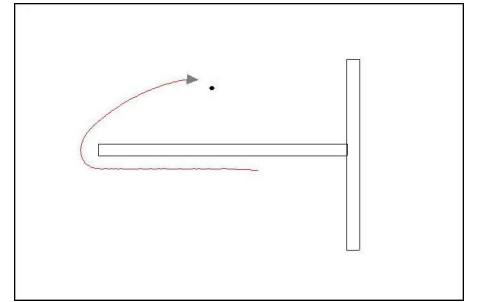

(a)

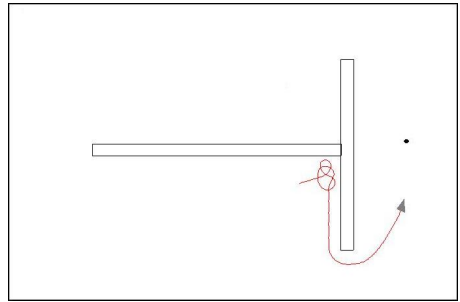

(b)

Figura 5.22: Trajetória do robô no simulador SS para o experimento do RC (a) Terceiro alvo; (b) Quarto alvo

aprendizagem adotado no sistema neural nebuloso.

Nos experimentos realizados para a validação do RC, verifica-se que o desempenho do sistema de navegação foi semelhante entre os simuladores (SR e SS) e no AR. Durante o processo 


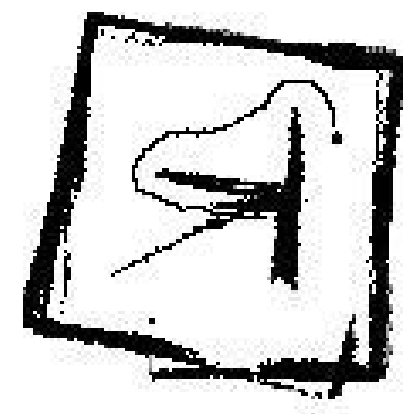

(a)

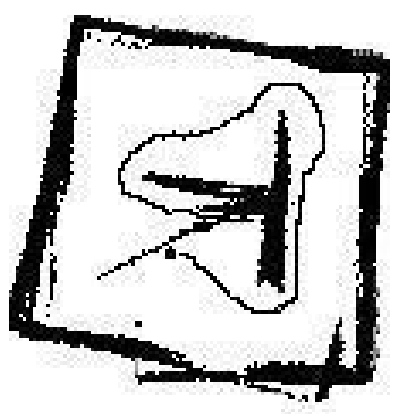

(b)

Figura 5.23: Trajetória do robô em AR no o experimento do RC (a) Primeiro alvo; (b) Segundo alvo

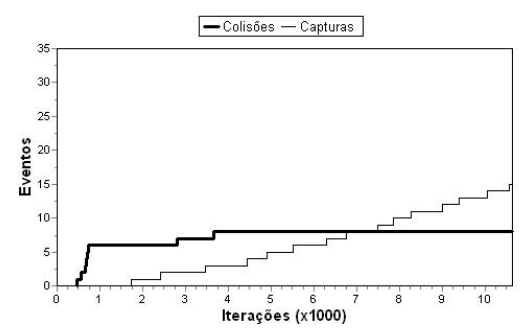

(a)

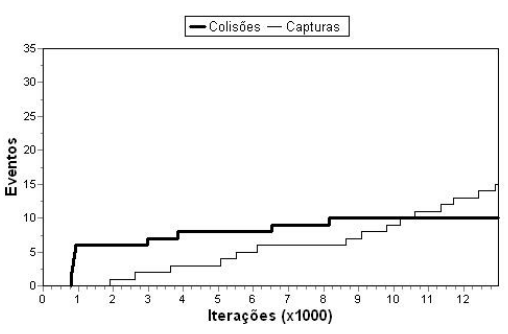

(b)

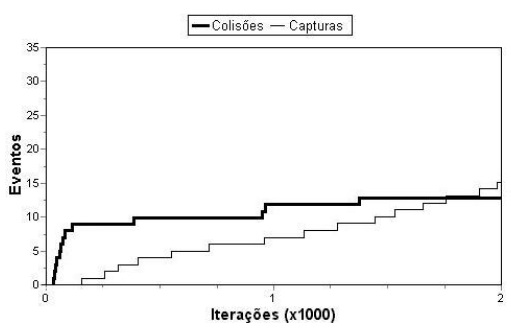

(c)

Figura 5.24: Desempenho do sistema de navegação autônomo para o sistema SBA em um ambiente com obstáculos (a) simulador SR; (b) simulador SS; (c) AR

de adaptação aos ambientes, o robô sofre seguidas colisões e a captura dos alvos o estimula a capturar novos alvos. Isto mostra que o sistema proposto anteriormente (Calvo e Figueiredo, 2003b), executado num ambiente idealizado (simulador SR) é robusto e funciona em aplicações de tempo real. Isto foi conseguido graças ao recurso agregado ao robô: o sensor laser (PLS). Os resultados obtidos pelos experimentos realizados nesta seção valida o sistema neural nebuloso para a sua aplicação em AR pelo fato de apresentar um desempenho semelhante ao simulador SR.

\subsection{Considerações Finais}

Neste capítulo foram apresentadas as alterações necessárias feitas na arquitetura original do controlador autônomo para tornar possível a tarefa de navegação em ambientes reais. As alterações se baseiam na combinação de um método de mapeamento com um método de localização denominados, Occupancy Grid e Monte Carlo, respectivamente. Tais métodos, sucintamente descritos, foram de fundamental importância para suprir a falta de sinais provenientes dos sensores de direção e distância ao alvo. Os métodos citados foram integrados na arquitetura do controlador autônomo no módulo LA com o intuito de fornecer informações sobre a posição do robô no ambiente de atuação com o mínimo de erro odométrico possível. Com esta informação, torna-se possível 
a obtenção dos dados referentes a distância entre o robô e o alvo, assim como a direção do alvo relativa à direção do robô, informações fundamentais para o funcionamento do sistema SBA e das redes neurais nebulosas RDA e RBA.

Além disso, nesse capítulo, foram aprsentados os resultados obtidos com a aplicação do mecanismo de aprendizado utilizado no sistema neural nebuloso em ambientes reais, validando esta abordagem através da análise de comparação entre os desempenhos dos experimentos realizados no simulador SR e em ambientes reais. Como intermédio entre esses dois tipos de experimentos, foram realizados experimentos utilizando o simulador SS que acompanha o Pioneer I. Considerando que este simulador apresenta comportamentos similares ao robô quando aplicados em ambientes reais, os resultados satisfatórios em SS demonstra que a abordagem apresentada em (Calvo e Figueiredo, 2003b) é consistente e adequada para sua aplicação em AR. No capítulo seguinte é apresentado um resumo das conlcusões obtidas durante o desenvolvimento do trabalho além de sugestões para sua continuidade contribuindo para a pesquisa desenvolvida no grupo de robótica do LABIC-ICMC-USP. 


\subsection{Conclusão}

A pesquisa em torno da navegação autônoma de robôs tem se mostrado de grande interesse aos pesquisadores da área de inteligência artificial. Propriedades encontradas em problemas desta natureza como aprendizagem, adaptação e autonomia motivam sua simulação em ambientes artificiais como o controle para navegação de robôs. O sistema de navegação descrito nesse trabalho tem como objetivo, guiar, sem influência externa, um robô móvel em ambientes descohecidos cumprindo simultaneamente duas tarefas distintas: desviar de obstáculos e capturar alvos dispostos arbitrariamente no ambiente de navegação.

O sistema de navegação autônoma possui capacidade de aprendizagem e adaptação que possibilitam que o robô, a partir da ausência de conhecimento inicial, adquira novos conhecimentos, coordene comportamentos conflitantes. $\mathrm{O}$ atendimento do objetivo de navegação deve ser buscado mesmo perante situações inesperadas. O sistema de navegação é reativo, isto é, atua somente com base e informaçòes instantâneas capturas pelos sensores. O processo de aprendizagem é disparado quando há ocorrência de colisão e caputra durante a navegação do robô. O evento de colisão dispara o processo de aprendizagem responsável pelo aprimoramento do comportamento de desvio de obstáculo, enquanto que o evento de captura dispara o processo de aprendizagem visando o aperfeiçoamento do comportamento de busca ao alvo. Ao mesmo tempo que a colisão é favorável ao comportamento de desvio, este evento causa o enfraquecimento do comportamento de busca. Análogo a colisão, o evento de captura enfraque o comportamento de desvio após inúmeras ocorrências. 
Resultados em simulação aprensentados em (Calvo e Figueiredo, 2003b) visaram demonstrar as virtudes do sistema e detectar deficiência. Porém, o objetivo deste trabalho consiste em validar o sistema de navegação em um robô móvel atuando em ambientes reais. O grande desafio em implantar o sistema de navegação em um robô deparando-se com dificuldades encontradas no mundo real foi superado com êxito. Adaptações foram necessárias para a aplicação do sistema de navegação em ambientes reais, tais como, a adaptação do sensor laser visto que os sonares acoplados no robô eram imprecisos, e a integração de um módulo para auxiliar na detecção dos alvos, uma vez que estes são definidos por coordenadas no ambiente real.

O sistema de navegação foi testado e validado por um extenso conjutno de experimentos de navegação. Os experimentos demonstraram que o sistema é aplicável em ambientes reais apresentando resultados semelhantes aos de simulação não perdendo sua característica de adaptabilidade e autonomia. Embora uma diversidade de experimentos tenha sido realizada, eles podem ser agrupados em 3 classes: 1) simulação em SR; 2) simulação no ambiente Saphira, designando um estágio anterior aos testes em ambientes reais por oferecer comportamentos do robô semelhantes aos comportamentos reais; 3 ) experimentos em AR.

Uma das contribuições desse trabalho está associada à integração do módulo LA, oferencendo autonomia ao sistema apresentado anteriormente (Bianchi e Romero, 2003). O mecanismo de aprendizado utilizado no sistema neural nebuloso serve de modelo para os trabalhos em andamento dsenvolvidos pelo grupo de robótica do LABIC.

\subsection{Trabalhos Futuros}

Como continuidade pretende-se estudar e analisar o efeito do crescimento das redes neurais nebulosas a cada ocorrência de um evento causador do disparo do processo de aprendizagem. Estudos já realizados, demonstram que a restrição do crescimento das redes não causam prejuízo no desempenho do sistema. Porém, até o momento somente testes em simulação em SR foram realizados. Há expectativas para que o desempenho seja mantido quando aplicados em AR.

Além disso, está previsto a ampliação do sistema de navegação com a implantação de sensores reais que detectam a orientação do alvo, como por exemplo, sensores de luminosidades. Dessa forma, o robô deve guiar um direção a uma fonte de luz posicionada em um local de um ambiente desconhecido. Para tanto, essa ampliação requer a utilização de ambientes a fontes de luz externas.

Outro ponto a ser pesquisado é a utilização do modelo da aquitetura do controlador autônomo juntamento com o mecanismo de aprendizado por reforço (a extensão da lei de Hebb) para apli- 
cação de tarefas envolvendo múltiplos robôs de forma cooperativa e/ou competitiva, como por exemplo, exploração de ambientes. Assim, prentede-se dotar cada robô de um contolador autônomo semelhante ao apresentado neste trabalho, diferenciando na natureza dos comportamentos inatos. 

Alur, R.; Das, A.; Eposito, J.; Fierro, R.; Grudic, G.; Hur, Y.; Kumar, V.; Lee, I.; Ostrowski, J.; Pappas, G.; Southall, B.; Spletzer, J.; TAYlor, C. J. A framework and architecture for multirobot coordination. In: Proceedings of the International Symposyum on Experimental Robotics, 2000.

Antonelo, E. A.; Figueiredo, M.; Baerveldt, A.; Calvo, R. Intelligent autonomous navigation for mobile robots: Spatial concept acquisition and object discrimination. Helsinki, Finland: CIRA'05, International Symposium on Computational Intelligence in Robotics and Automation, 2005.

Antsaklis, P. J. Scientific visualization: techniques and applications. IEEE Control Systems Magazine, v. 15, n. 3, p. 5-80, 1995.

Arai, T.; PAgello, E.; PArker, L. E. Guest editorial advances in mutirobot systems. IEEE Transaction on robotics and automation, v. 18, n. 5, p. 655 - 661, 2002.

ARKIN, R. C. Behavior-beased robotics. MIT Press, 1999.

ArnaUts, T.; Romero, R. A. F. A real time neuro-fuzzy production system for itaipu binacional. Vancouver, BC, Canada, 2001, p. $1015-1020$.

Barbosa, A. W. Sistema remoto para controle de robôs móveis via web. Dissertação de Mestrado, Instituto de Ciências Matemática e de Computação, Universidade de São Paulo, São Carlos, São Paulo, Brasil, 2005.

BAuM, W. M. Compreender o behaviorismo, p. 69-81. 1999.

Bellman, R. Appliedo dynamic programming. Princeton University Press, Princeton, N. J., 1957.

Berthold, M.; Hand, D. J. Intelligent data analysis: An introduction. Springer-Verlag, 1999. 
Bertsekas, D. P. Dynamic programming: Deterministic and stochastic models. Englewood Cliffs, NJ: Pentice-Hall, 1987.

Bianchi, R. E.; Romero, R. A. F. Robô mensageiro baseado em navegação probabilística. Universidade Estadual de Campinas, Bauru - SP, Brasil: VI Simpósio Brasileiro de Automação Inteligente, 2003.

Borenstein, J.; Everett, B.; Feng, L. Navigating mobile robots: Systems and techniques. K. Peters Ltd., 1996.

Borenstein, J.; Koren, Y. The vector field histogram - fast obstacle avoidance for mobile robots. IEEE Journal on Robotics and Automation, v. 7, n. 3, p. 278 - 288, 2001.

Brooks, R. A. Intelligence without reason. In: Myopoulos, J.; ReITER, R., eds. Proceedings of the 12th International Joint Conference on Artificial Intelligence (IJCAI-91), Sydney, Australia: Morgan Kaufmann publishers Inc.: San Mateo, CA, USA, 1991, p. 569-595.

Disponível em: citeseer.ist.psu.edu/article/brooks91intelligence. html

Burgard, W.; Moors, M.; Fox, D.; Simons, R.; S.Thrun Collaborative multi-robot exploration. In: Proceedings of the IEEE International Joint Conference on Robotics and Automation, 2000, p. $476-481$.

CAJAL, S. R. Textura del sistema nervioso del hombre y de los vertebrados. New York: Springer, 1899.

CALvo, R. Extensão da lei de hebb para modelagem de aprendizagem por reforço/punição para sistemas neurais nebulosos aplicado à navegação autônoma de robôs. Dissertação de Mestrado, Departamento de Informática, Universidade Estadual de Maringá, Maringá - PR, Brasil, 2003.

Calvo, R.; Delgado, M. R.; Figueiredo, M.; Lopes, H. Indução de regras nebulosas via sistemas classificadores para o controle da arquitetura em redes neurais construtivas para navegação autônoma. Universidade Federal do Maranhão, São Luís - MA, Brazil: IEEE Computer Society, 2004.

Calvo, R.; Figueiredo, M. Memória de trabalho em sistema neural aplicado à navegação autônoma com controle simultâneo de velocidade e direção. In: X Encontro Anual de Iniciação Científica, Ponta Grossa - PR, Brazil: Universidade Estadual de Ponta Grossa, 2001a.

Calvo, R.; Figueiredo, M. Sistema autônomo inteligente aplicado ao controle de direção e velocidade em robôs móveis. In: V Mostra de Trabalho de Informática da UEM, Departamento de Informática - UEM, Maringá - PR, Brazil: II FITEM, Fórum de Informática e Tecnologia de Maringá, 2001b. 
Calvo, R.; Figueiredo, M. Extensão da lei de hebb para modelagem de aprendizagem por reforço/punicão em sistemas neurais nebulosos aplicados à navegação autônoma de robôs. In: XI Encontro Anual de Iniciação Científica, Maringá - PR, Brazil: Universidade Estadual de Maringá, 2002.

Calvo, R.; Figueiredo, M. Extensão da lei de hebb e aprendizagem por reforço em redes neurais aplicadas à sistema de navegação autônoma. Universidade Estadual de Campinas, Campinas - SP, Brazil: ENIA’03, Encontro Nacional de Inteligência Artificial, XXIII Congresso da SBC, 2003a.

Calvo, R.; Figueiredo, M. Reinforcement learning for hierarchical and modular neural network in autonomous robot navigation. Portland - Oregon, USA: IJCNN'03,International Joint Conference on Neural Networks, 2003 b.

CAlvo, R.; Romero, R. A. F. A hierarchical self-organizing controller for navigation of mobile robots. Vancouver, BC, Canada: IJCNN'06,International Joint Conference on Neural Networks, 2006.

Campos, M.; Bonabeu, E.; Theraulaz, G.; Deneubourg, J. L. Dinamic schedule and division of labor in social insects. Adaptative Behavior, p. 93 - 96, 2000.

Carpenter, G. A.; Grossberg, S. Art 2: Self-organization of stable category recognition codes for analog input patterns. Applied Optics, , n. 26, p. $4919-4930,1987$ a.

Carpenter, G. A.; Grossberg, S. A massivel, parallel architecture for a self-organizing neural pattern recognition machine. Computer Vision, Graphics, and Image Processing, , n. 37 , p. $54-115,1987 b$.

Carpenter, G. A.; Grossberg, S. The art of adaptive pattern recognition by a self-organizing neural network. Computer, v. 21, n. 3, p. 77-88, 1988.

Carpenter, G. A.; Grossberg, S.; Reynolds, J. H. Artmap: Supervised real-time learning and classification of nonstationary ddta by a self-organizing neural network. Neural Networks, v. 4, p. $565-588,1991$ a.

Carpenter, G. A.; Grossberg, S.; Rosen, D. B. Fuzzy art: Fast stable learning and categorization of analog patterns by an adaptive resonance system. Neural Networks, v. 4, p. $759-771,1991 b$.

Castelfranchi, C. Modelling social action for ai agents. Artificial Life, p. 157 - 182, 1998.

CAtania, A. C. Aprendizagem: Comportamento, linguagem e cognição. Porto Alegre - RS, Brazil: ArtMed, 1999. 
CAZANGI, R. Uma proposta evolutiva para controle inteligente para navegação autônoma de robôs. Dissertação de Mestrado, Faculdade de Engenharia Elétrica e de Computação - UNICAMP, Campinas, São Pauo, Brasil, 2004.

CazAngi, R.; Figueiredo, M. Simultaneous emergence of conflicting basic behaviors and their coordination in an evolutionary autonomous navigation system. In: Proceedings of 2002 Congress on Evolutionary Computation, Honolulu - Hawai, USA: CEC'02, Congress on Evolutionary Computation, 2002, p. $466-471$.

Colombetti, M.; Dorigo, M.; Borghi, G. Behavior analysis and training - a methodology for behavior engineering. IEEE Transactions on Systems, Man, and Cybernetics - Part B: Cybernetics, v. 26, n. 3, p. $365-380,1996$.

Cordón, O.; Jesus, M. J.; Herrera, F.; Villar, P. A multiobjective genetic algorithm for feature selection and granularity learning in fuzzy-rule-based classification systems. In: Proceedings of 9th IFSA World Congress and 20th NAFIPS International Conference, Vancouver, Canada: Morgan Kaufmann publishers Inc.: San Mateo, CA, USA, 2001, p. 1253-1258.

CRestani, P. R. Sistemas inteligentes de navegação autônoma: Uma abordagem modular e hierárquica com novos mecanismos de memória e aprendizagem. Dissertação de Mestrado, Faculdade de Engenharia Elétrica e de Computação - UNICAMP, Campinas - SP, Brazil, 2001.

Crestani, P. R.; Figueiredo, M.; Zuben, F. V. A hierarchical neuro-fuzzy approach to autonomous navigation. In: Proceedings of 2002 International Joint Conference on Neural Networks, Honolulu - Hawai, USA: IJCNN'02, International Joint Conference on Neural Networks, 2002, p. $2339-2344$.

D. E. BRown, F. Z. B.; MARTIN, W. N. Fast genetic selection of features for neural netowork classifiers. 1992 , p. $342-328$.

Deco, G.; Rolls, E. T.; ZIHL, J. Neurobiology of attention, p. 593 - 599. 2005.

Delgado, M. R. Projeto automático de sistemas nebulosos: Uma abordagem co-evolutiva. Tese de Doutoramento, Faculdade de Engenharia Elétrica e de Computação - UNICAMP, Campinas - SP, Brasil, 2002.

Delgado, M. R.; Zuben, F. V.; Gomide, F. Hierarchical genetic fuzzy systems. In: Information Sciences, 2001, p. 29 - 52.

Disponível em: http://www.sciencedirect.com/science/article/ B6V0C-43DDW06-3/2/b48adbd19c164a5f5c5bb1682abf2416

Denenbourg, J.; Goss, S.; SAndini, G.; Ferrari, F.; DARio, P. Self-organizing collection and transport of objects in unpredictable environments. In Proceedings Japan - USA Symposium Flexible Automation, p. 1093 - 1098, 1990. 
Drogoul, A.; Ferber, J. From tom thumb to dockers: Some experiments with foraging robots. In Proceedings 2nd Internacional Conference Simulation of Adaptative Behavior, p. 451 - 459, 1992.

Edelman, G. Neural darwinism: The theory of neuronal group selection. New York, USA: Basic books, 1987.

ELFES, A. Using occupancy grids for mobile robot perception and navigation. Computer, v. 22, n. 6, p. 46-57, 1989.

Fahlman, S. E.; Lebiere, C. The cascade-correlation learning architecture. In Advances in Neural Information Processing Systems II, p. 524 - 532, 1990.

FAUSETT, L. Fundamentals of neural networks. Englewood Cliffs, New Jersey, USA: Prentice Hall, 1994.

FigueIREDO, M. Redes neurais nebulosas aplicadas em problemas de modelagem e controle autônomo. Tese de Doutoramento, Faculdade de Engenharia Elétrica e de Computação - UNICAMP, Campinas - SP, Brazil, 1997.

FIgUeIREDO, M. Navegação autônoma de robôs. VII Escola de Informática da SBC, p. 75 $103,1999$.

FIgUeIREDO, M.; GoMIdE, F. Evolving neurofuzzy networks for basic behaviors and a recategorization approach for their coordination. In Genetic Algorithms and Soft Computing, p. 533 $-552,1996$.

Fox, D.; Burgard, W.; Thrun, S. Markov localization for mobile robots in dynamic environments. Journal of Artificial Intelligence Research, v. 11, p. 391-427, 1999.

Disponível em: citeseer.ist.psu.edu/fox99markov.html

Fox, D.; Burgard, W.; Thrun, S.; Cremers, A. B. Position estimation for mobile robots in dynamic environments. In: AAAI/IAAI, 1998, p. $983-988$.

Disponível em: citeseer.ist.psu.edu/fox98position.html

FraCASSO, P. T.; REALI, A. H. Navegação reativa de robôs móveis autônomos utilizando lógica nebulosa com regras ponderadas. VII Simpósio Brasileiro de Automação Inteligente, 2005.

Fregene, K.; MAdHAVAN, R.; PARKER, L. Incremental multiagent robotic mapping of outdoor terrains. In: In Proceedings of the IEEE International Conference on Robotics and Automation, 2002, p. 1339 - 1346.

Disponível em: citeseer.comp.nus.edu.sg/fregene02incremental.html

Geman, S.; Bienenstock, E.; Doursat, R. Neural networks and the bias/variance dilemma. Neural Computation, , n. 4, p. 1 - 58, 1992. 
Gomide, F.; Pedrycz, W. An introduction to fuzzy sets: analysis and design. Cambridge, USA: The MIT Press, 1998.

Goonatilake, S.; KhebBal, S. Intelligent hybrid systems, v. 1. Jhon Wiley and Sons, 1995.

HAYKIn, S. Neural networks. New York, USA: Prentice Hall, 1994.

HEBB, D. O. The organization of behavior: a neuropsychological theory. New York, USA, 1949.

Hoffmann, F. Evolutionary algorithms for fuzzy control system design. In: Proceedings of the IEEE, 2001, p. 1318-1333.

HopfiEld, J. J. Neural networks and physical systems with emergent collective computational abilities. Proceedings of National Academy of Sciences, p. 2554 - 2558, 1982.

HowARD, R. A. Dynamic programming and markov process. Cambridge, MA: The MIT Press, 1960.

ITti, L.; Koch, C. Computational modelling of visual attention. Nature Reviews Neuroscience, , n. 2, p. $194-203,2001$.

JAnG, J.-S.; Sun, C.-T.; Mizutani, E. Neuro-fuzzy and soft computing. Prentice Hall, 1997.

JIM, K. C.; GILES, C. L. Talking helps: evolving communicating agents for predator-prey pursuit problem. Artificial Life, p. 237 - 254, 2001.

KAndel, E.; Schwartz, J.; Jessel, T. Principles of neural science. 1991.

KASABOV, N. K. Fundations of nerual networks, fuzzy systems, and knowledge engineering. MIT Press, 1996.

KoHonen, T. Self-organization formation of topologically correct feature maps. Biological Cybernetics, p. 59 - 69, 1982.

Mamdani, E. H.; Assilian, S. An experiment in linguistic synthesis with a fuzzy logic controller. In: International Journal of Man-Machine Studies, v. 7, p. 1 - 13, 1975.

MATARIC, M. J. Designing emergent behaviors: From local interations to collective intelligent. In Proceedings 2nd Internacional Conference Simulation of Adaptative Behavior, p. 432 - 441, 1992.

MATARIC, M. J. Learning in behavior-based multi-robot system: policies, models and other agents. Journal of Cognitive System Research, p. 81 - 93, 2001.

McCulloch, W.; Pitts, W. A logical calculus of the ideas imminent in nervous activity. Bulletin Mathematical Biophysics, p. 115-133, 1943. 
Medeiros, D. M.; Romero, R. A. F. Utilização de redes neurais para navegação de robôs móveis em um chão de fábrica. Revista de Iniciação Científica, , n. 6, p. 45 - 51, 2004.

Minsky, M. L.; PApert, S. A. Perceptrons. Massachusetts, USA: MIT Press, 1969.

Moore, B. Art 1 and pattern clustering. Proceedings of the 1988 Connectionist Models Summer School, p. $174-185,1988$.

MURPHY, R. R. Introduction to ai robotics. MIT Press, 2000.

Neumann, J. First draft of a report on the edvac. IEEE Ann. Hist. Comput., v. 15, n. 4, p. 27-75, 1993.

Nishimura, S. I.; IKEgAmi, T. Emergence of collective strategies in a prey-oredator game model. Artificial Life, p. 243 - 260, 1997.

NOLFI, S.; FlORIANO, D. Coevolving predator and prey robots: to arms races arise in artificial evolution? Artificial Life, p. 311 - 335, 1999.

Nolfi, S.; Floriano, D. Evolutionary robotics. MIT Press, 2000.

PARKER, L. E. Current state of the art in distributed autonomous mobile robotics. Proceedings of the 5th International Symposium on Distributed Autonomous Robotics Sytems, p. 3 - 12, 2002.

Parpinelli, R. S.; Lopes, H. S.; Freitas, A. A. Data mining with an ant colony optimization algorithm. IEEE Transactions on Evolutionary Computation, v. 6, n. 4, p. 321 - 332, 2002.

Pavlov, I. P. Conditioned reflexes. London, England: Oxford University Press, 1927.

Puterman, M. L. Markov decision processes: Discrete stochastic dynamic programming. New York, NY, USA: Inc. John Wiley and Sons, 1994.

QUILES, M. G. Sistema de visão baseado em redes neurais artificiais para o controle de robôs móveis. Dissertação de Mestrado, Instituto de Ciências Matemática e de Computação, Universidade de São Paulo, São Carlos - SP, Brazil, 2005.

R. PAREKH, J. YANG, V. H. Constructive neural-network learning algorithms for pattern classification. IEEE Transactions on Neural Networks, v. 11, n. 2, p. 436-451, 2000.

RAO, R. N.; FUENTES, O. Learning navigational behaviors using a predictive sparse distributed memory. In From Animals to Animats: Proceedings of the 4th International Conference on Simulation of Adaptive Behavior, p. 382 - 390, 1996.

REZENDE, S. O. Sistemas inteligentes: Fundamentos e aplicações. primeira edição ed. Manole, 2003. 
Ribeiro, C.; Costa, A. H. R.; Romero, R. Robôs móveis inteligentes: Princípios e técnicas. In: Martins, A. T.; Borges, D. L., eds. I Jornada de Atualização em Inteligência Artificial - JAIA'2001. Anais do XXI Congresso da Sociedade Brasileira de Computação, SBC, 2001, p. 257-306.

Rosemblatt, F. The perceptron: a probabilistic model for information storage and organization in the brain. Phychological Review, p. $386-408,1958$.

Rumelhart, D. E.; Hinton, G. E.; Willians, R. J. Learning representations of backpropagation errors. Nature, p. $536-553,1986$.

SHANAHAN, M. Reinventing shakey, p. 233-253. 2001.

Simmons, R. G.; Goodwin, R.; Haigh, K. Z.; Koenig, S.; O’Sullivan, J.; Veloso, M. M. Xavier: experience with a layered robot architecture. SIGART Bull., v. 8, n. 1-4, p. 22-33, 1997.

SKInNER, B. F. Science and human behavior. New YorkLondon, England, 1953.

Smithers, M. Autonomy in robots and others agents, brains and cognition. v. 34, p. $88-106$, 1997.

Su, C.-T.; Chiang, T.-L. Optimal design for a ball grid array wire bonding process using a neuro-genetic approach. 2002, p. $13-18$.

Takagi, T.; Sugeno, M. Derivation of fuzzy control rules from human operator's control actions. In Proceedings of the IFAC Symposium on Fuzzy Information, Knowledge Representation and Decision Analysis, p. 55 - 60, 1983.

TANI, J. Model-based learning for mobile robust navigation from the dynamical system perspective. IEEE Transaction on systems, Man, and Cybernetics, part B Cybernetics, v. 26, n. 3, p. 421-436, 2000.

Theraulaz, G.; Bonabeu, E. A brief history of stigmergy. Artificial Life, p. 97 - 116, 1999.

Thrun, S.; Fox, D.; Burgard, W.; Dellaert, F. Robust monte carlo localization for mobile robots. Artificial Intelligence, v. 128, n. 1-2, p. 99-141, 2000.

VERSHURE, P. A bottom up approach towards the acquisition and expression of sequential representations applied to a behaving real-world device: Distributed adaptive control iii. Neural Networks, v. 11, p. 1531-1549, 1998.

WIDROw, B.; HofF., M. Adaptive switching circuits. 1960 IRE WESCON Convention Record, Part 4, p. 96 - 104, 1960. 
YAGER, R. R.; FILEV, D. Essential of fuzzy modeling and control. John wiley and sons inc ed. New York, USA, 1994.

ZADeh, L. A. Fuzzy sets. Journal of Information and Control, v. 8, p. 338 - 353, 1965. 

APÊNDICE

\section{$A$}

\section{Sistemas Nebulosos SDO e SBA}

\section{A.1 Variáveis Lingüísticas e Termos Lingüísticos}

Nesta seção é apresentada a descrição dos sistemas SDO e SBA no que diz respeito às suas variáveis e seus termos lingüísticos utilizados assim como suas regras nebulosas. As variáveis antecedentes e conseqüente do sistema SDO definidas são ilustradas abaixo juntamente com seus termos lingüísticos.

A partir destas variáveis e de seus termos, utiliza-se as regras nebulosas a seguir para encontrar o ajuste adequado da direção:

1. Se o obstáculo estiver perto à esquerda, então gire muito para a direita.

2. Se o obstáculo estiver perto ao centro, então gire muito para a direita.

3. Se o obstáculo estiver perto à direita, então gire muito para a esquerda.

4. Se o obstáculo estiver médio à esquerda, então gire médio para a direita.

5. Se o obstáculo estiver médio ao centro, então gire médio para a direita.

6. Se o obstáculo estiver médio à direita, então gire médio para a esquerda.

7. Se o obstáculo estiver longe à esquerda, então gire pouco para a direita.

8. Se o obstáculo estiver longe ao centro, então gire pouco para a direita.

9. Se o obstáculo estiver longe à direita, então gire pouco para a esquerda. 


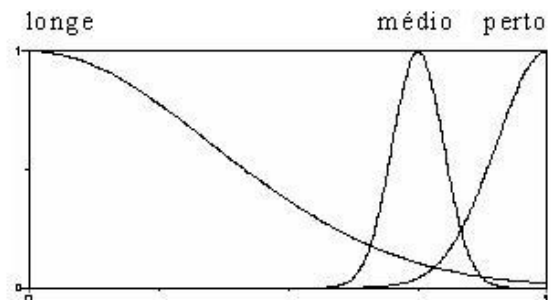

(a)

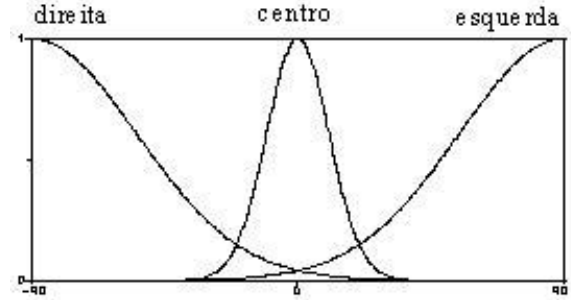

(b)

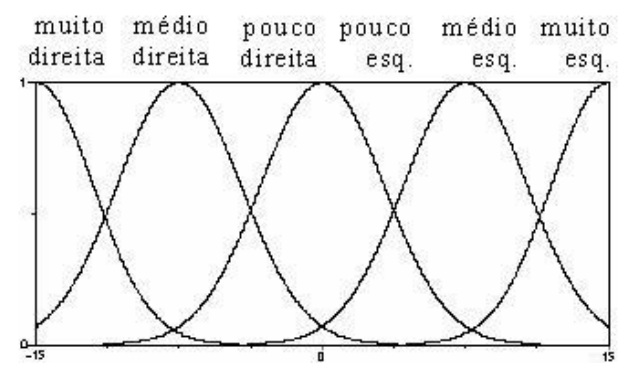

(c)

Figura A.1: Variáveis língüísticas e seus termos lingüísticos do sistema SDO (a) antecedente: distância do obstáculo; (b) antecedente: direção do obstáculo; (c) conseqüente: ajuste da direção do robô

As variáveis antecedentes e conseqüente do SBA definidas são ilustradas abaixo juntamente com os seus conceitos. A partir destas variáveis e de seus conceitos é possível construir as regras nebulosas utilizadas para o cálculo do ajuste adequado da direção.

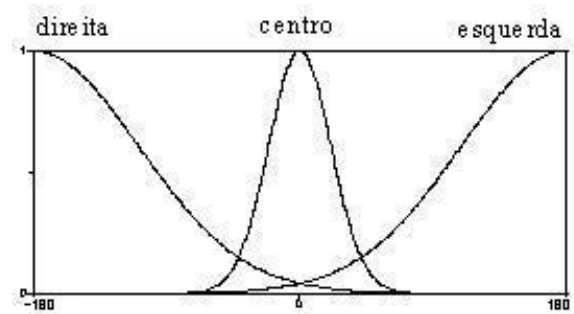

(a)

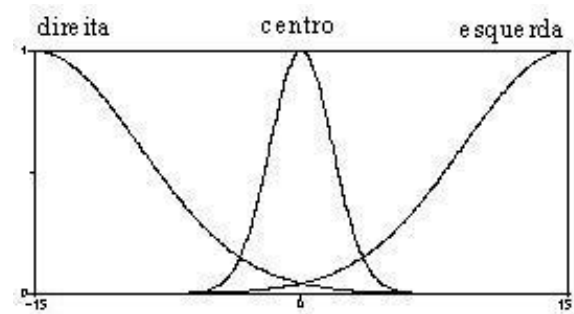

(b)

Figura A.2: Variáveis língüísticas e seus termos lingüísticos do sistema SBA (a) antecedente: direção do alvo; (c) conseqüente: ajuste da direção do robô

1. Se o alvo estiver à esquerda, então gire para a esquerda.

2. Se o alvo estiver ao centro, então gire para o centro (ou não gire).

3. Se o alvo estiver à direita, então gire para a direita. 